\title{
THE EFFECTS OF TWO VIDEO MODELING INTERVENTIONS ON THE INDEPENDENT LIVING SKILLS OF STUDENTS WITH AUTISM SPECTRUM DISORDER AND INTELLECTUAL DISABILITY
}

by

\section{Kaylee Stahr Wynkoop}

Bachelor of Science in Education, Miami University, 2005

Master of Education, University of Pittsburgh, 2007

Submitted to the Graduate Faculty of

The School of Education in partial fulfillment

of the requirements for the degree of

Doctor of Philosophy

University of Pittsburgh 


\title{
UNIVERSITY OF PITTSBURGH \\ SCHOOL OF EDUCATION
}

This dissertation was presented

by

\author{
Kaylee Stahr Wynkoop
}

It was defended on

April 6, 2016

and approved by

Steven R. Lyon, PhD, Department of Instruction and Learning

Douglas E. Kostewicz, PhD, Department of Instruction and Learning

Leanne Bowler, PhD, Library and Information Science Program

Dissertation Advisor: Rachel E. Robertson, PhD, Department of Instruction and

Learning 
Copyright (C) by Kaylee Stahr Wynkoop

2016 


\section{THE EFFECTS OF TWO VIDEO MODELING INTERVENTIONS ON THE INDEPENDENT LIVING SKILLS OF STUDENTS WITH AUTISM SPECTRUM DISORDER AND INTELLECTUAL DISABILITY}

Kaylee Stahr Wynkoop, PhD

University of Pittsburgh, 2016

Individuals with autism spectrum disorder (ASD) and intellectual disability (ID) often have independent living skill deficits. Video modeling (VM) may be one particularly effective intervention to improve skills in this area. However, the most effective and efficient variations have yet to be determined. The researcher conducted a search for studies investigating the effects of VM on the independent living skills of school-aged students with ASD and/or ID. Nineteen single-subject studies and 65 participants were coded according to a number of variables. Results of the review suggested that certain participant characteristics and intervention components were more often associated with increased intervention effectiveness. The researcher discusses possible correlations, shares potential implications for practitioners, and proposes directions for future research. Based on findings of the review, the researcher conducted a single-subject study and results are outlined. Using an adapted alternating treatments design, the researcher investigated the comparative effects of VM plus least-to-most prompting and reinforcement (VM+P\&R), continuous video modeling plus least-to-most prompting and reinforcement (CVM+P\&R), and least-to-most prompting plus reinforcement alone $(\mathrm{P} \& \mathrm{R})$ on the independent 
living skills of four adolescents with ASD and ID. Results indicated that two participants responded well to both $\mathrm{VM}+\mathrm{P} \& \mathrm{R}$ and $\mathrm{P} \& \mathrm{R}$ while $\mathrm{CVM}+\mathrm{P} \& \mathrm{R}$ was most effective for one participant. For the last participant, all interventions had only minimal effects on target skill performance and results were inconclusive. Overall, students required fewer adult-delivered prompts with $\mathrm{VM}+\mathrm{P} \& \mathrm{R}$ and/or $\mathrm{CVM}+\mathrm{P} \& \mathrm{R}$ but $\mathrm{P} \& \mathrm{R}$ required less preparation and instructional time. 
TABLE OF CONTENTS

PREFACE ...........................................................................................................

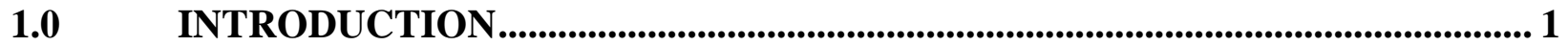

1.1 STATEMENT OF THE PROBLEM ….................................................. 5

2.0 REVIEW OF THE LITERATURE..................................................................... 7

2.1 VM: BENEFITS AND CHALLENGES .............................................................. 8

2.1.1 Intervention variations and descriptions.......................................................... 8

2.1.2 VM implementation....................................................................................... 9

2.1.3 Potential advantages of VM.................................................................................. 10

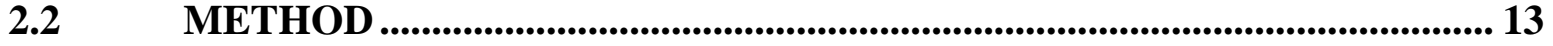

2.2.1 Literature search ...................................................................................... 13

2.2.1.1 ASD focused search................................................................................. 13

2.2.1.2 ID focused search .............................................................................. 14

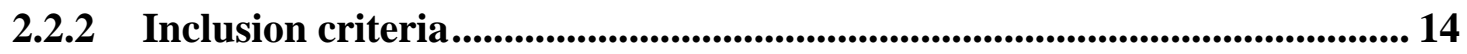

2.2.3 Article coding and analysis .............................................................................. 15

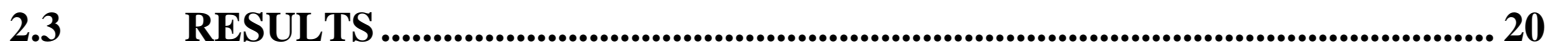

2.3.1 Overall study characteristics .............................................................................. 20

2.3.2 Efficacy of VM: Visual analysis and PND...................................................... 20

$2.4 \quad$ DISCUSSION ..................................................................................................... 24 


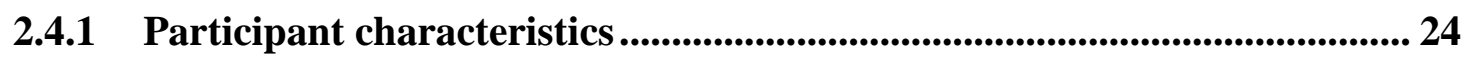

2.4.2 Research questions and experimental design................................................. 25

2.4.2.1 Comparative studies ..................................................................................... 25

2.4.2.2 Single intervention studies........................................................................ 29

2.4.3 Independent variables: Intervention variations and video components .. 30

2.4.3.1 Variations of VM........................................................................................... 30

2.4.3.2 Video components. ....................................................................................... 32

2.4.4 Dependent variables .............................................................................................. 33

2.4.4.1 Target skill acquisition ................................................................................. 33

2.4.4.2 Generalization and maintenance ........................................................... 34

2.4.5 Implications .............................................................................................................. 35

2.4.6 Directions for future research ........................................................................... 36

2.4.7 Rationale for study ............................................................................................. 38

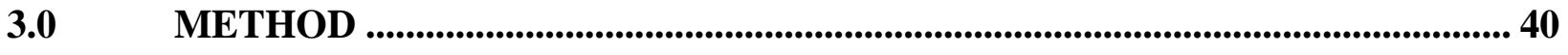

P.1 PARTICIPANTS AND SETTING ...................................................................... 40

MATERIALS ................................................................................................... 45

DEPENDENT VARIABLES ..................................................................... 46

3.3.1 Percentage of correct steps and number of sessions to mastery................. 46

3.3.2 Total number of adult-delivered prompts......................................................... 47

3.3.3 Time to skill completion ............................................................................................ 47

3.3.4 Total instructional time ........................................................................................ 48

INDEPENDENT VARIABLES............................................................................. 48

EXPERIMENTAL DESIGN ................................................................................ 49 


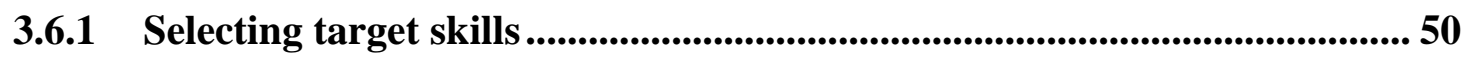

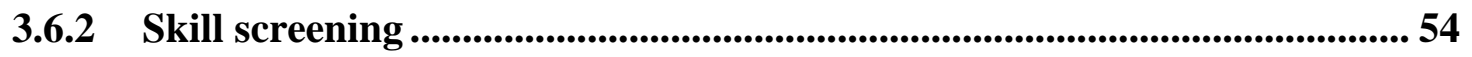

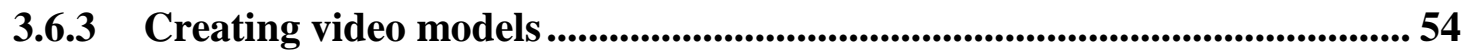

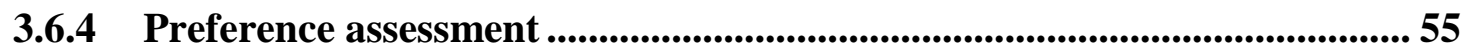

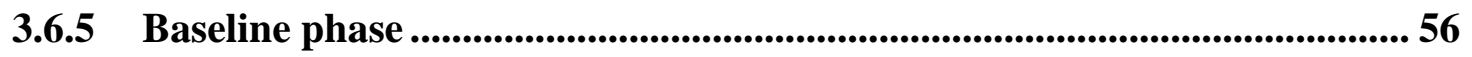

3.6.6 Intervention comparison phase ..................................................... 56

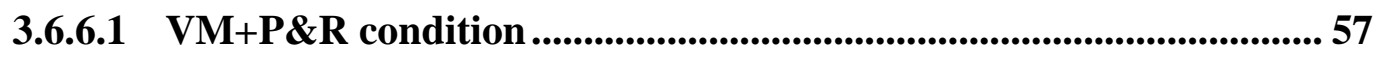

3.6.6.2 CVM+P\&R condition ................................................................ 57

3.6.6.3 P\&R condition .............................................................................. 58

3.6.6.4 Mastery criteria and "final best" replication phase ........................ 59

3.6.7 Accuracy, interobserver agreement, and procedural integrity ............... 59

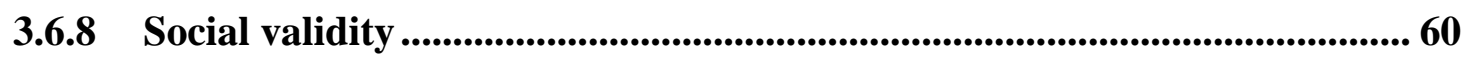

3.6.9 Data analysis ..........................................................................................6 61

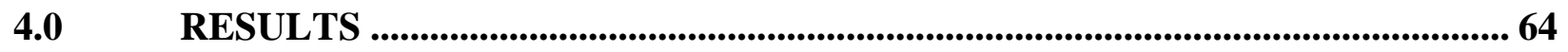

4.1 MSWO PREFERENCE ASSESSMENT .......................................................... 64

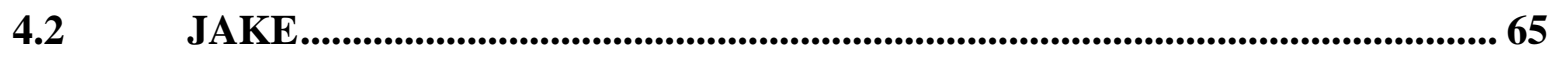

4.2.1 Percentage of correct steps and number of sessions to mastery............... 65

4.2.2 Total number of adult-delivered prompts...............................................67

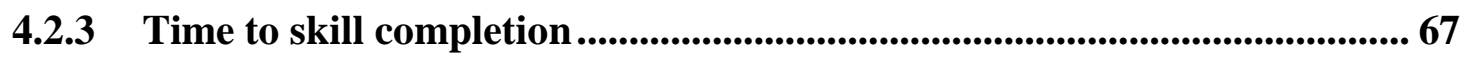

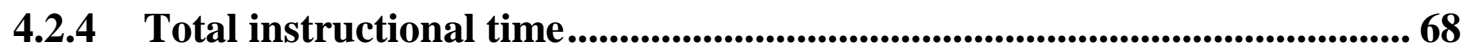

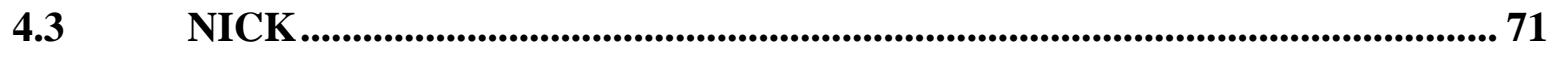

4.3.1 Percentage of correct steps and number of sessions to mastery................ 72 
4.3.2 Total number of adult-delivered prompts.................................................... 73

4.3.3 Time to skill completion ........................................................................... 74

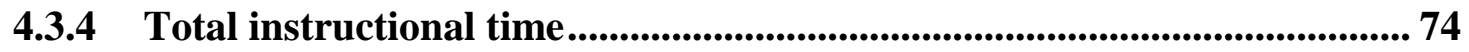

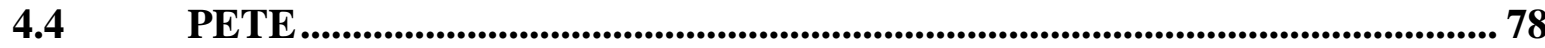

4.4.1 Percentage of correct steps and number of sessions to mastery................ 78

4.4.2 Total number of adult-delivered prompts........................................... 79

4.4.3 Time to skill completion ................................................................................... 79

4.4.4 Total instructional time ............................................................................ 79

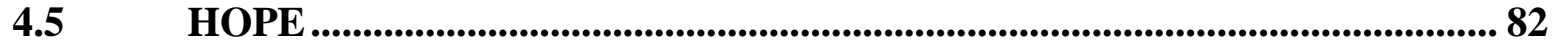

4.5.1 Percentage of correct steps and number of sessions to mastery............... 83

4.5.2 Total number of adult-delivered prompts.............................................. 84

4.5.3 Time to skill completion .................................................................. 86

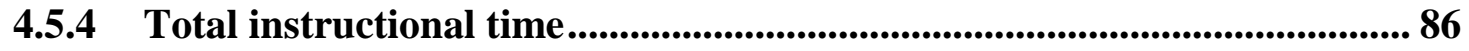

4.6 GROUP RESULTS: SECONDARY DEPENDENT VARIABLES ............. 90

4.6.1 Average number of adult-delivered prompts per session ....................... 90

4.6.2 Average time to skill completion per session................................................. 91

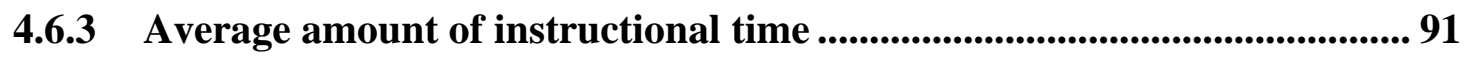

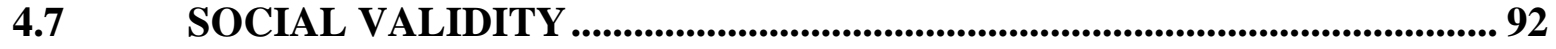

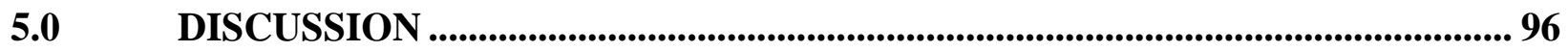

5.1 RESEARCH QUESTION \#1: COMPARATIVE INTERVENTION

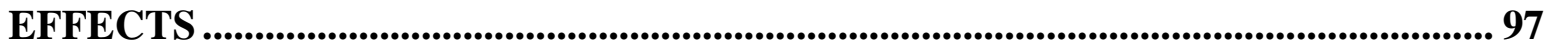

5.2 RESEARCH QUESTION \#2: STUDENT CHARACTERISTICS AND RESPONSE TO INTERVENTIONS................................................................. 99 
5.2.1 VM+P\&R responders.......................................................................................... 99

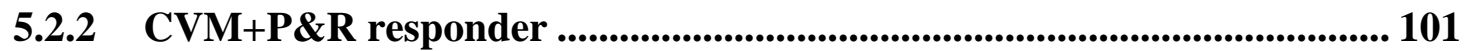

5.2.3 Non-responder and mixed findings................................................................. 103

5.3 OVERALL FINDINGS: SECONDARY DEPENDENT VARIABLES ..... 105

5.3.1 Time to skill completion and instructional time ............................................ 105

5.3.2 Instructional time versus independence ......................................................... 106

IMPLICATIONS FOR PRACTICE .................................................................. 107

LIMITATIONS................................................................................................ 109

5.6 CONCLUSIONS AND DIRECTIONS FOR FUTURE RESEARCH........ 111

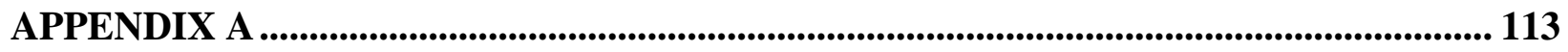

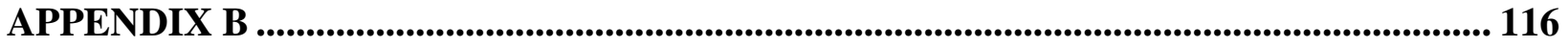

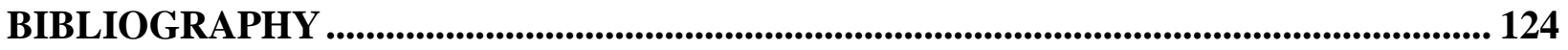




\section{LIST OF TABLES}

Table 1. Potentially relevant participant characteristics and study outcomes .......................... 17

Table 2. Potentially relevant intervention components..................................................... 18

Table 3. Target skills, dependent variable, visual analysis description, PND \& effects ............. 19

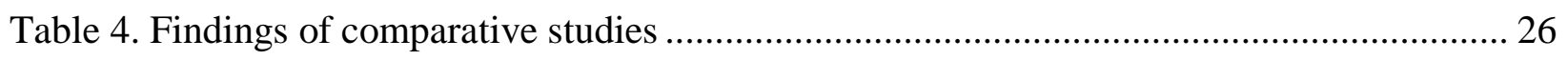

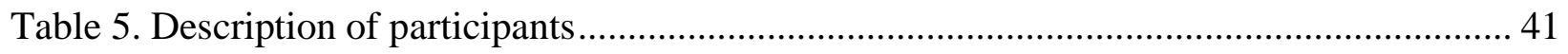

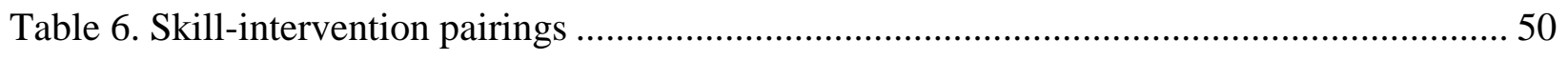

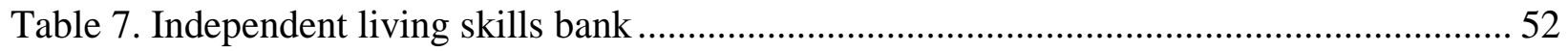

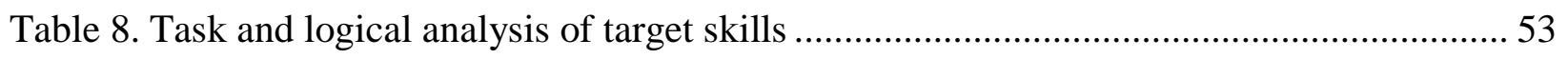

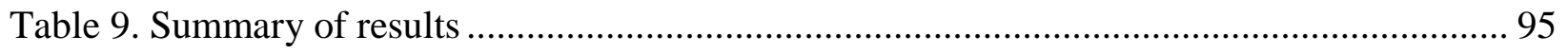




\section{LIST OF FIGURES}

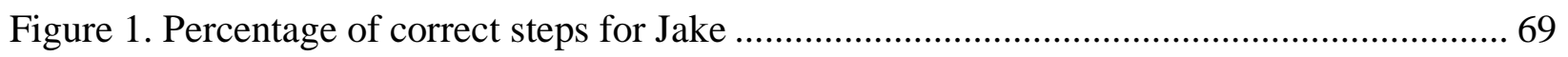

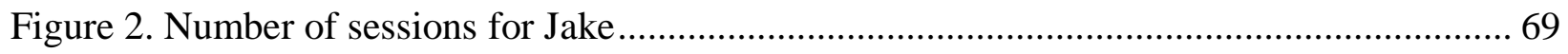

Figure 3. Total number of adult-delivered prompts for Jake ............................................. 70

Figure 4. Time to skill completion for Jake................................................................. 70

Figure 5. Total instructional time for Jake.................................................................. 71

Figure 6. Percentage of correct steps for Nick............................................................. 75

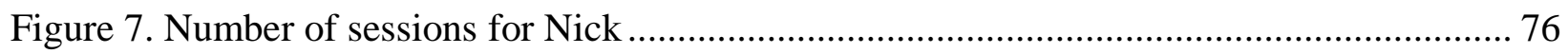

Figure 8. Total number of adult-delivered prompts for Nick ............................................. 76

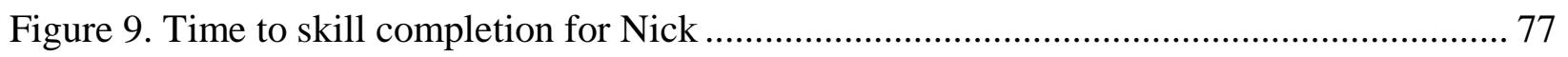

Figure 10. Total instructional time for Nick ............................................................... 77

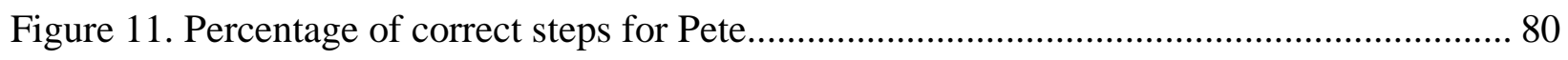

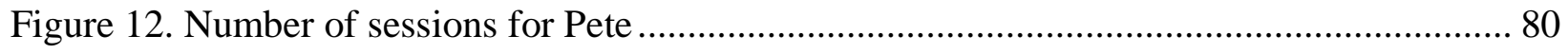

Figure 13. Total number of adult-delivered prompts for Pete ............................................ 81

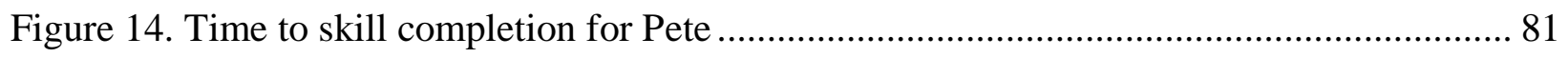

Figure 15. Total instructional time for Pete ..................................................................... 82

Figure 16. Percentage of correct steps for Hope.............................................................. 87

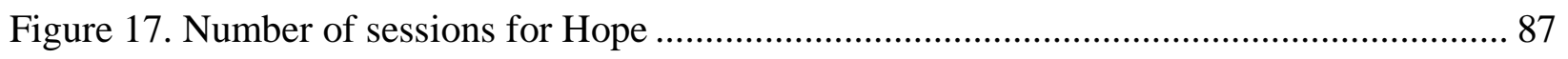

Figure 18. Total number of adult-delivered prompts for Hope ............................................. 88 
Figure 19. Type of adult-delivered prompt required to elicit a correct response from Hope ....... 88

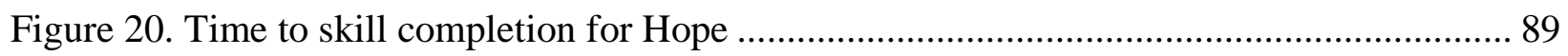

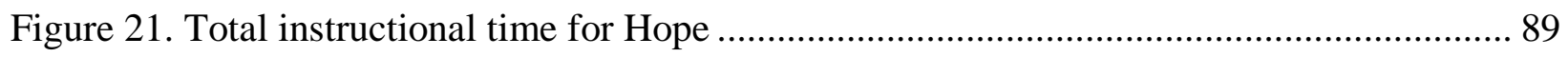

Figure 22. Average number of adult-delivered prompts per session across participants ............ 90

Figure 23. Average time to skill completion per session across participants ........................... 91

Figure 24. Average instructional time per session across participants ................................. 92

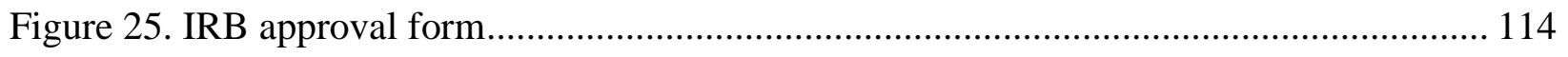

Figure 26. School permission to conduct research letter ................................................. 115

Figure 27. Data collection sheet: Take out trash............................................................ 116

Figure 28. Data collection sheet: Roll silverware .......................................................... 116

Figure 29. Data collection sheet: Wipe microwave tray ................................................... 117

Figure 30. Data collection sheet: Fold t-shirt............................................................ 117

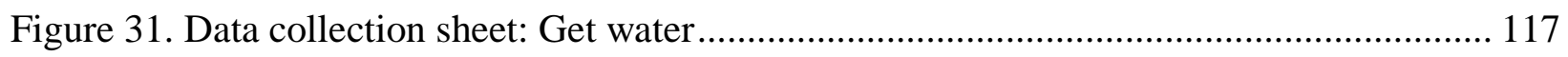

Figure 32. Data collection sheet: Fold and store socks................................................ 117

Figure 33. Procedural integrity form: Baseline............................................................ 118

Figure 34. Procedural integrity form: VM+P\&R.......................................................... 119

Figure 35. Procedural integrity form: CVM+P\&R ......................................................... 120

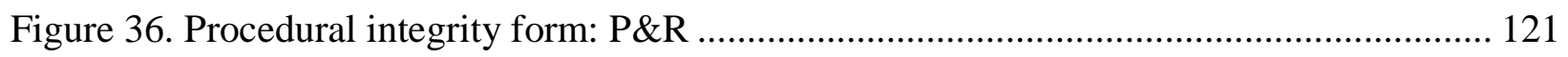

Figure 37. Social validity survey: Participant................................................................. 122

Figure 38. Social validity survey: Parent and teacher..................................................... 123 


\section{PREFACE}

I would like to, first, express my sincerest gratitude to Dr. Rachel Robertson for all of her help and guidance in conducting this research study as well as her assistance throughout my doctoral program. I would also like to thank my committee members, Dr. Douglas Kostewicz, Dr. Steven Lyon, and Dr. Leanne Bowler for their time, feedback, and support. Without the guidance and expertise from these faculty members, I would not have been able to complete this capstone project. I would also like to express my many thanks to my fellow students, who are all truly amazing and talented people. All of the faculty and students who make up the Special Education department of the University of Pittsburgh, School of Education, have made this difficult journey a wonderful experience.

Second, I would not have been able to get through a single class in my program if it were not for my family. Especially, to my husband and my mom, thank you for your patience, understanding, help, sacrifice, and confidence in me. I cannot begin to express my gratitude. Further, the help and support from my dad, brothers, aunt, grandmother, and in-laws has been essential and I would not have been able to make it this far without them. Finally, to my little girl, Gwen, you have been with me through all of this for your entire life and you have been more patient with me than any two-year-old should be. I love you to the moon and back. 


\subsection{INTRODUCTION}

Students with autism spectrum disorder (ASD) and intellectual disability (ID) make up approximately $7 \%$ and $7.4 \%$ of school-aged students receiving special education services, respectively (U.S Department of Education, 2013). For many individuals, ASD and ID exist concurrently (Schieve, Clayton, Durkin, Wingate, \& Drews-Botsh, 2015). The Autism and Developmental Disabilities Monitoring Network, funded by the Center for Disease Control (CDC), reported that 31\% of children with ASD are also identified as having an ID (i.e., IQ of less than 70) and 23\% have IQ scores placing them in the borderline range (i.e., IQ of 71 - 85). The Network also reported increasing rates of children diagnosed with ASD: one in 150 children (2002), one in 110 (2006), and one in 88 (2008). According to the most recent report, ASD affects one in 68 children (one in 42 boys and one in 189 girls) in the United States (CDC, 2014).

As young children with ASD and ID age, there will undoubtedly be an increase in young adults in need of support when they no longer qualify for services under Individuals with Disabilities Education Act (Burgess \& Cimera, 2014). Some estimate an increase of $230 \%$ in the number students with ASD making the transition to adulthood over the next eight years (Diament, 2015). Unfortunately, according to National Longitudinal Transition Study (NLTS-2) students with ASD and ID have among the lowest percentages of obtaining and maintaining employment and attending any type of postsecondary education after high school (Sanford et al., 2011). Researchers emphasize the importance of providing services to young adults with 
disabilities that result in greater independence, better quality of life, and reduced societal financial burden as individuals make the transition to adulthood (Burgess \& Cimera, 2014).

Although the idea of maintaining a focus on independent living skill instruction in schools seems to ebb and flow, many researchers, teachers, and parents have stressed the importance of recognizing and addressing needs in this area (Ayres, Lowery, Douglas, \& Sievers, 2011; Bouck, 2010). To better understand how deficits in adaptive behavior and independent living skills impact individuals with ASD and ID as they transition to adulthood, research on variables associated with improved adult outcomes has increased.

For example, Woodman, Mailick, Anderson, and Esbensen (2014) found that individuals with ID who had higher levels of adaptive behavior were more likely to live semi-independently or independently. Also, a recent study by Klinger, Klinger, Mussey, Thomas, and Powell (2015) showed that poor adaptive behavior in individuals with ASD was the strongest predictor of unemployment, social isolation, depression, and lower overall quality of life in adulthood. Finally, Taylor and Mailick (2013) found that, over a 10-year period, the educational and vocational activities of individuals with ASD between the ages of 18 and 52 remained at a staggering halt or demonstrated a steady downward trend. More importantly, the authors found a strong correlation between poor independent living skills and a decline in participation of educational and vocational activities (Taylor \& Mailick, 2013).

Evidence emphasizes the fact that adaptive and independent living skills strongly predict independent living outcomes for adults with disabilities such as ASD and ID. Findings speak to the importance of addressing adaptive behavior and independent living skills in children and adolescents with ASD and ID to better prepare them for the unavoidable transition to adulthood. 
Daily or independent living skills have been characterized as "personal self-care, domestic, and community living skills” (Gillham, Carter, Volkmar, \& Sparrow, 2000, p. 271). Examples of such skills include toileting (Bainbridge \& Myles, 1994), washing hands, brushing teeth (Charlop-Christy, Le, \& Freeman, 2000), tying shoelaces (Rayner, 2011), making a snack (Shrestha, Anderson, \& Moore, 2010), setting the table (Shipley-Benamou, Lutzker, \& Taubman, 2002), making a bed (Lasater \& Brady, 1995), purchasing items in a store (Haring, Breen, Weiner, Kennedy, \& Bednersh, 1995), putting a letter in the mailbox (Shipley-Benamou et al., 2002), and using an ATM machine (Mason, Davis, Boles, \& Goodwyn, 2013).

Children and young adults lacking independence with such skills are more inclined to allow parents or caregivers to complete tasks for them (Drahota, Wood, Sze, \& Van Dyke, 2010), which can lead to dependency on others (Koegel \& Egel, 1979). However, increased ability to complete independent living skills may help children with disabilities lead more selfreliant adult lives (Smith, M. D. \& Targett, 2009). Further, research shows that as a child's independent living skills improve, parent stress levels decrease (Green \& Carter, 2011). Improving independent living skills not only benefits individuals with disabilities but also their families.

When it comes to best practices for instructing students with ASD and ID, the importance of using systematic instruction cannot be overstated. Systematic instruction is a set of evidencebased strategies that involves thoughtful planning of teaching procedures, implementing procedures with fidelity, evaluating the effectiveness of the procedures, and modifying procedures based on student outcome data (Iovannone, Dunlap, Huber, \& Kincaid, 2003). Further, systematic instructional strategies have enabled many individuals with disabilities to become active members of our schools and communities (Hendricks, Smith, \& Wehman, 2009). 
Finally, Wehman et al. (2014) recommend using systematic instruction to address deficits related to independent living skills and predict that such instruction will help to improve overall outcomes as students move into adulthood.

Instructional practices such as visual supports (Hardman, Drew, \& Egan, 2014), reinforcement, prompting, task analysis, and modeling (Hendricks et al., 2009) have been effective in improving independent living skills of children with disabilities. Specifically with regard to individuals with ASD, using visual supports makes use of a relative strength of many students in this population. O’Riordan, Plaisted, Driver, and Baron-Cohen (2001) found that children with ASD often possess increased visual search skills compared to peers without ASD and visual supports have been used to successfully teach children with ASD to set a table and prepare an art project (West, 2008). Visual activity schedules have also been effective for students with ID (Koyama \& Wang, 2011).

Second, reinforcement, a central principal of behavior, elicits desired behaviors and increases the likelihood that the behaviors will occur more often in the future (Cooper, Heron, \& Heward, 2007). Barton, Lawrence, and Deurloo (2012) describe reinforcement as “crucial to the effectiveness of treatment and allows practitioners to deliver positive consequences for desired behavior” (p. 1209). The authors provide an example of how reinforcement procedures increased a young child's ability to follow a schedule. Third, prompting increases the likelihood that a child will respond correctly, minimizing the chance for error (Hendricks et al., 2009). Prompting strategies have been used to teach students with ASD to pack a lunch and order food at a restaurant (McConville, Hantula, \& Axelrod, 1998) and to teach telephone skills to students with ID (Manley, Collins, Stenhoff, \& Kleinhart, 2008). 
A fourth practice, task analysis, involves breaking a skill into small, manageable steps and teaching each step to a child in a systematic manner (Cooper et al., 2007). Bennet, Ramasamy, and Honsberger (2013) used a task analysis to teach students to use a folding board to fold T-shirts. Finally, modeling makes use of observational learning (Bandura, 1965) by having a child observe and learn from a model. In a study by Tekin-Iftar and Birkan (2010), students learned to prepare food and drinks through peer modeling. A group of three students with ASD were each taught a target food and drink preparation skill. While one student was completing his target skills, the others watched. When all skills were assessed, students demonstrated mastery of both target and non-target (observed) skills.

The aforementioned strategies can be effective when used individually, however, an adult or peer must be heavily involved in most aspects of each, resulting in decreased opportunities for independence. A strategy that can include each of these effective strategies while also allowing a child to engage in the task with greater independence is video modeling (VM; Hume, Loftin, \& Lantz, 2009). The increased opportunity for independence that VM offers may go hand in hand with addressing deficits in independent living skills. If the focus remains on increasing short and long-term independence, VM could be a strategy to help prepare children with ASD and ID to lead more independent adult lives.

\subsection{STATEMENT OF THE PROBLEM}

Recent research supports the use of interventions to improve the independent living skills of students with ASD and ID with the ultimate goal of increasing the likelihood of better adult outcomes (i.e., Klinger et al., 2015; Liss et al., 2001; Taylor \& Mailick, 2013; Woodman et al., 
2014). Moreover, students with ASD and ID are at risk for becoming reliant on adults around them to complete independent living skills (Giangreco \& Broer, 2007), which can lead to dependency on prompting and assistance (Koegel \& Egel, 1979). Therefore, we need to develop efficient and effective interventions to address independent living skill deficits while providing students with ASD and ID with more opportunities to complete skills with reduced reliance on adults. Promising interventions to meet this need include video modeling (VM) and a new form of VM called continuous video modeling (CVM).

However, many unanswered questions remain regarding the most effective and efficient VM and CVM interventions and for whom the interventions may be most effective. Specifically, it is still unclear which video-based intervention is most effective and differential effects of the interventions based on individual student characteristics have yet to be determined. Additionally, questions remain as to which of the many video components that may be included in the video model is most likely to lead to the highest level of performance. 


\subsection{REVIEW OF THE LITERATURE}

Video-based interventions, rooted in Albert Bandura's social learning theory and the idea of learning through observation, have been around for decades (Bandura, 1977). Researchers have been investigating how the use of video or film can be used to change and shape behavior since as early as 1968 (Thelen, Fry, Fehrenbach, \& Frautchi, 1979). VM interventions have been used to improve the skills of students with and without disabilities (Delano, 2007; Thelen et al., 1979). Video-based interventions have been effective for students with disabilities such as ASD, ID, emotional behavior disorder, and learning disabilities to address socio-communication, play, academic, adaptive behavior, and independent living skill deficits (Mason et al., 2013). Although VM has been identified as an evidence-based practice (Bellini \& Akullian, 2007; Plavnick, 2013) questions remain as to which types of VM are most effective, which of the various components that may be included into the intervention are most likely to yield positive outcomes, and for whom VM is most likely to be effective (Rayner, et al., 2009). 


\subsection{VM: BENEFITS AND CHALLENGES}

\subsubsection{Intervention variations and descriptions}

VM occurs when a student watches a video of a model performing a skill in its entirety and then is expected to complete the same skill in the same way (LeBlanc et al., 2003). A different intervention called video prompting (VP) occurs when a student watches a single video clip of a model completing one of multiple steps of a skill. The student completes the first step before returning to the video to view the next step in the skill sequence. The pattern continues for each step. Gardner and Wolfe (2013) reported that research investigating the comparative effects of the two interventions is limited (see Cannella-Malone et al., 2006; Cannella-Malone et al., 2011; Van Laarhoven \& Van Laarhoven-Myers, 2006).

One key distinction between the procedures used in VM versus VP is the amount of adult prompting and interaction. During VM students typically a) watch a video, b) receive an initial prompt to begin the task, and c) receive additional prompts as needed to complete the task (e.g., Charlop-Christy et al., 2000; Rosenberg, Schwartz, \& Davis, 2010; Shipley-Benamou et al., 2002; Shrestha et al., 2013). Conversely, during VP students often a) watch a video clip showing one step of a task, b) receive assistance to pause the video, c) are prompted to complete the step viewed, d) are prompted to return to the video, e) receive assistance to play the video, and then steps “b” through “e” are repeated until the task is complete (Sigafoos et al., 2005; Zisimopoulos, Sigafoos, \& Koutromanos, 2011). Based on descriptions of general procedures used in both video-based interventions, VP requires much more prompting and adult guidance. Prompt dependence is often a major concern when teaching students with ASD and ID. VM is an 
intervention that may require less adult prompting strictly based on intervention procedures (Hume et al., 2009).

\subsubsection{VM implementation}

Although general VM implementation remains fairly consistent, specific procedures used by researchers vary. Moreover, VM implementers have many options when it comes to incorporating different components into videos used for student viewing. Most VM interventions use custom-made videos as opposed to commercially made videos (Wang \& Koyama, 2014). Further, Rosenberg et al. (2010) found that custom-made videos were generally more effective than commercially made videos.

Rayner, Denholm, and Sigafoos (2009) described important factors to consider when creating custom-made videos including point-of-view, model type, narration, and text. Videos can be filmed using first-person or third-person. Videos filmed with first-person show a task completed from the student's perspective (i.e., an individual's hands are shown performing a task), while videos filmed in third-person make use of 'others' or 'self' (also called video selfmodeling) as models. When using 'others' as the model-type, a peer or an adult acts in the video. If a self-model is used, the teacher or researcher must capture footage of the student correctly performing the task. Implementers often record the student completing a task with adult assistance and prompting. The video is then edited to create a product in which the student appears to have completed the skill independently (Mason, Ganz, Parker, Burke, \& Camargo, 2012). Finally, all types of videos may include narration (i.e., voice over) and/or text to describe the model's actions (Rayner et al., 2009). 
VM implementers must also decide how to implement the intervention itself. For example, VM may be used as a package intervention (i.e., paired with visual cues, prompting, feedback, role play, reinforcement, time delay procedures; see Cannella-Malone, Mizrachi, Sabielny, \& Jimenez, 2013; Lasater \& Brady, 1995; Loughrey, Marshall, Bellizzi, \& Wilder, 2013; Rai, 2008; Shrestha et al., 2013) or as a stand-alone intervention (see Charlop-Christy et al., 2000; D’Ateno, Mangiapanello, \& Taylor, 2003; Lowy Apple, Billingsley, \& Schwartz, 2005). Another major consideration relates to how students view videos. Traditionally, videos have been viewed on televisions or computers (Miltenberger \& Charlop, 2015); however, researchers are beginning to investigate the effects of $\mathrm{VM}$ on smaller, more portable devices such as smartphones and tablets (Blood, Johnson, Ridenour, Simmons, \& Crouch, 2011; Cihak, Fahrenkrog, Ayres, \& Smith, 2010). Miltenberger and Charlop (2015) compared traditional and portable modes of viewing (i.e., TV versus $\mathrm{iPad}\left({ }^{\circledR}\right)$ and found that smaller devices lead to slightly slower acquisition, but suggested that research in this area should be continued due to the potential benefits of using portable devices.

\subsubsection{Potential advantages of VM}

Students with ASD and ID are especially at risk for become over-reliant on the adults around them because they often receive instruction in one-on-one settings or work one-on-one with a paraprofessional (Giangreco \& Broer, 2007). Shockingly, Giangreco and Broer (2005) reported that special education paraprofessionals reported spending $86 \%$ of their day within 3 feet of their assigned student. One of the most appealing potential advantages of VM is that the intervention

may provide opportunities for students with ASD and ID to work more independently (Hume et al., 2009). 
Other potential advantages noted in the broad VM literature include reduced costs and time efficiency (Charlop-Christy et al, 2000), increased skill generalization and maintenance (Haring, Kennedy, \& Pitts-Conway, 1987), and greater consistency with the delivery of instructional content (Mason et al., 2013). Additionally, VM may help students who are easily distracted by environmental elements to focus on the most relevant stimuli (McCoy \& Hermansen, 2007). Moreover, many children often enjoy using technology and watching videos (Charlop-Christy \& Daneshvar, 2003). VM may combine instruction with a preferred activity, which may increase a child's motivation to perform a skill (Hendricks et al, 2009).

Finally, the influx of technology in today's schools and society cannot be overlooked. Currently, $100 \%$ of public schools and $97 \%$ of classrooms in the U.S. have computers. Fiftyeight percent of schools have laptop carts. Moreover, schools are beginning to provide handheld devices to students for instructional purposes (National Center for Education Statistics; NCES, 2010) and almost 50\% of schools allow students to bring their own devices to class (Software \& Information Industry Association, SIIA, 2014).

Outside of the school environment, $78 \%$ of $12-17$ year olds have a cell phone, $47 \%$ of which are smartphones and percentages are consistently increasing. Additionally, $23 \%$ of teens have a tablet and 93\% have access to a computer at home (Madden, Lenhart, Duggan, Cortesi, \& Gasser, 2013). Finally, children between the ages of eight and 18 spend an average of seven hours and 38 minutes per day using electronic devices (The Henry J. Kaiser Family Foundation, 2010). Given these astounding facts and figures, it is obvious that technology is here to stay and children of all ages are becoming accustomed to using devices for many purposes such as downloading books, playing video games, accessing the internet, listening to music, and watching movies and TV content (The Henry J. Kaiser Family Foundation, 2010). Regardless of 
whether the infusion of technology is a problem or a benefit to our society, the fact that it exists is undeniable. Therefore, the social appropriateness, subtlety, and non-stigmatizing use of technology-based interventions such as VM should be given much consideration. Students are surrounded by technology and it is up to researchers and educators to find ways to use devices in ways that will benefit students.

Despite the many promises of VM, researchers and practitioners face challenges and questions when it comes to implementing the most effective VM interventions. Due to the wide variety of VM implementations (i.e., variations in procedures and video components), it is very possible that while one version of VM may be effective for one student, the same intervention is ineffective for another (Rayner et al., 2009). Moreover, some skill areas may be more conducive to VM or certain variations of VM than others (Delano, 2007). When it comes to teaching independent living skills, the most effective versions of VM are still unknown.

The purpose of the review was to analyze and synthesize the current literature base investigating the use of VM to teach independent living skills to students with ASD and ID. Research questions were: What were the characteristics of the participants and in what settings were studies conducted? What types of questions did researchers ask and what experimental designs were used? What variations of VM were used most frequently and what components were most often included in video models? What types of independent living skills were targeted and what types of outcome measures were used to evaluate the effects of VM? What was the overall efficacy of VM as determined through visual analysis and through calculation of the percentage of non-overlapping data (PND) across each study and for each participant? Finally, did any correlations exist between specific participant characteristics or intervention components and effective and/or ineffective interventions? 


\subsection{METHOD}

\subsubsection{Literature search}

\subsubsection{ASD focused search}

An initial literature search, intended to identify only studies including individuals with ASD, was conducted in March and April 2015. First, studies were located by conducting a computerized search using the PsycINFO, PsycArticles, and ERIC databases. Search terms included autism, ASD, or Asperger, and independent living, daily living, functional, adaptive, self-care, or selfhelp, and video modeling or videotape modeling. The initial search resulted in 885 total articles,

four of which met inclusion criteria. Following the computerized search, ancestral searches of the resulting articles led to an additional three articles. Next, 12 pertinent literature reviews were searched yielding three more articles. Finally, four relevant journals were hand searched, leading to three more articles.

Overall, the ASD focused literature search resulted in 13 studies (41 participants with ASD) published in nine journals (Alcantara, 1994; Alexander, Ayres, Smith, Shepley, Mataras, 2013; Allen, Wallace, Renes, Bowen, \& Burke, 2010; Allen, Wallace, Greene, Bowen, \& Burke, 2010; Cannella-Malone et al., 2011; Cihak \& Schrader, 2008; Hagiwara \& Myles, 1999; Mechling \& Ayres, 2012; Mechling, Ayres, Bryant, \& Foster, 2014a; Mechling, Ayres, Bryant, \& Foster, 2014b; Murzynski \& Bourret, 2007; Smith, M., Ayres, Mechling, \& Smith, 2013; Smith, K. A., Shepley, Alexander, Davis, \&Ayers, 2015; see Tables 1-3). 


\subsubsection{ID focused search}

A second search was conducted in December 2015 to identify VM studies including participants with ID who did not have an ASD diagnosis. First, the entire pool of studies from the original ASD search was reviewed to identify studies or participants initially excluded because of a lack of ASD diagnosis. This resulted in the identification of one new study and six new participants from four of the original ASD studies included in the analysis. Next, the 12 pertinent literature reviews previously searched were reviewed a second time and two more articles were identified. The computerized search from the ASD search was repeated using the same search terms except autism, ASD, or Asperger were replaced with intellectual disability(s), developmental disability(s), cognitive disability(s), mental retardation, or Down syndrome. This lead to 2,236 articles and the researcher reviewed all titles and, when the researcher needed more information, abstracts. No new articles were identified. Finally, three relevant journals were hand searched and three new articles were identified.

The ID focused search resulted in six new studies and 24 new participants with a diagnosis of ID without ASD published in three journals (Mechling, Gast, \& Gustofson, 2009; Mechling \& Collins, 2012; Scott, Collins, Knight, \& Kleinert, 2013; Taber-Doughty, Patton, \& Brennan, 2008; Taber-Doughty, Bouck, Tom, Jasper, Flanagan, \& Bassette, 2011; Van Laarhoven, Zurita, Johnson, Grider, \& Grider, 2009). Combined, the searches resulted in 19 studies with 65 participants diagnosed with ASD and/or ID across nine journals (see Tables 1-3).

\subsubsection{Inclusion criteria}

Articles included in this review were selected based on the following final criteria: researchers

(a) used a single-subject or group experimental design, (b) conducted the study in the United 
States, (c) published findings in a peer-reviewed journal, (d) included at least one school-aged (i.e., grade K-12 or age 5-21) participant with ASD or ID, (e) employed the independent variable to investigate the effects of VM or compared VM to VP, (f) collected data on student performance of independent living skills (i.e., dependent variable) (g) created custom-made video models, and (h) required the student to perform a task immediately following the viewing of the video (i.e., within 15 minutes) or while watching the video.

Studies conducted outside the U.S. were excluded as socio-technical systems have cultural practices attached to them and it is difficult to disentangle these practices from the research. Also, there is a social context to school systems within different countries that may affect how technology is adopted. Studies were also excluded if: (a) all participants were younger than 5 or older than 21 years of age, (b) investigations focused only on the effects of VP interventions, (c) the dependent variable was aimed at decreasing problem behavior, (d) only commercially made videos were used, and (e) the time between a student's viewing of a video model and performance of a target skill was greater than 15 minutes.

\subsubsection{Article coding and analysis}

For each study, the researcher coded participants by disability, age, gender, and IQ, the most commonly reported characteristics. Participants were also coded by reported Vineland Adaptive Behavior Scales (VABS) assessment scores; reading level; the existence of problem behaviors; communication and imitation skills; prior exposure to target skills; and his or her ability to work independently, follow directions, and attend to screen-based activities. The researcher also coded the following study components: setting, experimental design, description of dependent variables and target skills; description of independent variables (i.e., variations of VM) and description of 
video models; outcome measures including skill acquisition, generalization, and maintenance; and results of procedural integrity (PI), interobserver agreement (IOA), and social validity measures.

To analyze the efficacy of VM, graphs were visually analyzed by level, trend, and variability (Horner et al., 2005). Additionally, because all studies included baseline and intervention phases, PND (Scruggs, Mastropieri, \& Castro, 1987) was calculated for each participant by determining the percentage of data points in an intervention phase that exceeded the highest baseline data point (Scruggs \& Mastropieri, 2013). Further, average PND was calculated for each study by determining the average PND across all participants of the study. Intervention effectiveness was determined using the effect size rankings developed by Scruggs and Mastropieri (1998; i.e., 90\% and above indicates a highly effective intervention, 70-89\% indicates an effective intervention, 50\%-69\% indicates questionable effects, and $49 \%$ and below indicates an ineffective intervention). The researcher compared visual analysis results to the results of PND analysis and effect size rankings to ensure that intervention effects were described as accurately as possible in terms of each intervention's general effectiveness or ineffectiveness for the participants in the studies. 
Table 1. Potentially relevant participant characteristics and study outcomes

\begin{tabular}{|c|c|c|c|c|c|c|}
\hline Study & Gender & Race & Age & Disability & IQ Score & $\begin{array}{l}\text { Effect } \\
\text { Rank }\end{array}$ \\
\hline \multirow{2}{*}{ Alcantara (1994) } & TF & - & 8 & ASD & - & HE \\
\hline & $2 \mathrm{M}$ & & $9.11 \& 9.11$ & ASD \& MR & $-\& 55$ & $\mathrm{HE} \& \mathrm{HE}$ \\
\hline \multirow[t]{7}{*}{ Alexander et al. (2013) } & TF & $\overline{-}$ & 17.2 & ASD & 57 & $\mathrm{E}$ \\
\hline & $6 \mathrm{M}$ & & 15.1 & All ASD & 64 & HE \\
\hline & & & 17.6 & & 47 & NE \\
\hline & & & 17.6 & & - & NE \\
\hline & & & 17.8 & & 44 & E \\
\hline & & & 17.11 & & 32 & Q \\
\hline & & & 18.7 & & 48 & $\mathrm{E}$ \\
\hline Allen et al. (2010a) & $3 \mathrm{M}$ & $\overline{-}$ & $16,17,18$ & AIIASD & - & $\mathrm{NE}, \mathrm{NE}, \mathrm{B}$ \\
\hline Allen et al. (2010b) & $2 \mathrm{M}$ & - & $17 \& 19$ & Both ASD & - & E\&E \\
\hline \multirow{5}{*}{$\begin{array}{l}\text { Cannella-Malone et al. } \\
\text { (2011) }\end{array}$} & $2 \mathrm{~F}$ & Black \& White & TI\& 13 & Both ASD & - & $\mathrm{NE} \& \mathrm{NE}$ \\
\hline & $5 \mathrm{M}$ & 2 Black & Both 12 & ASD & & $\mathrm{NE}$ \\
\hline & & White & 13 & ASD & & NE \\
\hline & & Somali & 12 & ASD & & NE \\
\hline & & Biracial & 13 & MR & & $\mathrm{E}$ \\
\hline \multirow[t]{4}{*}{ Cihak \& Schrader (2008) } & $4 \mathrm{M}$ & $\overline{-}$ & 16 & AIIASD & 50 & HE \\
\hline & & & 17 & & 30 & E \\
\hline & & & 20 & & 35 & HE \\
\hline & & & 21 & & 45 & $\mathrm{HE}$ \\
\hline Hagiwara \& Myles (1999) & $2 \mathrm{M}$ & Both White & $7.11 \& 9.11$ & Both ASD & - & NE \& NE \\
\hline Mechling et al. (2009) & $\begin{array}{l}2 \mathrm{~F} \\
1 \mathrm{M}\end{array}$ & - & $\begin{array}{l}19.3 \& 21.3 \\
19.4\end{array}$ & AIIID & $\begin{array}{l}52 \& 45 \\
46\end{array}$ & HE for all \\
\hline \multirow[t]{4}{*}{ Mechling \& Ayres (2012) } & $4 \mathrm{M}$ & - & 19.9 & AII ASD & 40 & HE for all \\
\hline & & & 19.9 & & 51 & \\
\hline & & & 20.8 & & 54 & \\
\hline & & & 21.7 & & 64 & \\
\hline \multirow{2}{*}{ Mechling \& Collins (2012) } & $\mathrm{TF}$ & $\overline{-}$ & 19.7 & AIIID & 44 & HE for all \\
\hline & $2 \mathrm{M}$ & & $20.1 \& 21$ & & $-\& 39$ & \\
\hline \multirow[t]{2}{*}{ Mechling et al. (2014a) } & $2 \mathrm{~F}$ & - & $15.7 \& 17$ & Both ID & $44 \& 40$ & HE for all \\
\hline & $1 \mathrm{M}$ & & 15.5 & ASD & 48 & \\
\hline \multirow{2}{*}{ Mechling et al. (2014b) } & $2 \mathrm{~F}$ & $\overline{-}$ & $15.7 \& 17$ & Both ID & $44 \& 40$ & HE \& E \\
\hline & $1 \mathrm{M}$ & & 15.5 & ASD & 48 & $\mathrm{HE}$ \\
\hline Murzynki \& Bourret (2007) & - & - & $8 \& 9$ & Both ASD & - & $\mathrm{HE} \& \mathrm{HE}$ \\
\hline \multirow[t]{2}{*}{ Scott et al. (2013) } & $2 \mathrm{~F}$ & $\overline{-}$ & $19.1 \& 20.9$ & AIIID & $64 \& 40$ & HE for all \\
\hline & $1 \mathrm{M}$ & & 18.2 & & 54 & \\
\hline \multirow[t]{4}{*}{ Smith, M. et al. (2013) } & $4 \mathrm{M}$ & - & 14.6 & AII ASD & 58 & HE for all \\
\hline & & & 15.2 & & 58 & \\
\hline & & & 16.5 & & 60 & \\
\hline & & & 16.6 & & 86 & \\
\hline \multirow[t]{3}{*}{ Smith, K. A. et al. (2015) } & $3 \mathrm{M}$ & Black & 15.1 & AIIASD & $\overline{-}$ & $\mathrm{HE}$ \\
\hline & & Black & 16.4 & & & $Q$ \\
\hline & & White & 16.6 & & & $\mathrm{HE}$ \\
\hline Taber-Doughty et al. (2008) & $3 \mathrm{M}$ & $\overline{-}$ & $13,13,15$ & AIIID & $50,57,46$ & $\mathrm{E}, \mathrm{E}, \mathrm{HE}$ \\
\hline \multirow[t]{2}{*}{ Taber-Doughty et al. (2011) } & $2 \mathrm{~F}$ & Both White & $12 \& 13$ & AIIID & $72 \& 61$ & NE \& E \\
\hline & $1 \mathrm{M}$ & Black & 12 & & 63 & NE \\
\hline \multirow[t]{2}{*}{ Van Laarhoven et al. (2009) } & $2 \mathrm{~F}$ & - & $12 \& 15$ & AIIID & -830 & HE for all \\
\hline & $1 \mathrm{M}$ & & 17 & & 40 & \\
\hline
\end{tabular}




\section{Table 2. Potentially relevant intervention components}

\begin{tabular}{|c|c|c|c|c|c|c|c|c|c|c|}
\hline Study & $\begin{array}{l}\# \text { of } \mathrm{x} \\
\text { videos } \\
\text { viewed }\end{array}$ & $\begin{array}{l}\mathrm{VMA}, \\
\mathrm{VM}+\mathrm{P}, \\
\text { or both }\end{array}$ & $\mathrm{SR}+$ & $\begin{array}{l}\text { Task } \\
\text { Analysis } \\
\text { (\# steps) }\end{array}$ & POV & $\begin{array}{l}\text { Model } \\
\text { Type }\end{array}$ & $\begin{array}{l}\text { Video } \\
\text { Length }\end{array}$ & $\begin{array}{l}\text { Viewing } \\
\text { Device }\end{array}$ & Narrated & $\begin{array}{l}\text { Zoom } \\
\text { \&/or } \\
\text { Delay }\end{array}$ \\
\hline $\begin{array}{l}\text { Alcantara } \\
(1994)\end{array}$ & $1 x$ & Both & $\begin{array}{l}\text { SR+ w/o } \\
\text { PA \& VP }\end{array}$ & $\begin{array}{l}\text { Yes } \\
(32)\end{array}$ & $\begin{array}{l}1 \text { to } \& \\
3 n t\end{array}$ & Adult & Long & TV & Yes & No \\
\hline $\begin{array}{l}\text { Alexander et } \\
\text { al. (2013) }\end{array}$ & Varied & Both & VP & $\begin{array}{l}\text { Yes } \\
(5)\end{array}$ & $T^{m}$ & $\mathrm{NA}$ & $=$ & iPadQ & Yes & Yes \\
\hline $\begin{array}{l}\text { Allen et al. } \\
(2010 \mathrm{a})\end{array}$ & Varied & VMA & No & No & $\begin{array}{l}T^{m \&} \\
3 n\end{array}$ & $=$ & Long & $=$ & $=$ & No \\
\hline $\begin{array}{l}\text { Allen et al. } \\
(2010 \mathrm{~b})\end{array}$ & $2 x$ & VMA & No & No & $\begin{array}{l}T^{m+8} \\
3 n\end{array}$ & $=$ & Long & $=$ & Yes & No \\
\hline $\begin{array}{l}\text { Cannella- } \\
\text { Malone et al. } \\
(2011)\end{array}$ & Varied & Both & $\mathrm{NCR}$ & $\begin{array}{l}\text { Yes } \\
(18)\end{array}$ & $T^{10}$ & $\mathrm{NA}$ & $\begin{array}{l}\text { Long \& } \\
\text { short }\end{array}$ & Computer & Yes & No \\
\hline $\begin{array}{l}\text { Cihak \& } \\
\text { Schrader } \\
(2008) \\
\end{array}$ & Varied & $\mathrm{VM}+\mathrm{P}$ & VP & $\begin{array}{l}\text { Yes } \\
(10.75)\end{array}$ & $3 \pi$ & $\begin{array}{l}\text { Adult } \\
\text { vs. self }\end{array}$ & $\begin{array}{l}\text { Long \& } \\
\text { short }\end{array}$ & Computer & Yes & Yes \\
\hline $\begin{array}{l}\text { Hagiwara \& } \\
\text { Myles (1999) }\end{array}$ & $\mathrm{Tx}$ & VMA & No & $\begin{array}{l}\text { Yes } \\
(6)\end{array}$ & $3 \sqrt{d}$ & Self & - & Computer & $\begin{array}{l}\text { Yes, with } \\
\text { text }\end{array}$ & No \\
\hline $\begin{array}{l}\text { Mechling et } \\
\text { al. (2009) }\end{array}$ & $\mathrm{Tx}$ & VMA & No & $\begin{array}{l}\text { Yes } \\
(4.6) \\
\end{array}$ & $\begin{array}{l}1^{\text {th }} \& \\
\text { 3rd }\end{array}$ & Adult & Short & $\begin{array}{l}\text { Portable } \\
\text { DVD }\end{array}$ & Yes & No \\
\hline $\begin{array}{l}\text { Mechling \& } \\
\text { Ayres (2012) }\end{array}$ & $1 \mathrm{x}$ & VMA & $\mathrm{VP}$ & No & $T^{\text {tat }}$ & $\mathrm{NA}$ & Short & $\begin{array}{l}\text { Pocket PC } \\
\text { vs. } \\
\text { computer }\end{array}$ & Yes & Yes \\
\hline $\begin{array}{l}\text { Mechling \& } \\
\text { Collins } \\
(2012)\end{array}$ & $\mathrm{Tx}$ & VMA & $\begin{array}{l}\text { SR+w/o } \\
\text { PA }\end{array}$ & $\begin{array}{l}\text { Yes } \\
(26)\end{array}$ & Ist & Adult & Short & Computer & $\begin{array}{l}\text { With vs. } \\
\text { without } \\
\text { narration }\end{array}$ & No \\
\hline $\begin{array}{l}\text { Mechling et } \\
\text { al. }(2014 \mathrm{a})\end{array}$ & $\begin{array}{l}\text { During } \\
\text { task }\end{array}$ & Both & $\begin{array}{l}\mathrm{SR}+\mathrm{w} / 0 \\
\mathrm{PA} \& \mathrm{VP}\end{array}$ & $\begin{array}{l}\text { Yes } \\
(26.6)\end{array}$ & $\begin{array}{l}T^{m} \& \\
3 n\end{array}$ & Adult & Long & Computer & Yes & Yes \\
\hline $\begin{array}{l}\text { Mechling et } \\
\text { al. }(2014 \mathrm{~b})\end{array}$ & $\mathrm{Tx}$ & VMA & $\begin{array}{l}\mathrm{SR}+\mathrm{w} / 0 \\
\mathrm{PA} \& \mathrm{VP}\end{array}$ & No & $\begin{array}{l}1 \% 8 \\
3 n\end{array}$ & Adult & $=$ & Computer & Yes & Yes \\
\hline $\begin{array}{l}\text { Murzynki \& } \\
\text { Bourret } \\
(2007) \\
\end{array}$ & $\mathrm{Tx}$ & $\mathrm{VM}+\mathrm{P}$ & $\begin{array}{l}\text { SR+ w/o } \\
\mathrm{PA} \& \mathrm{VP}\end{array}$ & $\begin{array}{l}\text { Yes } \\
(8)\end{array}$ & $3 \sqrt{c}$ & Adult & $\begin{array}{l}\text { Long \& } \\
\text { short }\end{array}$ & TV & No & No \\
\hline $\begin{array}{l}\text { Scott et al. } \\
(2013)\end{array}$ & $\begin{array}{l}\text { During } \\
\text { task }\end{array}$ & $\mathrm{VM}+\mathrm{P}$ & VP & $\begin{array}{l}\text { Yes } \\
(16.5)\end{array}$ & Both & Peer & $=$ & IPods & Yes & Yes \\
\hline $\begin{array}{l}\text { Smith, M. et } \\
\text { al. (2013) }\end{array}$ & $\mathrm{Tx}$ & VMA & $\begin{array}{l}\mathrm{SR}+\mathrm{w} / 0 \\
\mathrm{PA} \& \mathrm{VP}\end{array}$ & $\begin{array}{l}\text { Yes } \\
(20.5)\end{array}$ & $3 \sqrt{4}$ & Adult & $\begin{array}{l}\text { Long \& } \\
\text { short }\end{array}$ & iPhoned & $\begin{array}{l}\text { With vs. } \\
\text { without } \\
\text { narration }\end{array}$ & No \\
\hline $\begin{array}{l}\text { Smith, K. A. } \\
\text { et al. (2015) }\end{array}$ & $\begin{array}{l}\text { During } \\
\text { task }\end{array}$ & Both & No & $\begin{array}{l}\text { Yes } \\
(7)\end{array}$ & $T^{\pi}$ & $\mathrm{NA}$ & $=$ & $\begin{array}{l}\text { Computer } \\
\& \text { phone }\end{array}$ & No & No \\
\hline $\begin{array}{l}\text { Taber- } \\
\text { Doughty et } \\
\text { al. (2008) }\end{array}$ & $\mathrm{Tx}$ & $\mathrm{VM}+\mathrm{P}$ & No & $\begin{array}{l}\text { Yes } \\
(9)\end{array}$ & $3 \pi$ & Adult & Long & TV \& ipod & Yes & No \\
\hline $\begin{array}{l}\text { Taber- } \\
\text { Doughty et } \\
\text { al. (2011) }\end{array}$ & $1 \mathrm{x}$ & Both & No & $\begin{array}{l}\text { Yes } \\
(10.1)\end{array}$ & Both & Adult & Long & $\begin{array}{l}\text { iPodx } \\
\text { Nano }\end{array}$ & Yes & Yes \\
\hline $\begin{array}{l}\text { Van } \\
\text { Laarhoven et } \\
\text { al. (2009) }\end{array}$ & $\mathrm{Tx}$ & $\mathrm{VM}+\mathrm{P}$ & No & No & Both & $\begin{array}{l}\text { Adult } \\
\text { vs. self } \\
\text { vs. } 1^{\text {nt }}\end{array}$ & - & Computer & $\begin{array}{l}\text { Yes, with } \\
\text { text }\end{array}$ & Yes \\
\hline
\end{tabular}


Table 3. Target skills, dependent variable, visual analysis description, PND \& effects

\begin{tabular}{|c|c|c|c|c|c|}
\hline Study & Target Skills & $\begin{array}{l}\text { Outcome } \\
\text { Measures }\end{array}$ & $\begin{array}{l}\text { (Baseline) } \\
\text { Level/Trend/ } \\
\text { Variability } \\
\end{array}$ & $\begin{array}{l}\text { (VM) } \\
\text { Level/Trend/ } \\
\text { Variability }\end{array}$ & $\begin{array}{l}\text { PND: } \\
\text { Effect } \\
\text { Rank }\end{array}$ \\
\hline Alcantara (1994) & Money & $\begin{array}{l}\text { \# of correct } \\
\text { steps }\end{array}$ & $\begin{array}{l}\text { Low \& high/Up \& down/ } \\
\text { High variability }\end{array}$ & $\begin{array}{l}\text { High/Stable/ } \\
\text { Stable }\end{array}$ & $\begin{array}{l}98.9 \%: \\
\mathrm{HE}\end{array}$ \\
\hline $\begin{array}{l}\text { Alexander et al. } \\
\text { (2013) }\end{array}$ & Job training & $\begin{array}{l}\text { \# of correct } \\
\text { tasks }\end{array}$ & $\begin{array}{l}\text { Low/Stable/ } \\
\text { Stable }\end{array}$ & $\begin{array}{l}\text { Low \& high/ } \\
\text { Stable/Stable }\end{array}$ & $\begin{array}{l}57.6 \%: \\
Q\end{array}$ \\
\hline Allen et al. (2010a) & Job training & $\begin{array}{l}\% \text { of intervals } \\
\text { with } 2+\text { skills }\end{array}$ & $\begin{array}{l}\text { Low/Stable/ } \\
\text { Minimal variability }\end{array}$ & $\begin{array}{l}\text { Mid/Up \& Down/ } \\
\text { High variability }\end{array}$ & $\begin{array}{l}43.6 \%: \\
\mathrm{NE}\end{array}$ \\
\hline Allen et al. (2010b) & Job training & $\begin{array}{l}\% \text { of intervals } \\
\text { with } 2+\text { skills }\end{array}$ & $\begin{array}{l}\text { Low/Up \& down/ } \\
\text { Some variability }\end{array}$ & $\begin{array}{l}\text { High/Upward/ } \\
\text { High variability }\end{array}$ & $\begin{array}{l}77.5 \%: \\
\text { E }\end{array}$ \\
\hline $\begin{array}{l}\text { Cannella-Malone } \\
\text { et al. (2011) }\end{array}$ & $\begin{array}{l}\text { Food prep \& } \\
\text { laundry }\end{array}$ & $\begin{array}{l}\% \text { of correct } \\
\text { steps }\end{array}$ & $\begin{array}{l}\text { Low/Stable/ } \\
\text { Stable }\end{array}$ & $\begin{array}{l}\text { Low/Stable/ } \\
\text { Stable }\end{array}$ & $\begin{array}{l}\text { 16.6\%: } \\
\text { NE }\end{array}$ \\
\hline $\begin{array}{l}\text { Cihak \& Schrader } \\
(2008)\end{array}$ & Job training & $\begin{array}{l}\% \text { of correct } \\
\text { steps }\end{array}$ & $\begin{array}{l}\text { Low/Stable/ } \\
\text { Stable }\end{array}$ & $\begin{array}{l}\text { Low to high/Upward/ } \\
\text { Stable }\end{array}$ & $\begin{array}{l}95.0 \%: \\
\mathrm{HE}\end{array}$ \\
\hline $\begin{array}{l}\text { Hagiwara \& Myles } \\
\text { (1999) }\end{array}$ & Self-care & $\begin{array}{l}\% \text { of correct } \\
\text { steps }\end{array}$ & $\begin{array}{l}\text { High/Stable' } \\
\text { Stable }\end{array}$ & $\begin{array}{l}\text { High/Stable/ } \\
\text { Stable }\end{array}$ & $\begin{array}{l}42.8 \%: \\
\mathrm{NE}\end{array}$ \\
\hline $\begin{array}{l}\text { Mechling et al. } \\
\text { (2009) }\end{array}$ & Self-care & $\begin{array}{l}\% \text { of correct } \\
\text { steps }\end{array}$ & $\begin{array}{l}\text { Low/Stable/ } \\
\text { Stable }\end{array}$ & $\begin{array}{l}\text { High/Stable/ } \\
\text { Stable }\end{array}$ & $\begin{array}{l}\text { TOO\%: } \\
\mathrm{HE}\end{array}$ \\
\hline $\begin{array}{l}\text { Mechling \& Ayres } \\
\text { (2012) }\end{array}$ & Job training & $\begin{array}{l}\text { \# of correct } \\
\text { tasks }\end{array}$ & $\begin{array}{l}\text { Low/Stable/ } \\
\text { Stable }\end{array}$ & $\begin{array}{l}\text { High/Upward/ } \\
\text { Some variability }\end{array}$ & $\begin{array}{l}97.9 \%: \\
\mathrm{HE}\end{array}$ \\
\hline $\begin{array}{l}\text { Mechling \& } \\
\text { Collins (2012) }\end{array}$ & Food prep & $\begin{array}{l}\% \text { of correct } \\
\text { steps }\end{array}$ & $\begin{array}{l}\text { Low/Stable/ } \\
\text { Stable }\end{array}$ & $\begin{array}{l}\text { Mid to high/Upward/ } \\
\text { Stable }\end{array}$ & $\begin{array}{l}\text { TOO\%: } \\
\text { HE }\end{array}$ \\
\hline $\begin{array}{l}\text { Mechling et al. } \\
\text { (2014a) }\end{array}$ & Job training & $\begin{array}{l}\text { \% of correct } \\
\text { steps }\end{array}$ & $\begin{array}{l}\text { Low/Stable/ } \\
\text { Stable }\end{array}$ & $\begin{array}{l}\text { Low to high/Upward/ } \\
\text { Stable }\end{array}$ & $\begin{array}{l}\text { 100\%: } \\
\mathrm{HE}\end{array}$ \\
\hline $\begin{array}{l}\text { Mechling et al. } \\
\text { (2014b) }\end{array}$ & Job training & $\begin{array}{l}\% \text { of correct } \\
\text { steps }\end{array}$ & $\begin{array}{l}\text { Low/Stable/ } \\
\text { Stable }\end{array}$ & $\begin{array}{l}\text { Mid to high/Upward/ } \\
\text { Some variability }\end{array}$ & $\begin{array}{l}93.77 \%: \\
\text { HE }\end{array}$ \\
\hline $\begin{array}{l}\text { Murzynki \& } \\
\text { Bourret (2007) }\end{array}$ & $\begin{array}{l}\text { Food prep \& } \\
\text { laundry }\end{array}$ & $\begin{array}{l}\text { \# of correct } \\
\text { steps }\end{array}$ & $\begin{array}{l}\text { Low/Stable/ } \\
\text { Stable }\end{array}$ & $\begin{array}{l}\text { Low to high/Upward/ } \\
\text { Stable }\end{array}$ & $\begin{array}{l}97.7 \%: \\
\mathrm{HE}\end{array}$ \\
\hline Scott et al. (2013) & Money & $\begin{array}{l}\% \text { of correct } \\
\text { steps }\end{array}$ & $\begin{array}{l}\text { Low/Stable/ } \\
\text { Stable }\end{array}$ & $\begin{array}{l}\text { High/Stable/ } \\
\text { Stable }\end{array}$ & $\begin{array}{l}\text { 100\%: } \\
\mathrm{HE}\end{array}$ \\
\hline $\begin{array}{l}\text { Smith, M. et al. } \\
\text { (2013) }\end{array}$ & Food prep & $\begin{array}{l}\% \text { of correct } \\
\text { steps }\end{array}$ & $\begin{array}{l}\text { Low/Stable/ } \\
\text { Stable }\end{array}$ & $\begin{array}{l}\text { Low to high/Upward/ } \\
\text { Stable }\end{array}$ & $\begin{array}{l}95.9 \%: \\
\mathrm{HE}\end{array}$ \\
\hline $\begin{array}{l}\text { Smith, K. A. et al. } \\
(2015)\end{array}$ & Job training & $\begin{array}{l}\% \text { of correct } \\
\text { steps }\end{array}$ & $\begin{array}{l}\text { Low/Stable/ } \\
\text { Stable }\end{array}$ & $\begin{array}{l}\text { Low to high/Upward/ } \\
\text { Stable }\end{array}$ & $\begin{array}{l}88.1 \%: \\
\text { E }\end{array}$ \\
\hline $\begin{array}{l}\text { Taber-Doughty et } \\
\text { al. }(2008)\end{array}$ & $\begin{array}{l}\text { Job training } \\
\text { skills }\end{array}$ & $\begin{array}{l}\% \text { of correct } \\
\text { steps }\end{array}$ & $\begin{array}{l}\text { Low \& mid/Stable/ } \\
\text { Stable }\end{array}$ & $\begin{array}{l}\text { Mid \& high/Upward } \\
\& \text { stable/Some } \\
\text { variability to stable }\end{array}$ & $\begin{array}{l}91.7 \%: \\
\text { HE }\end{array}$ \\
\hline $\begin{array}{l}\text { Taber-Doughty et } \\
\text { al. (2011) }\end{array}$ & Food prep & $\begin{array}{l}\% \text { of correct } \\
\text { steps }\end{array}$ & $\begin{array}{l}\text { Low \& high/Up \& down/ } \\
\text { High variability }\end{array}$ & $\begin{array}{l}\text { Mid \& high/Slight } \\
\text { upward/ High } \\
\text { variability }\end{array}$ & $\begin{array}{l}49.8 \%: \\
\mathrm{NE}\end{array}$ \\
\hline $\begin{array}{l}\text { Van Laarhoven et } \\
\text { al. (2009) }\end{array}$ & $\begin{array}{l}\text { Food prep \& } \\
\text { job training }\end{array}$ & $\begin{array}{l}\% \text { of correct } \\
\text { steps }\end{array}$ & $\begin{array}{l}\text { Low \& mid/Stable } \\
\text { Stable }\end{array}$ & $\begin{array}{l}\text { Mid to high/Slow } \\
\text { upward/Stable }\end{array}$ & $\begin{array}{l}95.3 \%: \\
\mathrm{HE}\end{array}$ \\
\hline
\end{tabular}




\subsection{RESULTS}

\subsubsection{Overall study characteristics}

Nineteen studies published between 1994 and 2015 were included in the literature review. Studies included a total of 65 participants (41 with ASD and 25 with ID) and ages ranged from seven to 21. Forty-six participants were male, 17 were female, and gender was not specified for two participants. Thirteen primary investigators and their colleagues conducted studies. Variations of multiple baseline designs were utilized in nine studies and variations of adapted alternating treatments or parallel treatments designs were used in 10 studies. Thirteen studies were conducted only in schools, four studies were conducted only in the community, and two studies were conducted in both school and community settings. Authors of most studies reported maintenance measures $(N=11)$ and some measured skill generalization $(N=6)$. All authors reported data regarding interobserver agreement (IOA), fifteen reported data on procedural integrity (PI), and nine collected social validity data. Table 1 and Table 2 provide information regarding the most frequently reported types of descriptive information.

\subsubsection{Efficacy of VM: Visual analysis and PND}

Table 1 also displays intervention effectiveness for each participant as determined through the calculation of PND and effect rankings (i.e., 90\% PND and above indicates the intervention was highly effective for the participant, 70-89\% indicates the intervention was effective, 50\%-69\% indicates the intervention had questionable effects, and $49 \%$ and below indicates the intervention 
was ineffective for the participant). Table 3 presents information on target skills addressed in each study; the outcome measures used across baseline and intervention phases; a general description of the level, trend, and variability (i.e., visual analysis results) of the graphs, and the PND and effectiveness rating for each study.

Authors of 15 studies investigated the effects of one VM intervention or compared the effects of two different variations of VM and most reported generally positive intervention effects. However, visual analysis of the level, trend, and variability across baseline and intervention phases for each participant and results of PND analysis showed slightly different results. Baseline data in most of the 15 studies implemented to investigate the effects of one or more VM interventions $(N=11)$ showed low, stable responding for most participants. In three studies (Alcantara, 1994; Allen et al., 2010a; Allen et al., 2014b) baseline levels appeared to be relatively low but with some variability. One study (Hagiwara \& Myles, 1999) displayed relatively high, stable levels of responding for all participants in baseline.

Intervention conditions of four of the 15 studies (Alcantara, 1994; Alexander et al., 2013; Mechling et al., 2009; Scott et al., 2013) showed immediate increases to high, stable levels of responding for most participants. However, two participants in the study by Alexander et al. (2013) remained at a low, stable level of responding with VM. Six studies (Cihak \& Schrader, 2008; Mechling \& Collins, 2012; Mechling et al., 2014a; Smith, M. et al., 2013; Smith, K. A. et al., 2015; Van Laarhoven et al., 2009) demonstrated clear upward trends culminating in high stable responding. Furthermore, graphs in three of the 15 studies (Allen et al., 2010b; Mechling \& Ayres, 2012; Taber-Doughty et al., 2008) displayed clear upward trends ending in high levels of responding but with some variability. With the introduction of VM, participants responded with high variability at mid-level in the study by Allen et al. (2010a). Finally, while responding 
was at a high stable level during intervention, there was very little change in responding with the introduction of VM in the study by Hagiwara \& Myles (1999).

Authors of the remaining four studies compared the effects of VM to one or more interventions that differed from VM (Cannella-Malone et al., 2011; Mechling et al., 2014b; Murzynski \& Bourret, 2007; Taber-Doughty et al., 2011). Cannella-Malone et al. (2011) demonstrated one major exception to the generally positive effects of VM. The authors compared VP to VM and found that VP was much more effective. Visual analysis showed consistently low and stable levels of responding, across baseline and intervention phases in the VM condition. Additionally, PND ratings indicated that VM was ineffective for six out of seven participants. All six of the participants with ASD did not respond to VM, while the one participant who did respond to VM was the only participant who did not have ASD. The study raises some very interesting considerations and may have implications that will be discussed.

Similar to Cannella-Malone et al. (2011), Taber-Doughty et al. (2011) also compared VM and VP. These authors reported that two participants responded better with VM while one participant responded better with VP. However, results of visual analysis and PND calculations show that only one participant clearly responded to VM. Further, VP had questionable results for one participant and was ineffective for two. Overall, there was a great deal of overlap and variability in the data for two of the three participants under both VM and VP conditions and the authors' conclusions should be interpreted with caution. However, results did suggest that VM was somewhat more effective than VP in this study.

Mechling et al. (2014b) and Murzynski and Bourret (2007) conducted comparison studies in which VM appeared to be much more effective than the VM interventions implemented by Cannella-Malone et al. (2011) and Taber-Doughty et al. (2011). Mechling et al., (2014b) 
investigated the effects of VM, CVM, and VP and found that all three interventions lead to improved performance for each set of target skills assigned to each intervention. Looking at only VM data, all students demonstrated low, stable baseline levels for all three skill sets and showed immediate increases in their levels of responding, resulting in mid to high, stable performance for most skill sets. Very similar results were seen for skills taught via CVM. Overall PND was 93.8\% (including data from both VM and CVM conditions), suggesting VM and CVM were highly effective, however VP appeared to have the greatest impact on performance with CVM equal to or slightly below VP for most students on most skills. All three interventions improved student behavior.

Similarly, visual analysis of the study by Murzynski \& Bourret (2007), who compared VM plus least-to-most prompting and least-to-most prompting alone, showed low and stable responding in baseline followed by clear upward trends culminating in high stable responding during intervention. In this study, all participants acquired skills much faster with VM plus prompting than with prompting alone.

Calculated PND for each of the 65 participants showed that VM was highly effective for 37 individuals (56.9\%), effective for 12 (18.5\%), had questionable effects for two participants (3.1\%) and was ineffective for 14 students (21.5\%). Calculating the average PND for each study yielded similar findings. VM was highly effective in 12 of the 19 studies (63.2\%), effective in two studies (10.5\%), had questionable effects in two studies (10.5\%) and was ineffective in three studies (15.8\%; see Tables 1 and 3 for all PND results). 


\subsection{DISCUSSION}

\subsubsection{Participant characteristics}

The wide variety with which participant characteristics were reported made it difficult to associated participant characteristics and intervention effects. However, several conclusions may be drawn when comparing the most frequently reported participant characteristics and the effects of VM. First, it appears that VM was somewhat more effective for students who are older. For students who did not respond to VM or for whom VM had questionable results, the average age was 14.9 years (range of 7.11 - 17.11) and the average age of participants for whom VM was effective or highly effective was 16.3 years (range of 8 -21.7). It may be that older participants responded better to VM interventions or that participants enrolled in studies that implemented more effective interventions were older.

Second, when comparing disability category (e.g., ASD or ID) and effect rankings, somewhat contradictory findings were seen compared to the broader VM literature. First, participants with ASD were more often associated with ineffective or questionable interventions (34.1\%) whereas only $8.3 \%$ of participants with ID were associated with ineffective or questionable interventions. It is possible that authors who enrolled participants with ASD were more likely to implement ineffective or questionable interventions. It is also possible that participants with ASD were less likely to respond well to VM interventions than participants with ID. Related to the discussion of the effects of VM on students with ASD versus ID, the study by Cannella-Malone et al. (2011) was of particular interest. In the study, all students with ASD responded poorly to VM but for the one participant without ASD (ID only), VM was effective. 
Overall, most participants responded well to VM interventions. No other potentially significant comparisons or correlations were found between participant characteristics such (i.e., gender, IQ score) and intervention effect rankings. Such characteristics did not appear to be associated with more or less effective interventions. However, several other factors related to specific video and intervention components yielded relevant findings.

\subsubsection{Research questions and experimental design}

\subsubsection{Comparative studies}

Table 4 briefly describes findings of the 10 studies in which two or more interventions were compared. Six of the 10 sets of authors compared two or more variations of VM. Overall, most authors reported that while one variation of VM may have been slightly more effective for individual participants, generally, all variations of VM had an effect on participant performance. Visual analysis and PND calculations support the claims. It is possible that, while all three sets of authors counter-balanced skills and VM variations, systematically exposing participants to a particular variation of VM, all participants in comparative studies were exposed to a "doubledose” of VM which may have increased overall response to the general procedures of VM. All students acquired or improved new skills in most comparative studies. However, some students learned skills slightly faster with one version of VM over another. Also of note, some authors reported that students and/or teachers preferred one version to another. Authors also reported slight advantages of one intervention over another (i.e., creating videos in one condition was easier than the other). See Table 4 for details. 
Table 4. Findings of comparative studies

\begin{tabular}{|c|c|c|c|}
\hline & \multirow[b]{2}{*}{ Study } & \multicolumn{2}{|l|}{ Research } \\
\hline & & Question(s) & Findings \\
\hline \multirow[t]{4}{*}{$\begin{array}{l}\text { Compared VM } \\
\text { to other } \\
\text { intervention(s) }\end{array}$} & $\begin{array}{l}\text { Cannella-Malone et al. } \\
\text { (2011) }\end{array}$ & VM versus VP? & $\begin{array}{l}\text { VP appeared to be much more effective } \\
\text { than VM for all participants. VM had little } \\
\text { to no effect for } 6 / 7 \text { participants. Much } \\
\text { more reliance on adults in VP. }\end{array}$ \\
\hline & Mechling et al. (2014b) & $\begin{array}{l}\text { VM versus CVM } \\
\text { versus VP? }\end{array}$ & $\begin{array}{l}\text { VP appeared to be more effective than } \\
\text { CVM and CVM appeared to be more } \\
\text { effective than VM. Effects seen across all } \\
\text { interventions. Implications for which } \\
\text { target skills may be best suited for each } \\
\text { intervention. }\end{array}$ \\
\hline & $\begin{array}{l}\text { Murzynki \& Bourret } \\
\text { (2007) }\end{array}$ & $\begin{array}{l}\mathrm{VM}+\text { prompting } \\
\text { versus prompting } \\
\text { alone? }\end{array}$ & $\begin{array}{l}\mathrm{VM}+\text { prompting appeared to be more } \\
\text { effective than prompting alone. }\end{array}$ \\
\hline & $\begin{array}{l}\text { Taber-Doughty et al. } \\
\text { (2011) }\end{array}$ & VM versus VP? & $\begin{array}{l}\text { VM appeared to be more effective for } 2 / 3 \\
\text { participants. VM and VP appeared to be } \\
\text { equally effective for } 1 / 3 \text { participant. }\end{array}$ \\
\hline \multirow[t]{6}{*}{$\begin{array}{l}\text { Compared } \\
\text { variations of } \\
\text { VM }\end{array}$} & Cihak \& Schrader (2008) & $\begin{array}{l}\text { Adult versus self- } \\
\text { model? }\end{array}$ & $\begin{array}{l}\text { Self-model appeared to be more effective } \\
\text { for } 1 \text { participant and there appeared to be } \\
\text { no difference between adult and self for } 3 \\
\text { participants. Adult-modeled videos much } \\
\text { easier to create. }\end{array}$ \\
\hline & Mechling \& Ayres (2012) & $\begin{array}{l}\text { Large versus } \\
\text { small screen size? }\end{array}$ & $\begin{array}{l}\text { Large screen appeared to be more } \\
\text { effective but effects seen in both } \\
\text { conditions. }\end{array}$ \\
\hline & Mechling \& Collins (2012) & $\begin{array}{l}\text { VM with } \\
\text { narration versus } \\
\text { VM without } \\
\text { narration? }\end{array}$ & $\begin{array}{l}\text { VM with narration appeared to be more } \\
\text { effective for } 2 / 3 \text { participants. VM without } \\
\text { narration appeared to be more effective for } \\
1 / 3 \text { participant. Effects seen with both } \\
\text { interventions for all participants. }\end{array}$ \\
\hline & Smith, M. et al. (2013) & $\begin{array}{l}\text { VM with } \\
\text { narration versus } \\
\text { VM without } \\
\text { narration? }\end{array}$ & $\begin{array}{l}\text { VM with narration appeared to be more } \\
\text { effective for } 2 / 4 \text { participants. VM with and } \\
\text { without narration were equally effective } \\
\text { for } 2 / 4 \text { participants. All participants } \\
\text { preferred VM with narration. }\end{array}$ \\
\hline & $\begin{array}{l}\text { Taber-Doughty et al. } \\
(2008)\end{array}$ & $\begin{array}{l}\text { Simultaneous } \\
\text { VM versus } \\
\text { Delayed VM? }\end{array}$ & $\begin{array}{l}\text { For } 2 / 3 \text { participants, simultaneous VM } \\
\text { appeared to be more effective. For } 1 / 3 \\
\text { participant, delayed VM appeared to be } \\
\text { more effective. Effects seen in both } \\
\text { conditions for all participants. }\end{array}$ \\
\hline & $\begin{array}{l}\text { Van Laarhoven et al. } \\
\text { (2009) }\end{array}$ & $\begin{array}{l}\text { Adult versus self } \\
\text { versus } 1^{a t} \text { person } \\
\text { model? }\end{array}$ & $\begin{array}{l}\text { For } 2 / 3 \text { participants adult model was more } \\
\text { effective than } 1^{\text {tt }} \text { person. For } 1 / 3 \\
\text { participants } 1^{\text {ta }} \text { person was more effective } \\
\text { than adult. For all } 3 \text { participants, self was } \\
\text { the least effective. }\end{array}$ \\
\hline
\end{tabular}


With regard to authors investigating the comparative effects of VM and one or more different interventions, Murzynski and Bourret (2007) demonstrated the clearest example of the overall efficacy of VM. The authors compared VM plus least-to-most prompting to least-to-most prompting alone. Both participants demonstrated much faster skill acquisition in the VM condition versus the prompting alone condition. The greatly reduced number of sessions it took students to master skills is a noted benefit of VM.

One major counter-argument to using VM is the comparative study conducted by Cannella-Malone et al. (2011). Findings showed that VP was much more effective than VM for the participants with ASD, with little to no change in behavior seen under the VM condition. However, for the participant with ID, VM was effective. Results beg the question, why was VM so ineffective for students with ASD and why did the participant without ASD respond relatively well to VM? A closer look at the procedures during VP may shed some light the dramatic discrepancy between VM outcomes compared to the other 18 studies. During VP, students watched short video clips of one step of a skill being performed followed by a prompt from a researcher to perform the step previously viewed. An adult constantly interacted with each student during each trial; the student was not required to complete any skill sequence without a video model and an adult prompt. Conversely, during VM, students simply watched a video of an entire skill and were then told to complete the skill with no further prompts or feedback. It is no surprise that participants were more successful when given step-by-step modeling and adult prompting. It is possible that the procedures in the VP condition interacted with student performance in the VM condition in that students became reliant on the constant modeling and prompting and were, therefore, much less likely to complete tasks with the removal of the stepby-step viewing of the video model and prompting from the adult. With that said, findings of the 
study are undeniably in favor of VP over VM, warranting careful consideration of the results. However, this does not explain the differential responding between the students with and without ASD.

To add further confusion to the argument of the use of VP versus VM, Taber-Doughty et al. (2011) reported that VM was actually more effective than VP for two out of three participants. However, results of this study should be interpreted with caution due to great variability and overlap seen in the data. The authors do note that students needed much less prompting with VM compared to VP, indicating that students completed tasks more independently with VM over VP.

Mechling et al. (2010b) conducted a similarly designed study to that of Cannella-Malone et al. (2011) and showed that VP, CVM and VM were all effective in improving independent living skills of participants. VP was slightly more effective than CVM followed by VM, but all three interventions lead to improved performance. Interestingly, Mechling et al. (2014b) used different VP procedures than Cannella-Malone et al. (2011), whose procedures relied heavily on adults to start and stop the video between steps and to reorient the student between the video and the task. Conversely, Mechling et al. (2014b) held the participants responsible for starting and stopping the video and for moving between the video and the task. Further, the CVM and VM procedures used in the study were very similar to one another. The major difference being that the participants had access to the video, which was played on a continuous loop, while they completed the task in CVM. In the VM condition, students watched the video one time and then completed the task without the looped video. The possible interaction between the different procedures used by Mechling et al. (2014b) and the increased performance levels seen in the CVM and VM conditions in the study should not be overlooked and may have major 
implications when planning future VM interventions. With these results in mind, it may be possible to incorporate components of the more student-driven VP intervention implemented by Mechling et al. (2014b) into future versions of VM.

\subsubsection{Single intervention studies.}

Nine studies investigating the effects of a single VM intervention employed the intervention in a staggered fashion across participants, settings, or skills. Six authors demonstrated clear, positive intervention effects. Three of the nine studies yielded ineffective or questionable results. Results in the study by Alexander et al. (2013) showed that VM was highly effective or effective for four participants, but had questionable effects or was ineffective for three participants. This finding speaks to the importance of providing detailed descriptions of participants. Why VM was effective for some, but not all, of the participants in the same study could not be determined. Further, the multiple-baseline designs in the studies by Allen et al. (2010a) and Hagiwara and Myles (1999) both showed low PND scores. Interestingly, Allen et al. (2010a) replicated the study (see Allen et al., 2010b) with different participants and results of the second study showed that VM was effective for both participants. There were no apparent changes made to the intervention from the first to the second study. The lack of reported participant information does not allow for a determination as to why some participants responded better to the same intervention.

Finally, low PND for participants in the study by Hagiwara and Myles (1999) was clearly an issue due to the relatively high levels of responding for both participants during baseline. Responding ranged from 55\% - 83\% for Participant 1 and 75\% - 83\% for Participant 2 . Intervention sessions ranged from $75 \%$ - 100\% and $83 \%$ - 93\%, respectively. Both participants in 
this study had relatively high levels of responding during baseline compared to most other participants included in the review.

\subsubsection{Independent variables: Intervention variations and video components}

\subsubsection{Variations of VM}

First, VM interventions paired with prompting or error correction strategies were more effective than studies using VM alone. Of the 10 studies in which VM was paired with some form of prompting or error correction procedure, eight were effective or highly effective ( $N=80 \%)$. Further, among the three studies in which VM was ineffective, VM was implemented without prompting or error correction. It is important to note that researchers using prompting or error correction procedures from the beginning of the intervention faded the procedures until the student no longer needed to be prompted or corrected, thereby increasing the independence with which participants completed tasks.

Next, although no studies reported conducting preference assessments to identify reinforcers, authors implementing interventions that used some form of clear reward system for correct responses (e.g., edibles or verbal praise) appeared to have greater effects. No ineffective studies used rewards contingent on correct responses or skill completion while 93.3\% of VM interventions paired with rewards or reinforcement for correct responding were effective or highly effective. Moreover, only $11.1 \%$ of authors of ineffective or questionable studies reported using verbal praise for correct responses, whereas $88.9 \%$ of authors of highly effective and effective studies did so. Findings suggest that using prompting or error correction procedures and providing feedback for correct responding may increase the likelihood of implementing a successful VM intervention. Finally, authors of the three studies in which VM was least effective 
did not pair VM with prompting from the start of the study nor did they deliver rewards or verbal praise contingent on participants’ correct responding (Allen et al., 2010a; Cannella-Malone et al., 2011; Hagiwara \& Myles, 1999).

Another important aspect of VM is how students view videos. One study (e.g., Mechling \& Ayres, 2012) investigated the effects of VM on a large screen (e.g., computer) versus a small screen (e.g., a pocket PC). The authors reported that, while both devices lead to improved performance, students made faster and greater gains using the larger screens. While these findings suggest that VM should be implemented using a large screen rather than a hand-held device, very few studies have evaluated the effects of VM on smaller devices. Surprisingly, Mechling and Ayres (2012) conducted later studies also included in the current review (i.e., Mechling et al., 2014a \& Mechling et al., 2014b) and the authors reported that a limitation of their later studies was the use of a computer instead of a smaller device. The authors found it challenging to ensure the computer was positioned so that the screen was visual to the student but did not interfere with the tasks. They surmised that use of a mobile device could have made the interventions even more effective, which contradicts findings of their previous study (Mechling et al., 2014b).

In the current review, only five of the 19 studies used portable devices. This finding is surprising given the influx of personal devices used within our schools (NCES, 2010; SIIA, 2014), the increased social acceptability of personal devices (Madden, et al. 2013; The Henry J. Kaiser Family Foundation, 2010), and greater ease with which VM may be applied across a variety of settings and skills with personal devices compared to larger devices (Mechling et al., 2014b; Smith, K. A. et al., 2015). The investigation of VM on smaller, portable devices warrants further investigation. 
Finally, three sets of authors conducted preliminary investigations of new forms of VM. Mechling et al. conducted two studies on the effects of CVM (2014a \& 2014b), K.A. Smith et al. (2015) investigated self-instruction through VM, and Taber-Doughty et al. (2008) studied simultaneous VM. During each of these interventions, participants had access to video models while they performed tasks. The “doing-while-viewing” aspect of the intervention may have major implications for future implementations of VM. Moreover, the independence with which students performed new skills as demonstrated in the studies suggest that effective ways to incorporate strategies to not only improve student performance but also increase independence can be a major benefit of VM.

\subsubsection{Video components.}

When creating custom-made videos, researchers included a variety of components. An analysis of intervention effects and video components lead to mixed findings. Authors used first-person, third-person, or a combination of both: each of which resulted in highly effective to ineffective interventions. With regard to model type, 57.1\% of effective or highly effective studies used adult models and eight of the nine interventions using an adult model were effective or highly effective.

Several authors investigated the relative effects of specific video components. For example, Cihak and Schrader (2008) studied the effects of video self-modeling versus using an adult model. The authors found both model types lead to improved performance. However, according to social validity data, all students reported a preference for self-models but teachers found the adult-modeled videos easier and less time consuming to make. Teachers also liked that videos could be reused with new students. Both model types appear to be equally effective: the downfalls and benefits of each should be carefully weighed. 
Next, both Mechling and Collins (2012) and M. Smith et al. (2013) compared the effects of using videos with and without narration. Similar to the findings of Cihak and Schrader (2008), both sets of authors found that VM with and without narration were effective in improving skills, however, four of the seven students responded faster with narration and most students showed a preference for videos with narration. Again, weighing costs and benefits of each component is an important part of VM. The relative simplicity with which narration can be added into videos may be a component worth including.

Finally, components such as zoom and the use of strategies to focus on certain aspects of the video were included in some videos. Authors of six studies reported "zooming in" to highlight the most relevant parts of a skill or step. Four of these interventions were found to be highly effective while two were found to have questionable effects. Moreover, five highly effective interventions used videos in which clear distinctions were made between each step of a skill. For example, M. Smith et al. (2013) inserted a black screen displaying the step number immediately before the step played and Mechling et al. (2014a and 2014b) inserted a threesecond pause between each step. Making distinctions between each step may have helped increase the effectiveness of VM or CVM in the studies.

\subsubsection{Dependent variables}

\subsubsection{Target skill acquisition}

All studies included in the current review addressed independent living skills; therefore all studies, from those highly effective to ineffective included similar types of skills. Target skills were divided into five categories: money, self-care, food prep, laundry, and job-training. When comparing target skill categories to effect rankings, most of the effective or highly effective 
interventions (80\%) were aimed at addressing job-training skills (i.e., preparing kits, completing office related tasks, cleaning or repairing equipment). However, this finding could be simply due to the fact that the majority of VM interventions targeted job-training skills $(N=10)$.

\subsubsection{Generalization and maintenance}

Six studies assessed the effects of VM on skill generalization. Generalization was a focus of the study by Alexander et al. (2013) and results were mixed; four of the seven participants generalized skills taught via VM, while VM had no effect on skill generalization for three students. However, all participants in studies conducted by Allen et al. (2010b), Mechling et al. (2009), Scott et al. (2013), Taber-Doughty et al. (2008), and Van Laarhoven et al. (2009) maintained or increased performance in novel settings or with different materials.

More authors measured maintenance than generalization. While researchers conducted maintenance probes with great variability overall maintenance effects are impressive. Ten of the eleven studies for which maintenance probes were conducted showed that all participants maintained or improved performance over time. However, participants in the study by Allen et al. (2010a) displayed variable performance in the maintenance phase. Interestingly, the baseline and intervention phases of the study were conducted and completed in one day for all participants as the researchers measured the number of correct responses during one-minute intervals. The maintenance measure was conducted approximately one month after the sole intervention session. Additionally, results of the study were deemed ineffective due to high variability during the intervention phase. Findings suggest that, for the effects of VM to be

maintained, stability should be demonstrated during the skill acquisition phase and increased exposure (i.e., more than one day of intervention) may be required. 


\subsubsection{Implications}

When considering who may be most likely to benefit from VM and which skills to address, practitioners should consider the following. VM appeared to be slightly more effective for students who were older and was effective for students with both ASD and ID. However, students with ID appeared to respond to VM more often than students with ASD (91.7 \% vs. $65.9 \%$, respectively). Further, based on evidence from the review, practitioners may want to use VM to address job-training skills, as studies addressing this skill area were most likely to be effective.

Conclusions from comparison studies may provide interesting information for practitioners wondering how to implement VM. However, it is important to carefully weigh the costs (i.e., time and effort) and benefits of certain variations. For example, video-self modeling requires extensive time to capture quality footage and edit the video (Bellini \& Akullian, 2007; Rayner, et al., 2009) and results of the study by Cihak and Schrader (2008) showed that all students mastered all skills under both modeling conditions. Some students needed a few additional sessions with the adult model. It is possible that the extra time needed to capture quality footage of the student and create the video would cause a greater delay in implementing the intervention, resulting in later skill acquisition, than if teacher created the video simply using an adult model. Additionally, for participants in the study by Van Laarhoven et al. (2009) video self-modeling was the least efficient version of VM for all participants. With regard to narration, the relative ease with which the component may be added and the evidence from the literature in support of VM with narration implies that it may be beneficial for teachers to narrate videos. Finally, teachers need to consider the costs and benefits of using a larger screen compared to 
using a smaller, more portable device. The device used may depend on the target skills addressed and the setting in which students perform the skills.

Practitioners should also strongly consider including prompting and reinforcement procedures from the beginning of the intervention, with a plan in place to fade prompts as the student becomes more independent. Also, reward or reinforcement procedures for correct responding should be paired with VM to help increase the likelihood that the intervention will be more effective.

\subsubsection{Directions for future research}

Based on results of the literature review, VM was highly effective or effective in improving the independent living skills of $75.4 \%$ of the 65 participants included in the studies reviewed. However, VM had questionable effects or was ineffective in improving skills for $24.6 \%$ of participants. VM was effective for most, but not all students. More research is needed to identify variations of $\mathrm{VM}$ that are most effective in improving independent living skills and which students are most likely to respond to VM. Researchers need to report more detailed descriptions of students and begin to make connections between how student characteristics relate to how they respond to VM. Continued research is needed to identify potential matches between participant characteristics (i.e., IQ, adaptive behavior ratings, prerequisite skills) and effective video or intervention components. The limited research attempting to draw connections between variations of VM and participant characteristics display mixed results.

With respect to video components, multiple researchers have begun to investigate the differential effects of video point-of-view, model types, and narration. Generally speaking, future research with regard to such components should focus on matching participant characteristics to 
specific components that are most likely to yield effective outcomes. Initial findings seen in the recent investigations involving the use of a zoom function and other strategies to focus on certain aspects of the video (i.e., numbering or pausing between each step in the video) warrant continued investigation.

As for further investigation of intervention components, much more research is needed in the area of VM on portable devices. While results of preliminary studies do not clearly show increased effects of VM on smaller devices, the potential benefits of VM in this fashion warrant additional research. It is very likely that the prevalence of technology use today is only going to increase. Researchers, teachers, and parents need to find ways to utilize technology that will benefit children with ASD and ID and build independence. If conducted on portable devices, VM may be a socially appropriate, non-stigmatizing, subtle, and effective intervention for students with ASD and ID.

Finally, more research is needed to understand the extreme differential effects between VM and VP seen in the study by Cannella-Malone et al. (2011). Clearly, there are procedural differences that dramatically impacted student outcomes but perhaps there are ways of combining components of VP (i.e., continued student-model interaction, clearer and more structured task guidance) with VM while keeping a focus on increasing student independence. For example, excluding the procedures most often seen in VP, such as the constant cycle of adult prompting and navigation assistance. VM procedures such as those seen in CVM may lead to improvements in student performance while also emphasizing the importance of independence. 


\subsubsection{Rationale for study}

In their study on self-instruction through VM, K.A. Smith et al. (2015) highlighted the importance of investigating the use of video-based interventions to increase the level of independence with which students complete independent living skills. Further, the newest form of VM, CVM, may be an intervention conducive to incorporating effective components of VP (i.e., increased student-model interaction and more structured task guidance), but with reduced adult assistance. In CVM, the student has access to the video model while completing the skill because the video is played on a continuous loop (Mechling et al., 2014).

To date, only two studies have investigated the effects of CVM on independent living skills of adolescents with ASD or ID; only one of which compared CVM to other video-based interventions (e.g., CVM versus VM versus VP). Preliminary research indicates CVM may be highly effective in improving the independent living skills of students with ASD and ID, however more research is needed to better understand the comparative effects of the interventions. Additionally, more research is needed on the effects of CVM when paired with components often included in highly effective VM interventions such as prompting and reinforcement. While the use of prompting strategies requires increased adult support initially, providing extra support during the skill acquisition phase and systematically fading out prompts has been shown to lead to more effective VM interventions. Therefore, it is possible that pairing CVM with least-to-most prompting will also increase the intervention's effectiveness. Using least-to-most prompting rather than delivering multiple prompts during each step (as seen in VP) may decrease the likelihood that students will become dependent on prompts, leading to greater independence with task completion. 
While many authors paired VM with verbal praise or rewards for correct responding, no authors reported the use of a preference assessment to identify reinforcers. Positive reinforcement has been said to be an important component for the implementation of effective interventions (Barton et al., 2012). Combining CVM with prompting and reinforcement procedures may lead to further increases in the interventions effectiveness. The effects of this intervention package have not been investigated.

VM research has shown that videos including an adult model (Cihak \& Schrader, 2008; Mason et al., 2013) with narration (Mechling \& Collins, 2012; Smith, M. et al, 2013) are effective video components. Further, researchers have recently started investigating the effects of adding a pause between steps of a task while displaying the upcoming step number in the video. Preliminary investigations of such video components are promising (Mechling et al., 2014a; Mechling et al., 2014b; Smith, M. et al., 2013). Adding these features into CVM incorporate effective aspects of VP by providing students with clearer, more structured task guidance without relying on an adult.

Based on findings from the literature, the researcher conducted a study to compare the effects of CVM and VM when paired with effective intervention and video components on independent living skill completion for school-aged students with ASD and ID. The primary research question was: What are the comparative effects of VM plus least-to-most prompting and reinforcement ( $\mathrm{VM}+\mathrm{P} \& \mathrm{R}), \mathrm{CVM}$ plus least-to-most prompting and reinforcement $(\mathrm{CVM}+\mathrm{P} \& \mathrm{R})$, and least-to-most prompting and reinforcement alone (P\&R) on the independent living skills of adolescents with ASD and ID? Secondary research questions were: Will participants respond differently to each intervention? Are there correlations between participant characteristics and responses to each intervention? 


\subsection{METHOD}

\subsection{PARTICIPANTS AND SETTING}

To begin recruitment, the researcher contacted the special education coordinator of a suburban school district in Western Pennsylvania and shared a description of the purpose and procedures of the study as well as a description of students who may be eligible to participate. The special education coordinator sent study information to middle and high school special education teachers who worked with students with ASD and ID. Interested teachers were put in contact with the researcher. Teachers received letters describing the study from the researcher that they distributed to parents. Parents interested in having their child participate were put in contact with the researcher. Over a brief phone screening, parents answered a series of questions to determine if their child met the initial eligibility criteria. Students meeting the following criteria were considered for participation in the study: the student (a) was in middle or high school, (b) had a diagnosis of ASD and/or ID, (c) could not already perform the potential independent living skills

to be addressed, (d) could sit and watch a video for at least five minutes, (e) did not have physical disability that would interfere with completion of target skills, and (f) typically had good attendance (i.e., absent less than 5 school days per grading period). 
While five participants were recruited, only four were ultimately found eligible for the study. One participant demonstrated independent living skills that were more advanced than the focus of the study. Table 5 presents demographic information for the four included participants.

Table 5. Description of participants

\begin{tabular}{|c|c|c|c|c|c|c|c|c|}
\hline & \multirow[b]{2}{*}{ Age } & \multirow[b]{2}{*}{ Gender } & \multirow[b]{2}{*}{ Race } & \multirow[b]{2}{*}{ Home Language } & \multirow[b]{2}{*}{ Disability } & \multirow[b]{2}{*}{ IQ } & \multicolumn{2}{|c|}{$\begin{array}{c}\text { VABS-II: DLS } \\
\text { (SS: Adaptive Level) }\end{array}$} \\
\hline & & & & & & & Parent & Teacher \\
\hline Jake & 15.5 & $\mathrm{M}$ & Caucasian & English \& Dutch & ASD \& ID & $\mathrm{NA}^{*}$ & 23: Low & 38: Low \\
\hline Nick & 16.10 & $\mathrm{M}$ & Caucasian & English & $\begin{array}{c}\text { ASD, ID, \& seizure } \\
\text { disorder }\end{array}$ & $30 * *$ & 43: Low & 50: Low \\
\hline Pete & 14.5 & M & $\begin{array}{c}\text { African- } \\
\text { American }\end{array}$ & English & ID \& Down syndrome & $48^{* * *}$ & 58: Low & 55: Low \\
\hline Hope & 14.7 & $\mathrm{~F}$ & Caucasian & English & ID, ADHD, \& Anxiety & $40^{* * * * *}$ & 45: Low & 51: Low \\
\hline \multicolumn{9}{|c|}{$\begin{array}{l}\text { Note: } \mathrm{M}=\text { male; } \mathrm{F}=\text { female; }{ }^{*}=\mathrm{SON}-\mathrm{R} \text { Nonverbal Intelligence Test (Unable to obtain a reliable score); }{ }^{* *}=\text { Wechsler } \\
\text { Nonverbal Scale of Ability (WNV); }{ }^{* * *}=\mathrm{Kaufman} \text { Assessment Battery for Children- } 2^{\text {sd }} \text { Edition }(\mathrm{KABC}-\mathrm{II}) ;{ }^{* * * *}= \\
\text { Stanford Binet Intelligent Scales-5 }{ }^{\boldsymbol{*}} \text { Edition }(\mathrm{SB}-\mathrm{V}) ; \mathrm{VABS}-\mathrm{II}=\text { Vineland Adaptive Behavior Scales-2nd Edition; SS }= \\
\text { standard score; DLS = daily living skills domain }\end{array}$} \\
\hline
\end{tabular}

Jake was diagnosed with ASD at age four. He was the only participant for whom an IQ score was unavailable. An educational psychologist administered the SON-R when Jake was 5 years, 7 months but due to behavioral challenges, a reliable score was not obtained. The psychologist did indicate, however, that Jake could be classified as having a "serious mental disability." At the time of the study, he typically communicated through basic sign approximations and occasionally used a communication device with prompting. He imitated fine and gross motor movements and did so often but required frequent prompting to complete single and multi-step tasks. Occasionally, he engaged in tasks for up to 1-minute independently. Jake was a non-reader. He enjoyed taking walks, watching videos, and swimming. At times, Jake engaged in challenging behaviors such as hitting himself and/or others, head-butting, screaming and work refusal. He often threw items or slammed objects on the table. He also engaged in stereotypical behaviors such as hand-flapping, finger-flicking, and vocalizations. His parent reported that Jake never completed cleaning or food prep tasks at home but sometimes hung garments on a hook. In school, Jake practiced a variety of independent living activities but 
required frequent prompting to complete such tasks. Jake's teacher reported that he sometimes washed the window, vacuumed with a wand, used an upright vacuum, used a toaster, handwashed dishes, put clothes in drawers, and hung a shirt on a hanger. She also reported that he often cleared and wiped the table, got a glass of water, and folded towels, shirts, and pants. Jake used computers and iPads ${ }^{\circledR}$ daily to watch movies or listen to music.

Nick was diagnosed with ASD when he was six years old. He was verbal and communicated through the use of short phrases. He imitated gross and fine motor movements but needed prompting to complete multi-step tasks. Nick worked independently on tasks between one and five minutes. He identified basic sight words. Nick enjoyed watching videos, listening to music, and sitting in a rocking chair. He was also highly motivated by food (i.e., chips, candy, cereal). Nick occasionally engaged in challenging behaviors such as hitting, biting, scratching, and pinching himself. He also occasionally hit, kicked, bit, scratched, pinched, and head-butted others. He often engaged in stereotypical behaviors such as finger-flicking and repetitive talk. Nick's parent reported that he never completed tasks related to cleaning, food prep, or laundry at home. In school, Nick practiced a variety of independent living activities but required frequent prompting to complete such tasks. According to his teacher, Nick sometimes washed the window, vacuumed with a wand, used an upright vacuum, got a glass of water, used the toaster, poured a drink, hand-washed dishes, put clothes in drawers, and hung a shirt on a hanger. He often cleared and wiped the table and folded socks, towels, and pants. Nick used computers and iPads ${ }^{\circledR}$ daily to watch videos.

Pete was diagnosed with Down syndrome at birth. He typically communicated using single words and short phrases. Pete imitated gross and fine motor movements and did so often. He completed one-step tasks independently but needed frequent prompting to complete multi- 
step tasks. Pete worked for about one-minute independently. He read at the pre-primer level. He enjoyed having free time on the iPad® or computer and liked to play video games and watch videos. Pete did not engage in any challenging behaviors. His parent reported that Pete completed in a variety of cleaning, food prep, and laundry tasks at home but that he required constant supervision and frequent prompting to complete any tasks. In school, Pete practiced a variety of independent living activities but required frequent prompting to complete such tasks. Pete's teacher reported that he sometimes wiped down chairs and tables, cleaned the sink and counter, used a toaster, made popcorn, cleared the table, served food, set the table, put clothes in drawers, and folded towels. He often hand-washed dishes and hung garments on a hook. Pete used computers and iPads ${ }^{\circledR}$ daily to go on the Internet and watch videos.

Hope was diagnosed with an intellectual disability when she was seven months old. She typically communicated using single words or short phrases. Hope imitated gross and fine motor movements. She usually completed one-step tasks independently, but required frequent prompting to complete tasks with multiple steps. At home she reportedly worked on activities for one to five minutes independently, but needed frequent redirection to complete tasks at school. She read between the pre-primer and Kindergarten levels. She enjoyed watching videos, playing with cards and fidgets, coloring, playing outside, and shopping. At home, Hope engaged in challenging behaviors such as pushing or hitting others, screaming, and work refusal. In school, she rarely engaged in challenging behaviors, however, she became easily distracted and immediately got off task when she heard or saw other students or adults. She was very interested in what others were doing and asked repetitive questions about her friends and teachers. At home or when she was out in the community Hope sometimes wiped the table, packed a lunch, emptied the dishwasher, used a vending machine, and put clothes in drawers. In school, Hope practiced a 
variety of independent living activities but required frequent prompting to complete such tasks. Hope's teacher reported that she sometimes wiped down chairs and tables, cleaned the sink and counter, got a glass of water, used a toaster, made popcorn, served food, set and cleared the table, put clothes in a drawer, folded socks, and did laundry. She often poured a drink in a glass, handwashed dishes, hung a garment on a hook, and folded towels. Hope used computers and iPads ${ }^{\circledR}$ daily to get on the Internet and watch videos and she occasionally listened to music.

The study was conducted in the participants' public high school during the school day. The school was located in a Western Pennsylvania suburb. Approximately 1,419 students were enrolled in the high school (grades 9-12) and district enrollment was approximately 4,240. Approximately 556 students had IEPs across the district and approximately $17.3 \%$ of students were eligible for free or reduced price lunch at the high school.

Sessions took place in a classroom designated as an "intensive teaching classroom" for students with severe disabilities. All students participated in a curriculum that emphasized functional skills. Students completed vocational-prep tasks daily in their classroom and around the school and all participants had IEP goals aimed at improving independent living or functional skills. The classroom was approximately 28 x 18 feet. There was also a large bathroom and break room attached to the classroom. The room contained several tall storage and file cabinets that also served as dividers, three long student worktables with chairs, and one round student worktable with chairs. All study sessions took place individually with each participant. Sessions for Pete and Hope took place at the worktable located at the front of the classroom against a wall or in the bathroom connected to the classroom. Due to the timing of sessions for Nick and behavioral challenges for Jake, all sessions for Nick and Jake took place at the worktable located at the front of the classroom. There was a microwave and small refrigerator next to the 
worktable. Sessions took place three to five times per week over period of approximately two months.

\subsection{MATERIALS}

To help with the selection of target skills, recruitment of participants, and screening procedures, the researcher created and used a number of materials. First, prior to recruiting any participants, the researcher created and distributed surveys to typically developing middle or high school students and their parents to help determine the most important and relevant independent living skills for adolescents. Second, the researcher created letters describing the study and distributed them to the special education coordinator, teachers, and parents. Third, the researcher created a parent interview phone screening script and a phone screening response-recording form and used them to determine if a student met the initial eligibility criteria. Fourth, the parent and teacher forms of the Daily Living Skills Domain of the Vineland Adaptive Behavior Scales-2nd Edition (VABS-II) were distributed the participants' parent(s) and teacher. Finally, the researcher created a questionnaire and distributed it to parents and teachers to collect information regarding other important student characteristics not captured in the VABS-II.

Materials needed to carry out the interventions included, a hand-held video camera to film the video models, a retractable camera stand, the iMovie video application to edit videos, the vloop application to play CVM+P\&R videos on a loop, and iPad® Minis on which students viewed videos. The researcher delivered a variety of reinforcing items/activities to students as part of the reinforcement component of the interventions. The researcher created data collection sheets which were used to record participant performance of each skill (a) while observing 
students perform skills during study sessions and (b) when video taped sessions were reviewed by the researcher and the research assistant to collect accuracy and interobserver agreement data. The researcher also created procedural integrity checklists, which the research assistant used to collect data regarding the integrity with which the intervention was delivered. Finally, surveys were created to assess the social validity of the interventions and procedures.

Finally, materials for target skills included a small trashcan with a full trash bag (removing a bag of trash from the trashcan); a microwave and a cleaning wipe (wiping the tray in the microwave); a cup and access to a sink and a counter (filling a cup with water from the faucet); two containers that held plastic forks and spoons and a cloth napkin (rolling silverware); a laundry basket and a t-shirt (folding a t-shirt); a pair of socks and a storage bin with a lid (folding and storing sock).

\subsection{DEPENDENT VARIABLES}

\subsubsection{Percentage of correct steps and number of sessions to mastery}

The primary dependent variable was the percentage of correctly completed steps according to the task analysis of each target skill. Steps were scored as correct or prompted. A step was considered correct if the student's behavior matched that of the model's behavior in the video or the description of the step in the task analysis. Additionally, all steps had to be independently initiated within three seconds of a) the initial prompt given by the researcher or b) the completion of the previous step. The step also had to be completed independently within 30 seconds of initiation. If a prompt was needed, the step was considered incorrect. The researcher also 
calculated the number of instructional sessions to mastery, which was simply the number of intervention sessions it took a participant to master a skill (i.e., $100 \%$ of steps correctly and independently completed during three consecutive sessions).

\subsubsection{Total number of adult-delivered prompts}

During intervention sessions, all steps were scored as independent or prompted. For steps during which a student required a prompt, the type of prompt needed to ensure the student completed the step correctly was recorded (e.g., verbal + gestural task prompt, verbal prompt to watch the video, physical prompt). The total number of prompts required across each intervention condition and target skill was calculated to determine which intervention conditions required the most and least prompting from the researcher.

\subsubsection{Time to skill completion}

Time to skill completion was the total number of seconds it took a participant to complete each skill during intervention sessions. To measure time to skill completion, all sessions were video recorded and reviewed at a later time. Start times (i.e., immediately after the researcher told the student to begin the skill) and end times (e.g., immediately after the student completed the skill) were recorded. Total time was calculated individually for all skills during every session and the researcher recorded time to skill completion in seconds. 


\subsubsection{Total instructional time}

Total instructional time was the cumulative amount of time spent on instruction for each target skill under a particular condition. Instructional time included time spent completing individual target skills as well as watching videos during $\mathrm{VM}+\mathrm{P} \& \mathrm{R}$ and $\mathrm{CVM}+\mathrm{P} \& \mathrm{R}$. For students who met the mastery criterion for one or both of the video-based interventions and in the P\&R condition, total instructional time was compared to determine which intervention required the most and least amount of instructional time. Further, the amount of time required to create one video model was taken into consideration when making comparisons between video-based interventions and P\&R to determine whether making the videos was an efficient use of time.

\subsection{INDEPENDENT VARIABLES}

Three independent variables were under investigation: $V M+P \& R, C V M+P \& R$, and $P \& R$. $\mathrm{VM}+\mathrm{P} \& \mathrm{R}$ was the condition in which a participant viewed a video of a model performing a target skill in its entirety one time and was then directed to complete the skill without any further viewings of the video. Within this intervention, a system of least-to-most prompts was delivered when/if an error was made or no response occurred. Additionally, a total-task reinforcement procedure was implemented by delivering a reinforcer once the student completed the skill sequence, with or without prompting.

CVM+P\&R was the condition in which a participant viewed a video of a model performing a target skill in its entirety one time and then was directed to complete the skill while the video restarted and continued to play on a loop. Again, a system of least-to-most prompts 
was used if an error was made or no response occurred. Also, a reinforcer was delivered once the student completed the whole sequence of steps in a skill, with or without prompting.

Finally, P\&R was the condition in which a participant did not view a video, but was simply asked to perform a skill while being provided with least-to-most prompts from the researcher in addition to the delivery of a reinforcer when the student completed all steps of a skill.

\subsection{EXPERIMENTAL DESIGN}

An adapted alternating treatments design (AATD) with baseline (Sindelar et al., 1985) and comparison conditions (Wolery, Gast, \& Ledford, 2010) was used to evaluate the effects of the interventions. This is similar to the design used by Cihak and Schrader (2008), Mechling and Ayers (2012), and Smith, M. et al. (2013). A “final best" phase was also used to attempt to replicate the effects of the intervention that emerged as the superior treatment for a particular student.

In addition to putting in place extensive procedures to ensure target skills were of equal difficulty (see 3.6.1 Selecting Target Skills), the inclusion of a baseline condition in the AATD helped "demonstrate the equivalence of performance" on sets of skills (Sindelar et al., 1985, p 70). Including a baseline condition also helped verify that the appropriate skills were assigned to the student (see 3.6.2 Skill Screening). Further, a baseline condition evaluated participants' initial levels of performance on each task over multiple occasions (i.e., for a minimum of five sessions) and demonstrated that he or she was unable to successfully complete each task prior to exposure to the interventions. 
During the comparison and "final best" phases, each student completed all target skills. While participants completed some of the same target skills, several skills differed across participants as some of the participants demonstrated the ability to complete one or two skills during screening or baseline sessions. Target skills for each participant were ultimately selected based on individual student performance of each skill. Skills that remained at low, stable levels during screening and/or baseline sessions were selected as skills to which interventions were applied. An attempt to counter-balance skills across the three independent variables as much as possible was made to account for any potentially confounding variables regarding task difficulty. Table 6 displays the skill-intervention pairings for each participant.

Table 6. Skill-intervention pairings

\begin{tabular}{cccc} 
& VM+P\&R & CVM+P\&R & P\&R \\
\hline Jake & Take out trash & Roll silverware & Fold \& store socks \\
Nick & Roll silverware & Take out trash & Fold t-shirt \\
Pete & Get water & Fold t-shirt & Take out trash \\
Hope & Wipe microwave tray & Take out trash & Roll silverware \\
\hline
\end{tabular}

\subsection{PROCEDURES}

\subsubsection{Selecting target skills}

Several steps were taken to ensure the social validity of the target skills selected. First, a bank of independent living skills was developed for each of the three skill areas (i.e., cleaning, food prep, and laundry). Included in the bank were skills targeted in the literature base investigating the effects of VM. Also included in the bank were cleaning, food prep, and laundry skills listed in 
the Murdoch Center Program Library (Wheeler et al., 2001) and in the Daily Living Skills Domain of the VABS-II. See Table 7 for the Independent Living Skills Bank.

Second, a survey was created and distributed to middle and high school students without disabilities and their parents in an attempt to identify the most relevant independent living skills for adolescents. In the survey, respondents were asked to indicate which of the skills listed (i.e., skills from the Independent Living Skills Bank) were in their (or their child's) repertoire and which were performed most often. Responses were analyzed and skills were ranked according how often skills were performed by adolescents. Results of the survey guided the selection of the target skills to be addressed in the study.

Ensuring that all target skills are of equal difficulty is imperative when implementing AATD (Wolery et al., 2014). To account for this limitation of AATD, an analysis of the responses and discriminations required to perform each skill correctly was conducted (Wolery et al., 2014). First, task analyses were created for each skill, which were based on the task analyses presented in the Murdoch Center Program Library (Wheeler et al., 2001) or task analyses provided in the literature by authors investigating the effects of VM interventions on similar skills. Further, the researcher performed all skills multiple times to ensure that the task-analyzed steps actually lead to successful completion of the skill. All skills contained 5 steps.

Next, a team of competent adults performed each skill to determine the average length of time required to complete each skill. All skills took between 12.8 and 14.5 seconds to complete. After performing the skills all team members agreed that the skills were of similar difficulty. Further logical analysis of each skill showed that each skill required three object displacements (i.e., the student must pick up or move an object three times), two fine motor movements, and did not require travel from one place to another. See Table 7. 
Cleaning, food prep, and laundry skills were broken into two groups. Group 1 included skills or skills similar to those ranked as the most relevant and most often performed by students without disabilities and their parents on the skill survey. Group 2 included skills or skills similar to those ranked as the second most relevant types of skills by survey respondents.

Table 7. Independent living skills bank

\begin{tabular}{|c|c|c|}
\hline Cleaning Skills & Food Prep Skills & Laundry Skills \\
\hline Dusting & $1{ }^{*}$ Getting glass of water from faucet & Putting clothes in drawers \\
\hline Filling mop bucket & Using toaster & Hanging garment on hook \\
\hline Mopping the floor & Packing lunch & Folding socks \\
\hline Cleaning the wall & Making cup of instant drink & Folding towel \\
\hline Dust mop the floor & Pouring drink in a glass & 1*Folding pullover shirt \\
\hline $1 \star$ Emptying the trash & $2 *$ Rolling silverware in a napkin & Hanging shirt on hanger \\
\hline Wiping the chair & Operating drink machine & Folding pants \\
\hline Lining the trash can & Making popcorn (microwave) & $2 *$ Folding and storing clothes \\
\hline Washing the window & Using snack vending machine & Folding button up shirt \\
\hline $2{ }^{\star}$ Wiping the microwave tray & Clearing table without tray & Rolling folded towel \\
\hline Vacuuming with wand & Serving food family style & Doing laundry \\
\hline Using upright vacuum & Preparing frozen meal/snack & \\
\hline Cleaning the sink & Hand washing dishes & \\
\hline Cleaning kitchen counter & Setting the table & \\
\hline
\end{tabular}

Note: ${ }^{*}=$ skill ranked as one of the most relevant skills for adolescents based on survey results; 1= Group 1 Skill; $2=$ Group 2 Skill 
Table 8. Task and logical analysis of target skills

\begin{tabular}{|c|c|c|c|c|c|c|}
\hline \multirow[b]{2}{*}{ Participants } & \multicolumn{2}{|c|}{ Cleaning } & \multicolumn{2}{|c|}{ Food Prep } & \multicolumn{2}{|c|}{ Laundry } \\
\hline & All & Hope & Pete & Jake, Nick, Hope & Nick, Pete & Jake \\
\hline Skills & $\begin{array}{l}\text { Removing bag of trash } \\
\text { from trashcan }\end{array}$ & $\begin{array}{l}\text { Wiping the } \\
\text { microwave tray }\end{array}$ & $\begin{array}{l}\text { Filling cup with water } \\
\text { from faucet }\end{array}$ & Rolling silverware & Folding t-shirt & $\begin{array}{l}\text { Folding and storing } \\
\text { socks }\end{array}$ \\
\hline Step 1 & $\begin{array}{l}\text { Unhook top of trash } \\
\text { bag from trashcan (f) }\end{array}$ & $\begin{array}{l}\text { Open microwave } \\
\text { door (f) }\end{array}$ & $\begin{array}{l}\text { Pick up cup from } \\
\text { counter }(\mathrm{o})\end{array}$ & Pick up fork (o) & $\begin{array}{l}\text { Pick up shirt from } \\
\text { basket }(0)\end{array}$ & $\begin{array}{l}\text { Match bottom of socks } \\
\text { (o) }\end{array}$ \\
\hline Step 2 & $\begin{array}{l}\text { Grasp strings on either } \\
\text { side of bag (f) }\end{array}$ & Pick up wipe (o) & Turn on cold water (f) & Pick up spoon (o) & $\begin{array}{l}\text { Place shirt flat on } \\
\text { table with bottom } \\
\text { facing you (o) }\end{array}$ & $\begin{array}{l}\text { Fold top of socks } \\
\text { down so socks stay } \\
\text { together (f) }\end{array}$ \\
\hline Step 3 & $\begin{array}{l}\text { Pull strings to close bag } \\
\text { (o) }\end{array}$ & Wipe tray (f) & Fill cup with water (o) & $\begin{array}{l}\text { Lay fork and spoon } \\
\text { on corner of napkin } \\
\text { (o) }\end{array}$ & $\begin{array}{l}\text { Fold shirt in half } \\
\text { length-wise (match } \\
\text { sleeves) (f) }\end{array}$ & Open lid of bin (f) \\
\hline Step 4 & $\begin{array}{l}\text { Lift bag out of trashcan } \\
\text { (o) }\end{array}$ & $\begin{array}{l}\text { Close microwave } \\
\text { door (o) }\end{array}$ & Turn off water (f) & $\begin{array}{l}\text { Fold corner over } \\
\text { fork and spoon (f) }\end{array}$ & $\begin{array}{l}\text { Fold shirt in half } \\
\text { bringing bottom up } \\
\text { to neck (f) }\end{array}$ & Put socks in bin (o) \\
\hline Step 5 & $\begin{array}{l}\text { Place bag in hallway } \\
\text { (o) }\end{array}$ & $\begin{array}{l}\text { Throw away wipe } \\
\text { (o) }\end{array}$ & Place cup on tray (o) & $\begin{array}{l}\text { Roll fork and spoon } \\
\text { in napkin (f) }\end{array}$ & $\begin{array}{l}\text { Place shirt in basket } \\
\text { (o) }\end{array}$ & Replace bin lid (o) \\
\hline Average time & 12.9 seconds & 14.3 seconds & 14.1 seconds & 14.5 seconds & 13.9 seconds & 12.8 seconds \\
\hline (t) Travel & None & None & None & None & None & None \\
\hline $\begin{array}{c}\text { (o) Object } \\
\text { displacement }\end{array}$ & $3 x$ & $3 x$ & $3 x$ & $3 x$ & $3 x$ & $3 \mathrm{x}$ \\
\hline (f) Fine motor & $2 \mathrm{x}$ & $2 x$ & $2 \mathrm{x}$ & $2 \mathrm{x}$ & $2 x$ & $2 \mathrm{x}$ \\
\hline Video time & 43 seconds & 44 seconds & 38 seconds & 41 seconds & 41 seconds & 38 seconds \\
\hline $\begin{array}{l}\text { \# of Steps } \\
\text { using zoom }\end{array}$ & 3 & 3 & 2 & 3 & 2 & 2 \\
\hline
\end{tabular}




\subsubsection{Skill screening}

To ensure that the most appropriate skills were selected for each student, the researcher screened participants on their current levels of performance on Group 1 skills. If a participant performed 0, 1 or 2 steps correctly ( $40 \%$ or below) on each skill, the participant was assigned to the three skills in Group 1. If a participant completed more than 3 steps correctly for a skill, he or she was assessed on a skill(s) from Group 2 until three skills were identified on which the participant performed at or below $40 \%$ of steps correctly. Once the researcher assigned three target skills to a student, he or she entered the baseline condition. Four of the five recruited participants remained eligible for the study after screening. One of the original five participants performed three or more steps correctly for all skills. This student was dismissed because his skills were deemed too advanced for the scope of the study. All skill screenings took place approximately one month before the first baseline session.

\subsubsection{Creating video models}

The researcher created video models for each target skill. The same video components were incorporated into all videos under both video-based intervention conditions (e.g., CVM+P\&R and $\mathrm{VM}+\mathrm{P} \& \mathrm{R})$. The only major difference between each video was the target skill demonstrated by the model. All videos were filmed using a Sony HD Handycam and were edited using the iMove application. All videos depicted an adult model (the researcher) completing skills at a slightly slower pace (e.g. 75\% of "normal" pace in iMovie) with narration. Video footage was primarily shot from a third-person perspective with close up views of the tasks being completed (i.e., the researcher's hands or arms). Additionally, a three second pause was inserted between 
each step of the skill and a black screen with a white number corresponding to the step that followed was shown. The vloop application was used to play CVM+P\&R videos on a loop.

The researcher attempted to replicate procedures similar to those taken by a special education teacher implementing VM in a classroom. The videos were not professionally made. The researcher filmed the videos by using a retractable camera stand that was manipulated to capture the clearest footage as possible. The researcher kept track of the time it took to make the video models. It took approximately one hour to film the raw footage and approximately three hours to edit, narrate, finalize, upload videos to the $\mathrm{iPad}{ }^{\circledR}$ Minis, and upload videos a second time to the vloop app so they could be played on a loop during CVM+P\&R. The researcher spent a total of approximately four hours making video models with an average time of 40 minutes per video.

\subsubsection{Preference assessment}

The researcher conducted a series of multiple-stimulus without replacement (MSWO; DeLeon \& Iwata, 1996) preference assessments with each participant to determine the item(s) most likely to be reinforcing. Information provided by participants' parents and teachers helped determine items included in the MSWO. Briefly, arrays of three to five objects/activities/food items were displayed in front of a student. The researcher asked the student to "pick one" and recorded the student's response while he or she engaged with the object/activity or ate the food item. The selection was then either removed (object/activity) or not replaced (food item), and the

researcher asked the student to "pick one" of the remaining items. This procedure was repeated until all items were selected or the student indicated that he or she did not want the final item(s). 
The entire MSWO procedure was conducted at least six times for each student or until one or two objects/activities/food items emerged as the most preferred item.

\subsubsection{Baseline phase}

Sessions were carried out in a similar manner to sessions conducted by Cihak and Schrader (2008). During baseline sessions, the researcher directed the student to either the worktable or the classroom bathroom. All materials needed to complete the skill were available. The researcher delivered an initial prompt to begin completing the target skill. No feedback was given for any step completed correctly or incorrectly. If the student did not respond by correctly completing a step within 20 seconds, the student was given a second prompt during which the researcher told the student to try to complete any steps he or she knows. The researcher counted any steps correctly completed according to the skill task analysis as correct, regardless of the order in which they were completed. The student was given 10 seconds to initiate performance of a step after the second prompt was given. If they did not respond or continued to make errors, the probe was discontinued. The researcher conducted at least five baseline sessions with each student.

\subsubsection{Intervention comparison phase}

Three independent variables were under investigation: $\mathrm{VM}+\mathrm{P} \& \mathrm{R}, \mathrm{CVM}+\mathrm{P} \& \mathrm{R}$, and $\mathrm{P} \& \mathrm{R}$ and each intervention was paired with a target skill. During each condition, the participant was directed to the worktable or the classroom bathroom. All materials were available including the iPad ${ }^{\circledR}$ Mini, on which the student viewed videos during VM+P\&R and CVM+P\&R probes. The 
researcher used a data sheet listing the steps of each target skill to record whether each step was completed independently or with a prompt.

\subsubsection{VM+P\&R condition}

The researcher directed the student to view a video in its entirety one time and delivered verbal prompts to "watch the video" if a student looked away. When the video ended, the researcher told the student to begin completing the target skill. The participant was given three seconds to begin the first step of the skill independently. If he or she did not begin or made an error during the first step, the researcher began the least-to-most prompting procedure. First, the researcher delivered a verbal plus gestural task prompt (e.g., "Get the cup” while pointing to the cup) and waited three seconds. If the student still did not begin the skill or did not correct the error, the researcher physically guided the student to complete the first step correctly. The student was then expected to initiate the second step within three seconds; if not, the prompting procedure was implemented accordingly. This pattern continued until the task was completed and the researcher delivered a reinforcer.

\subsubsection{CVM+P\&R condition}

The second intervention was conducted in a similar way to $\mathrm{VM}+\mathrm{P} \& \mathrm{R}$ with one major difference; the video was set to play on a constant loop using the vloop application, providing students with continuous access to the video. The researcher directed the student to view the video in its entirety one time, delivering verbal prompts as needed. After the student watched the video all the way through one time, the researcher told the student to begin the target skill just before the video restarted at the first step. The participant had three seconds to begin the first step of the skill independently. If he or she did not begin or made an error, the researcher began a slightly 
altered least-to-most prompting procedure. First, the researcher delivered a verbal plus gestural video prompt (i.e., "Watch the video" while pointing to the video) and directed the student to watch the video as it looped around to the step on which the student made an error. The researcher prompted the student to attend to the looped video in an attempt to teach the student to use the video model rather than rely on the adult. The verbal plus gestural video prompt was not used in $\mathrm{VM}+\mathrm{P} \& \mathrm{R}$ because the participant only viewed the video one time; it was not played on a loop in $\mathrm{VM}+\mathrm{P} \& \mathrm{R}$. Once the step during which an error occurred played, the student was given three seconds to correctly begin the skill. If the student still did not begin the skill or did not correct the error, the researcher physically guided the student to complete the first step correctly. The student was then expected to initiate the second step within three seconds, if not, the prompting procedure was implemented accordingly. This pattern continued until the task was completed and the researcher delivered a reinforcer.

\subsubsection{P\&R condition}

There was no video for the student to view in this condition. The researcher directed the student to the worktable or the classroom bathroom and told the student to begin target skill. The participant had three seconds to begin the first step of the skill independently. If he or she did not begin or made an error in the first step, the researcher began the same least-to-most prompting procedure used in $\mathrm{VM}+\mathrm{P} \& \mathrm{R}$. First, the researcher delivered a verbal plus gestural task prompt (e.g., "Pick up the t-shirt" while pointing to the t-shirt) and waited three seconds. If the student still did not begin the skill or did not correct the error, the researcher physically guided the student to complete the first step correctly. The student was then expected to initiate the second step within three seconds, if not, the prompting procedure was implemented accordingly. This pattern continued until the task was completed and the researcher delivered a reinforcer. 


\subsubsection{Mastery criteria and “final best” replication phase}

Students completed each target skill using the assigned intervention (i.e., VM+P\&R, $\mathrm{CVM}+\mathrm{P} \& \mathrm{R}$, or $\mathrm{P} \& \mathrm{R})$ until the student reached the mastery criterion of $100 \%$ of steps correctly completed across three consecutive sessions under one of the intervention conditions. The researcher considered the condition under which the student reached mastery criterion first the superior or "final best" intervention for that student. Sessions continued until a) the student met the mastery criterion for at least one additional skill/intervention or b) until performance of the other two skills appeared relatively stable without meeting criterion. In the case of situation "b,” a "final best" replication condition was implemented during which the presumed superior intervention was applied to a skill that had previously been receiving a different intervention without meeting criterion.

\subsubsection{Accuracy, interobserver agreement, and procedural integrity}

Johnston and Pennypacker (2009) define accuracy as "the extent to which observed values approximate to the events that actually occurred” (p.141). To assess for accuracy on the percentage of correctly completed steps, the researcher collected data during each session and videotaped each session so that student performance could be viewed again at a later time. The researcher viewed each video recorded session until performance could be accurately scored. Data collected during live observations was compared to data collected during later viewings of the videos for $100 \%$ of sessions. Percentage of accuracy for Jake was $99.1 \%, 99.7 \%$ for Nick, $100 \%$ for Pete, and $99.5 \%$ for Hope and was $99.6 \%$, overall.

In addition, a research assistant was trained in the coding procedure and interobserver agreement (IOA) data was collected on $34.2 \%$ of sessions across all phases of the study. Point- 
by-point agreement was calculated for both IOA training sessions and actual study sessions by dividing the number of agreements by the sum of agreements and disagreements and multiplying by 100 (Johnston \& Pennypacker, 2009). Training on scoring procedures was conducted during multiple sessions and consisted of reviewing task analyses of similar skills, watching videos of students completing the skills, and scoring steps as correct or prompted. A criterion of $90 \%$ agreement or higher was set for training sessions. The research assistant viewed a total of 22 training videos and IOA during training was $97 \%$.

For actual study sessions, IOA was $99.8 \%$, overall. IOA was $99.1 \%$ across $36.2 \%$ of sessions for Jake, $100 \%$ across $33.3 \%$ of sessions for Nick, $100 \%$ across $33.3 \%$ of sessions for Pete, and $100 \%$ across $33.8 \%$ of sessions for Hope.

Procedural integrity data was also collected on an average of 34.2\% of sessions across all conditions and all participants. The same research assistant was trained on the procedures for implementing baseline, $\mathrm{VM}+\mathrm{P} \& \mathrm{R}, \mathrm{CVM}+\mathrm{P} \& \mathrm{R}$, and $\mathrm{P} \& \mathrm{R}$ and was provided with a checklist of procedures for each phase or condition. The research assistant used the checklist when viewing the IOA videos and recorded whether the researcher completed each step of the procedure correctly. The researcher calculated procedural integrity by dividing the number of procedural steps completed correctly by the total number of procedural steps and multiplying by 100 . Procedural integrity was $100 \%$ for all students.

\subsubsection{Social validity}

At the end of the study, participants were asked to respond to several questions to assess their opinions of the target skills selected and the use of video models. They were also asked to indicate their preferred intervention. Additionally, the researcher shared results of the study with 
the teacher and parent of each participant including a final written report of results, a graphical display of data, and pre- and post-intervention video clips. Teachers and parents then completed a brief survey to determine how appropriate they felt the target skills were for their student(s) or child, how effective they felt the interventions were in improving the independent living skills of their student(s) or child, which intervention appeared to be most effective, if they would consider implementing a video-based intervention in his or her classroom or home and, if so, which intervention would they be most likely to use.

\subsubsection{Data analysis}

The purpose of this study was to compare the effects of $V M+P \& R, C V M+P \& R$, and $P \& R$ on the independent living skills of students with ASD and ID. Data displaying the primary dependent variable, percentages of steps completed correctly and independently for each skill, were graphed and visually analyzed by level, trend, variability and immediacy (Riley-Tilman, Burn, \& Gibbons, 2013) to determine the effects of the interventions. In addition to visual analysis, the percentage of non-overlapping data (PND) was calculated across baseline and comparison phases for each skill to determine the amount of overlap in performance before and after exposure to an intervention (Scruggs \& Mastropieri, 2013). Finally, PND was also calculated for the $\mathrm{VM}+\mathrm{P} \& \mathrm{R}, \mathrm{CVM}+\mathrm{P} \& \mathrm{R}, \mathrm{P} \& \mathrm{R}$ conditions during the comparison phase to identify consistent differences between data point values of each of the conditions (Wolery et al., 2014). This was done by identifying the percentage of sessions during which performance with CVM+P\&R, $\mathrm{VM}+\mathrm{P} \& \mathrm{R}$, and $\mathrm{P} \& \mathrm{R}$ resulted in the highest level of performance.

In additional to analyzing data according to the percentage of correct steps during each session, the number of sessions a participant needed to meet the mastery criteria for a skill was 
also graphed and analyzed. The researcher compared the number of sessions needed to meet criteria for each skill to determine comparative intervention effects.

The total number of adult-delivered prompts was calculated by tallying the number of steps during which a participant required a prompt from the researcher to complete the step correctly. The researcher created and visually analyzed bar graphs showing the total number of prompts required for each skill and intervention condition to determine the intervention during which a participant required the least and most prompts to complete a skill sequence correctly. Finally, the researcher created and visually analyzed a bar graph displaying the total number of prompts required during the intervention comparison phase for all students and the total number of prompts required across all students under each intervention condition to determine which intervention, overall, allowed students to complete steps with the most and least amount of independence (i.e., least and most prompting).

To analyze data on the time to skill completion for each participant, the researcher graphed the number of seconds it took a participant to complete each skill. Time to completion data were only graphed and analyzed during the comparison and "final best" phases. Time was not considered during baseline because no student completed all steps during baseline. The researcher wanted to measure the time it took a student to actually complete all steps of a skill, with or without prompting. Graphs were visually analyzed to determine, overall, which interventions were most often associated with the fastest and slowest times to skill completion. The team of competent adults completed all skills in a similar amount of time $(R=12.8-14.5$ seconds). Student times were compared to the average times of skill completion for the team of competent adults. Finally, the researcher calculated an average time to completion across all 
sessions for each intervention for every student as well as an overall average time to skill completion for each intervention.

Finally, the researcher calculated the cumulative amount of instructional time participants spent on each skill with its assigned intervention and a bar graph was created. Instructional time included time spent watching videos. Cumulative instructional times were compared across each intervention for every student. Specifically, if a participant, met the mastery criterion for one or both of the video-based interventions as well as P\&R, times were compared to determine which intervention took the least amount of instructional time to master. Also considered in this analysis was the approximate time it took to make a single video used in one of the video-based interventions, which was approximately 40 minutes. 


\subsection{RESULTS}

\subsection{MSWO PREFERENCE ASSESSMENT}

Based on information provided by parents and teachers, the researcher gathered a variety of potential reinforcers to conduct the MSWO preference assessment. Potential reinforcers for Jake were iPad® videos, a pin art toy, a stack of playing cards, Swedish Fish®, pieces of donut, and Goldfish ${ }^{\circledR}$ crackers. During 6 out of 6 sessions, Jake selected the pin art toy first, indicating that this item was his most preferred item. Potential reinforcers for Nick were Goldfish® crackers, Swedish Fish®, m\&m’s®, Skittles ${ }^{\circledR}, \mathrm{iPad} \circledast$ videos, and a pin art toy. During 4 out of 6 sessions, Nick selected either Smarties ${ }^{\circledR}$ or Swedish Fish ${ }^{\circledR}$ first, indicating that these items were his most preferred items. Potential reinforcers for Pete were iPad® videos, a remote control car, a pin art toy, Swedish Fish ${ }^{\circledR}$, and Goldfish ${ }^{\circledR}$ crackers. During 6 out of 6 sessions, Pete chose iPad® games or the remote control car first, indicating that these were his most preferred items. Potential reinforcers for Hope were a stack of playing cards, time to make a sticker charm bracelet, a pin art toy, iPad® videos, and a 3D puzzle. During 6 out of 6 sessions, Hope chose $i P a d ®$ videos or time to work on sticker charm bracelet first, indicating that these items were her most preferred items.

For Nick, Pete, and Hope, two items emerged as being equally preferred above all other items. During intervention sessions for these students, immediately after the student completed 
the skill, the researcher presented both items, offering a choice of the two. For all students, one item eventually emerged as the most preferred item over the course of several intervention sessions (i.e., one of the two items was consistently selected). Nick always selected Smarties ${ }^{\circledR}$, Pete always selected games on the $\mathrm{iPad} \AA$, and Hope always selected $\mathrm{iPad} \circledast$ videos.

\subsection{JAKE}

Figures 1-5 display results for Jake. Figure 1 displays Jake's percentage of correct steps for each skill during baseline, comparison, and "final best" phases. Figure 2 displays the number of instructional sessions Jake required to meet the mastery criterion for two skills and the total number of instructional sessions conducted for the skill not mastered. Figure 3 displays the total number of prompts Jake needed to correctly complete each skill under the assigned intervention condition during the comparison phase (i.e., left bar) and "final best" phase (i.e., right bar). Figure 4 displays the amount of time it took Jake to complete each skill. Figure 5 shows the cumulative number of instructional minutes for each skill during the comparison phase (i.e., bottom bar) and "final best” phase (i.e., top bar).

\subsubsection{Percentage of correct steps and number of sessions to mastery}

During baseline, Jake's skill performance was low and stable. He consistently performed $0 \%$ of steps correctly for folding and storing socks and taking out the trash. During the first baseline session, he was able to perform $20 \%$ of steps correctly for rolling the silverware, but consistently performed $0 \%$ of steps correctly during all other sessions. During the intervention comparison 
phase, Jake’s performance with taking out the trash immediately improved with VM+P\&R and steadily increased. He met the mastery criteria for taking out the trash with VM+P\&R in nine intervention sessions. Jake also immediately improved with folding and storing the socks when P\&R was applied to the skill. However, his performance stabilized between $40-60 \%$ of steps completed correctly during the intervention comparison phase. When asked to roll the silverware with CVM+P\&R, Jake’s improvement was slower and also stabilized at around $40-60 \%$ of steps correct. During the intervention comparison phase, $\mathrm{VM}+\mathrm{P} \& \mathrm{R}$ appeared to be the most effective intervention for Jake.

During the "final best" phase, VM+P\&R was applied to rolling silverware instead of $\mathrm{CVM}+\mathrm{P} \& \mathrm{R}$. With the application of VM+P\&R, Jake’s performance immediately improved to $80 \%$ of steps completed correctly, however, his performance stabilized here. Jake maintained his performance with taking out the trash with VM+P\&R, completing the skill with $100 \%$ accuracy. P\&R remained in effect with folding and storing socks and, over time, Jake's performance improved. He was able to reach the mastery criterion with P\&R in 17 sessions.

Visual analysis of Jake's graph indicated that VM+P\&R appeared to be most effective, followed by P\&R. PND analysis supports this conclusion. From baseline to intervention sessions, PND for taking out the trash (VM+P\&R) and folding socks (P\&R) was $100 \%$, while PND for rolling silverware $(C V M+P \& R)$ was $77.8 \%$. Further, PND between the three interventions during the comparison phase showed that Jake's performance was higher than or equal to $\mathrm{P} \& \mathrm{R}$ for $100 \%$ sessions and was highest with $\mathrm{VM}+\mathrm{P} \& \mathrm{R}$ during $77.8 \%$ of the sessions. See Figure 1.

A total of 17 instructional sessions were conducted with Jake: nine sessions during the comparison phase and eight sessions during the "final best" phase. Jake mastered taking out the 
trash in nine sessions with $\mathrm{VM}+\mathrm{P} \& \mathrm{R}$ and mastered folding and storing socks in 17 sessions. Jake did not meet the mastery criterion for rolling silverware with $C V M+P \& R$ or VM+P\&R. See Figure 2.

\subsubsection{Total number of adult-delivered prompts}

During the comparison phase, Jake required the least number of prompts to take out the trash with $\mathrm{VM}+\mathrm{P} \& \mathrm{R}(N=14)$. He needed a similar number of prompts from the researcher to roll the silverware with $\mathrm{CVM}+\mathrm{P} \& \mathrm{R}$ and to fold and store the socks with $\mathrm{P} \& \mathrm{R} \quad(N=24$ and $N=23$, respectively). During the "final best" phase, Jake did not require any adult prompts to take out the trash with $\mathrm{VM}+\mathrm{P} \& \mathrm{R}$ and the number of prompts he needed to roll silverware when $\mathrm{VM}+\mathrm{P} \& \mathrm{R}$ was applied instead of $\mathrm{CVM}+\mathrm{P} \& \mathrm{R}$ dropped from an average of 2.7 prompts per session to an average of 1 prompt per session. However, the number of adult prompts required also dropped from the comparison phase to the "final best" phase when Jake folded and stored socks with $P \& R$ from an average of 2.56 to an average of 0.63 prompts per session. See Figure 3.

\subsubsection{Time to skill completion}

During the comparison phase, rolling silverware with $\mathrm{CVM}+\mathrm{P} \& \mathrm{R}$ always took longer $(M=90.8$ seconds) than taking out the trash with $\mathrm{VM}+\mathrm{P} \& \mathrm{R}$ ( $M=23.8$ seconds) or folding and storing socks with P\&R ( $M=39.7$ seconds) for Jake. During the “final best” phase, Jake did appear to increase his speed with all skills. However, when VM+P\&R was applied to rolling silverware, Jake’s time to skill completion dropped from an average of 90.8 seconds to an average of 8.9 seconds. His time also reduced from averages of 23.8 seconds to 9.25 seconds when taking out the trash and 
reduced from averages of 39.7 seconds to 15.8 seconds when folding and storing socks. The greatest reduction in time to skill completion was seen in rolling silverware when VM+P\&R was applied instead of CVM+P\&R. Overall, Jake consistently performed skills faster with VM+P\&R. Jake eventually took out the trash and rolled silverware faster than the team of competent adults completed the skills. See Figure 4.

\subsubsection{Total instructional time}

During the comparison phase, Jake spent the most instructional time rolling silverware with CVM+P\&R ( $N=19.8$ minutes), followed by taking out the trash with $\mathrm{VM}+\mathrm{P} \& \mathrm{R}$ ( $N=10$ minutes), and folding and storing socks with P\&R ( $N=6$ minutes). During the "final best" phase, Jake also spent more instructional time taking out the trash and rolling silverware ( $N=7$ minutes and 6.7 minutes, respectively) with $\mathrm{VM}+\mathrm{P} \& \mathrm{R}$ than he did with folding and storing socks with $\mathrm{P} \& \mathrm{R}$ ( $N=2$ minutes). See Figure 5. 


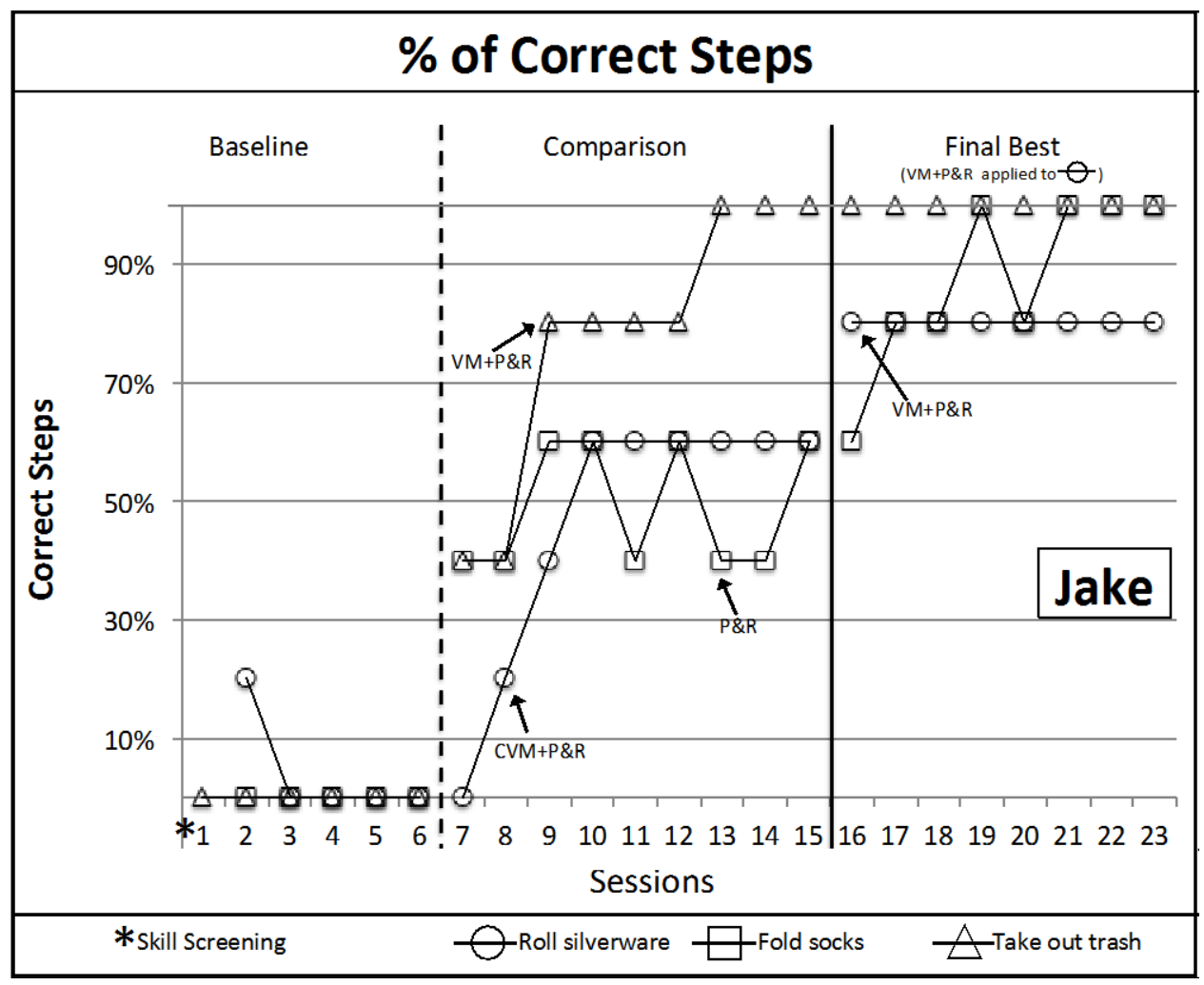

Figure 1. Percentage of correct steps for Jake

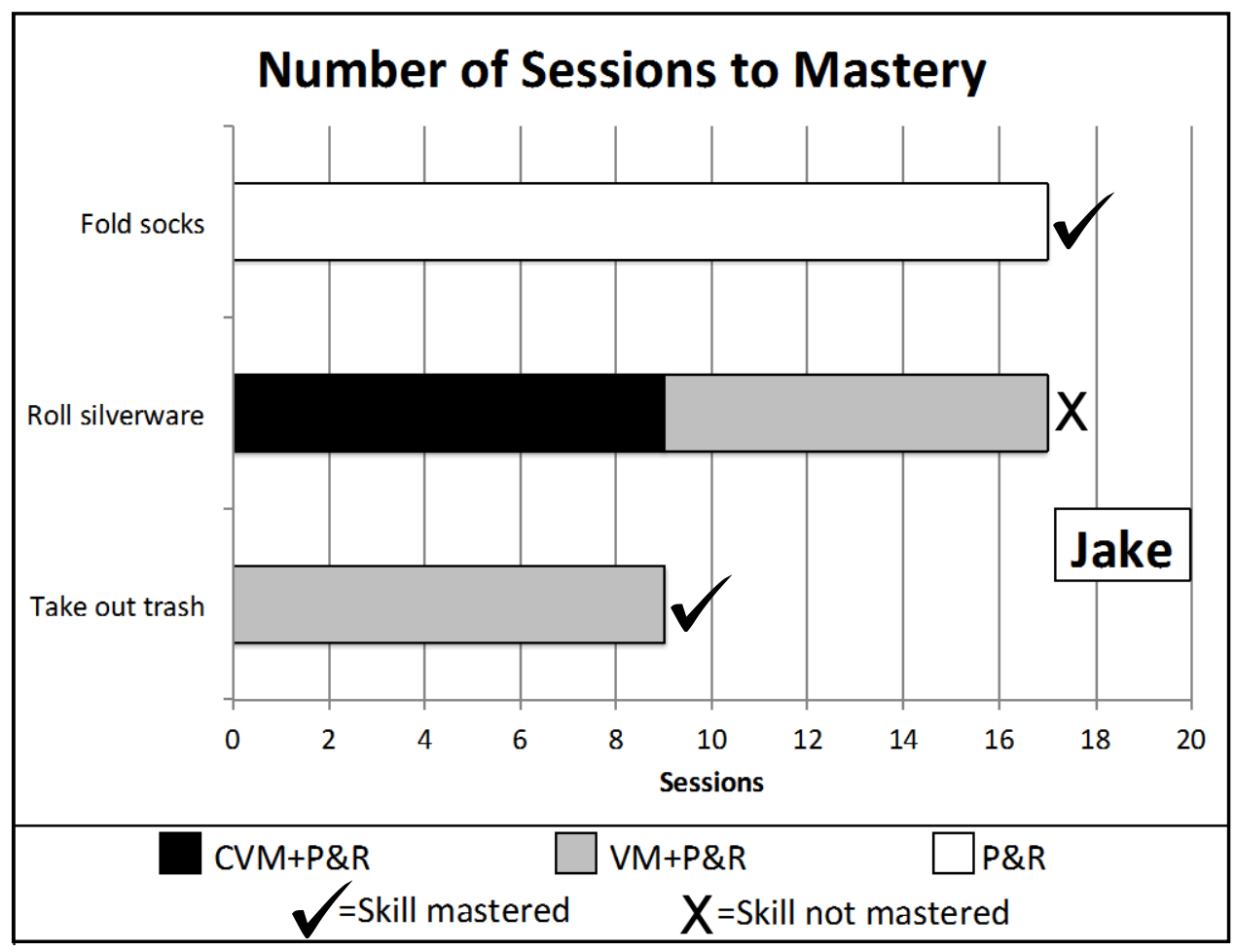

Figure 2. Number of sessions for Jake 


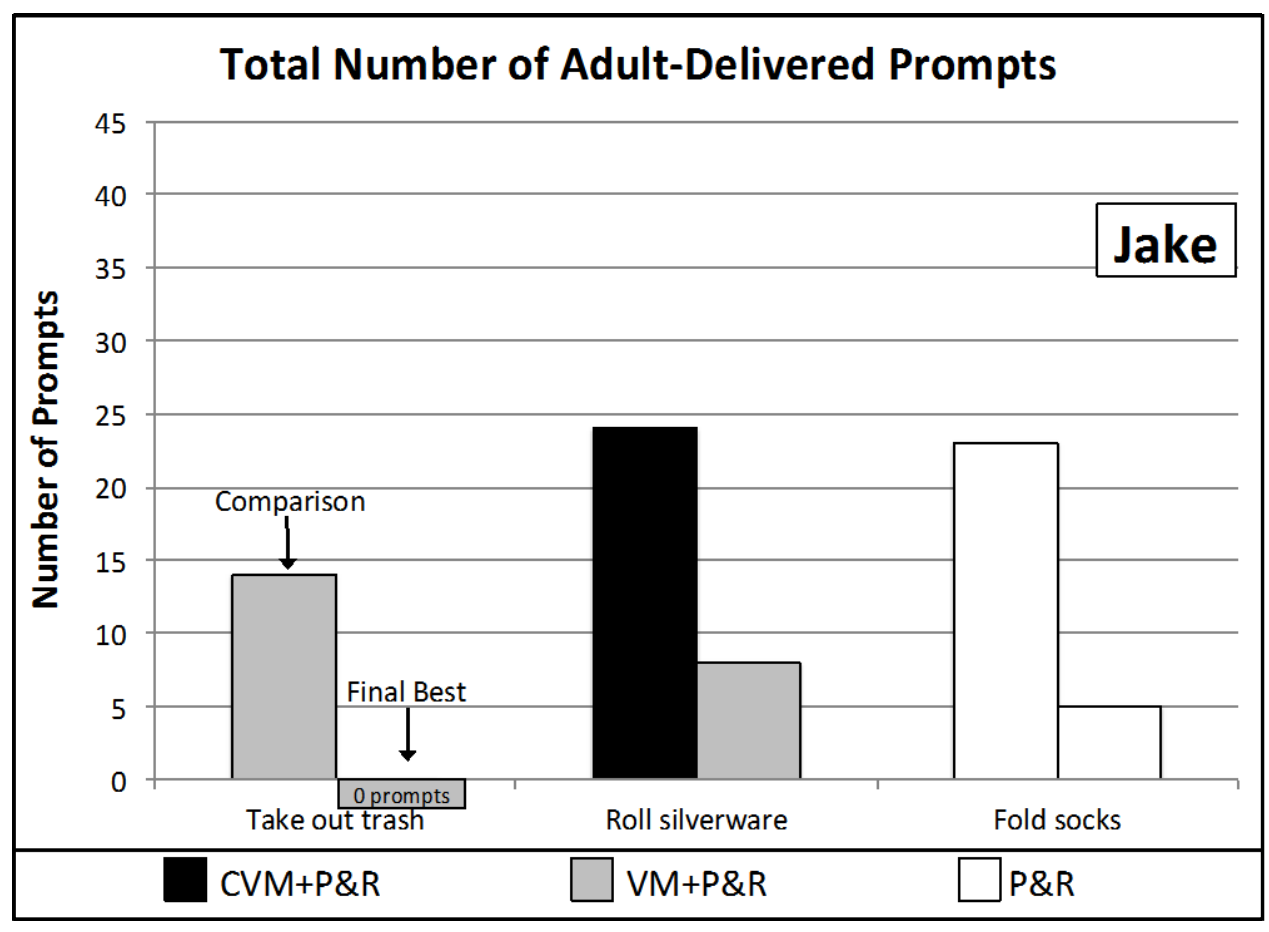

Figure 3. Total number of adult-delivered prompts for Jake

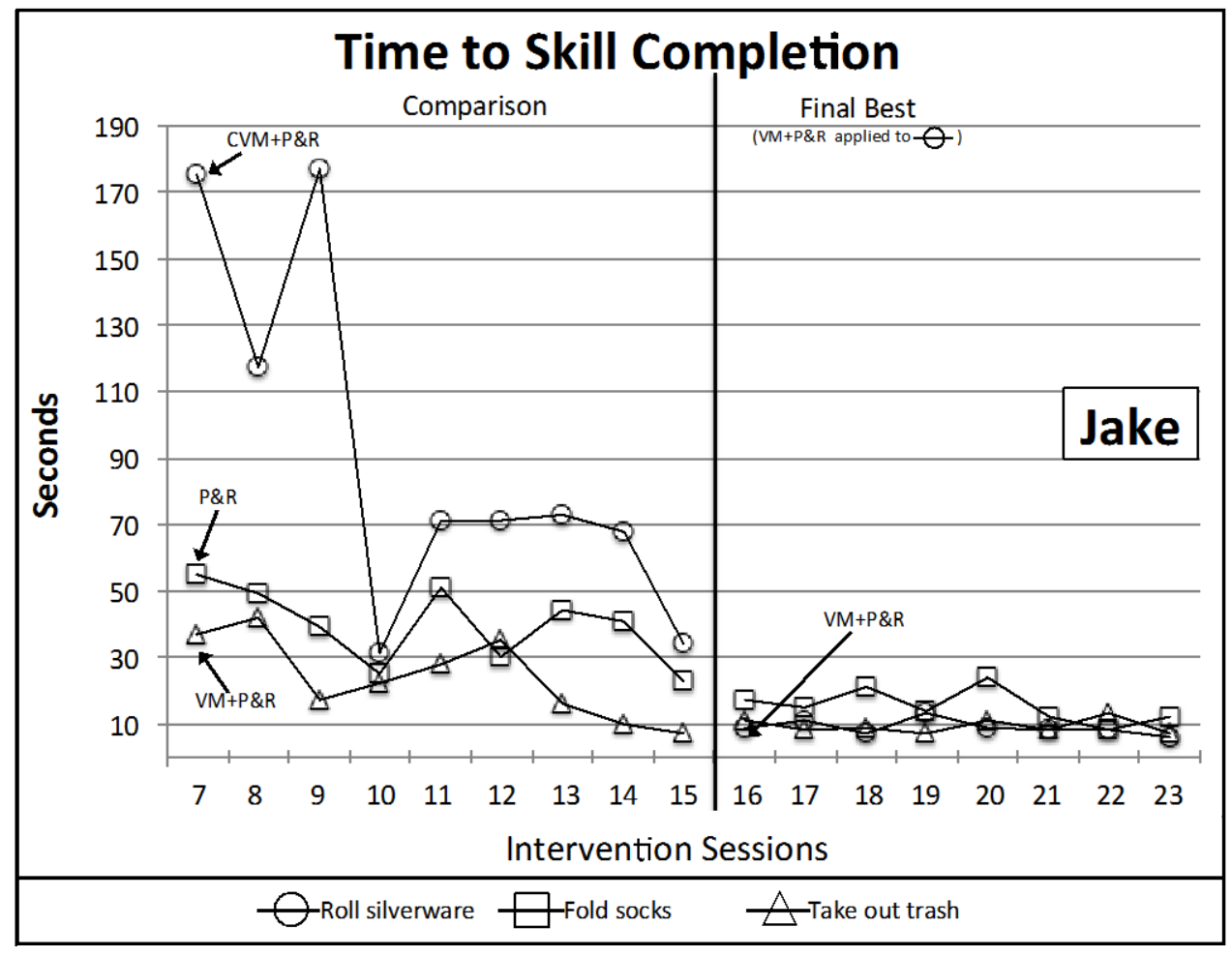

Figure 4. Time to skill completion for Jake 


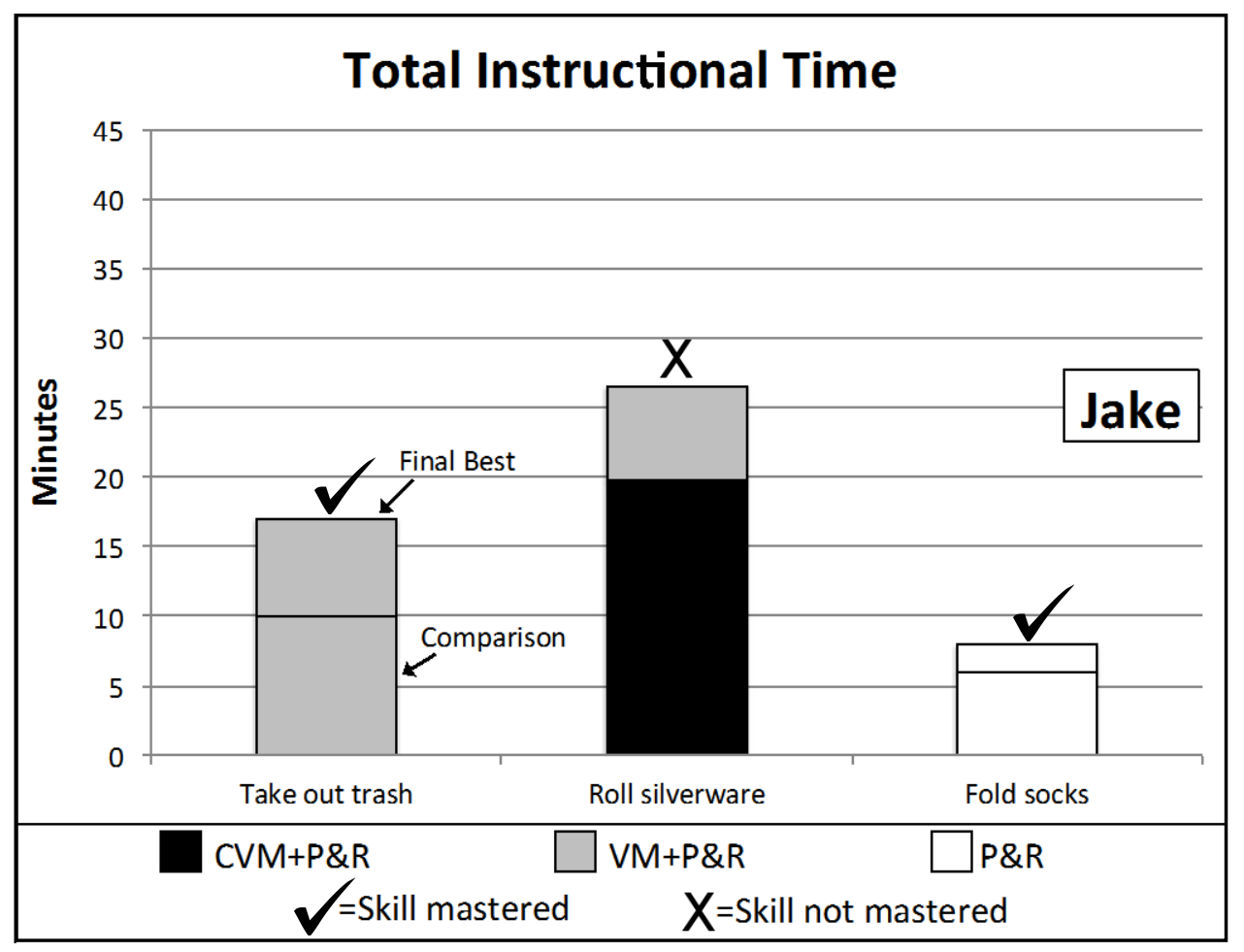

Figure 5. Total instructional time for Jake

\subsection{NICK}

Figures 6-10 display results for Nick. Figure 6 displays Nick's percentage of correct steps for each skill during baseline, comparison, and "final best” phases. Figure 7 displays the number of instructional sessions Nick required to meet the mastery criterion for a skill and the total number of instructional sessions conducted for the two skills not mastered. Figure 8 displays the total number of prompts Nick needed to correctly complete each skill under the assigned intervention condition during the comparison phase (i.e., left bar) and the "final best” phase (i.e., right bar). Figure 9 displays the amount of time it took Nick to complete each skill. Figure 10 shows the cumulative number of instructional minutes for each skill during the comparison phase (i.e., bottom bar) and "final best” phase (i.e., top bar). 


\subsubsection{Percentage of correct steps and number of sessions to mastery}

During baseline, Nick’s skill performance was low and stable. He consistently performed 0\% of steps correctly for rolling silverware and taking out the trash. He was able to perform $20 \%$ of steps correctly for folding the t-shirt for most baseline sessions. During the comparison phase, Nick's performance with taking out the trash immediately improved with CVM+P\&R. Performance steadily increased and Nick met the mastery criteria for taking out the trash with $\mathrm{CVM}+\mathrm{P} \& \mathrm{R}$ in 10 intervention sessions. When asked to roll silverware with $\mathrm{VM}+\mathrm{P} \& \mathrm{R}$ Nick's performance initially fluctuated between $0 \%$ and $40 \%$ and stabilized between $20-40 \%$. For folding the t-shirt with $\mathrm{P} \& \mathrm{R}$, Nick’s performance remained similar to his baseline performance. Little to no change was seen in Nick’s skill performance with VM+P\&R and P\&R.

During the "final best" phase, CVM+P\&R was applied to rolling silverware instead of $\mathrm{VM}+\mathrm{P} \& \mathrm{R}$. With the application of $\mathrm{CVM}+\mathrm{P} \& \mathrm{R}$, Nick's performance immediately improved to $100 \%$ of steps completed correctly, however, his performance stabilized at $80 \%$. Nick did not meet the mastery criterion for rolling silverware with $C V M+P \& R$ but his performance was at a much higher level than with $\mathrm{VM}+\mathrm{P} \& \mathrm{R}$. His performance with folding the t-shirt remained similar to his performance during the comparison condition with P\&R. Little to no change was seen in his ability to fold the t-shirt with P\&R over 15 sessions.

Visual analysis of Nick’s graph indicated that CVM+P\&R appeared to be most effective, followed by $V M+P \& R$. P\&R appeared to be the least effective intervention for Nick. PND analysis supports this conclusion. From baseline to intervention sessions, PND for taking out the trash (CVM+P\&R) was 100\%, while PND for rolling silverware (VM+P\&R) was 50\% and 20\% for folding the t-shirt (P\&R). Further, PND between the three interventions during the 
comparison phase showed that Nick's skill performance with CVM+P\&R was higher than both VM+P\&R and P\&R across $100 \%$ of sessions. See Figure 6.

A total of 15 instructional sessions were conducted with Nick: ten sessions during the comparison phase and five sessions during the "final best" phase. Nick mastered taking out the trash in ten sessions with $C V M+P \& R$. Nick did not meet the mastery criterion for rolling silverware with $\mathrm{VM}+\mathrm{P} \& \mathrm{R}$ or $\mathrm{CVM}+\mathrm{P} \& \mathrm{R}$ nor did he meet the mastery criterion for folding the tshirt with P\&R. However, a clear change in the level of his performance resulted with the application of CVM+P\&R instead of VM+P\&R for rolling silverware. See Figure 7.

\subsubsection{Total number of adult-delivered prompts}

During the comparison phase, Nick required the least number of prompts to take out the trash with $\mathrm{CVM}+\mathrm{P} \& \mathrm{R}(N=8)$. He needed a few more prompts from the researcher to roll the silverware with $\mathrm{VM}+\mathrm{P} \& \mathrm{R}(N=42)$ than he did to fold the t-shirt with $\mathrm{P} \& \mathrm{R}(N=38)$. During the "final best" phase, the average number of prompts Nick needed to take out the trash with $\mathrm{CVM}+\mathrm{P} \& \mathrm{R}$ reduced slightly from an average of 0.8 prompts per session to an average of 0.4 prompts per session. The number of prompts he needed to roll silverware when CVM+P\&R was applied instead of $\mathrm{VM}+\mathrm{P} \& \mathrm{R}$ dramatically reduced from an average of 4.2 prompts per session to an average of 0.8 prompts per session while the number of adult prompts required remained fairly stable with P\&R. During the comparison phase, Nick needed an average of 3.8 prompts per session and an average of 3.6 prompts per session during the "final best" phase to fold the t-shirt with P\&R. See Figure 8. 


\subsubsection{Time to skill completion}

During the comparison phase, taking out the trash with $C V M+P \& R$ initially took longest for Nick to complete, however, after two sessions, the amount of time required to take out the trash greatly reduced and taking out the trash eventually took him the least amount of time. Omitting the first two sessions during the comparison phase, taking out the trash with CVM+P\&R took the shortest amount of time ( $M=51.6$ seconds), followed by rolling the silverware with $\mathrm{VM}+\mathrm{P} \& \mathrm{R}$ ( $M=62$ seconds), and folding the t-shirt with $\mathrm{P} \& \mathrm{R}(M=88.4$ seconds). During the "final best" phase, Nick's time with folding the t-shirt remained similar to his time during the comparison phase. When $C V M+P \& R$ was applied to rolling silverware instead of $V M+P \& R$, Nick's time immediately decreased, however, his time to completion eventually returned to a level similar to that of his time in the comparison phase. His average time for taking out the trash with $\mathrm{CVM}+\mathrm{P} \& \mathrm{R}$ was slightly longer during the "final best” phase than during the comparison phase. Ultimately, during the final two sessions, it took Nick a very similar amount of time to complete each of the skills, which was longer than the average time it took the team of competent adults to complete the skills. See Figure 9.

\subsubsection{Total instructional time}

During the comparison phase, Nick spent the most instructional time taking out the trash with $\mathrm{CVM}+\mathrm{P} \& \mathrm{R}$ ( $N=19$ minutes), followed by rolling the silverware with $\mathrm{VM}+\mathrm{P} \& \mathrm{R} \quad(N=17.6$ minutes), and folding the t-shirt with $\mathrm{P} \& \mathrm{R}$ ( $N=14.8$ minutes). During the "final best" phase, Nick

also spent more instructional time taking out the trash and rolling silverware $(N=9.3$ minutes and 
9.4 minutes, respectively) with $\mathrm{CVM}+\mathrm{P} \& \mathrm{R}$ than he did with folding the t-shirt with $\mathrm{P} \& \mathrm{R}(N=7.6$ minutes). See Figure 10.

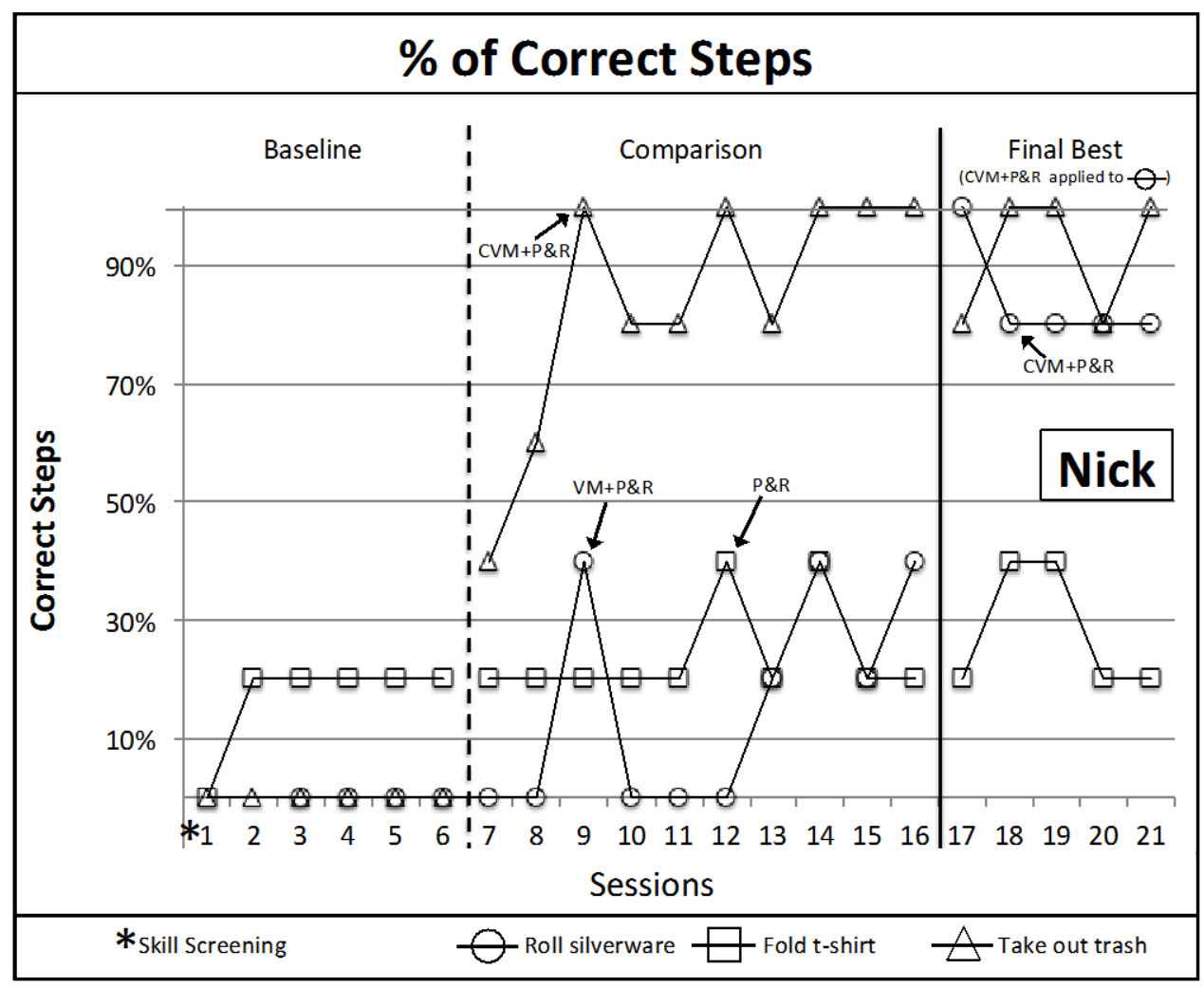

Figure 6. Percentage of correct steps for Nick 


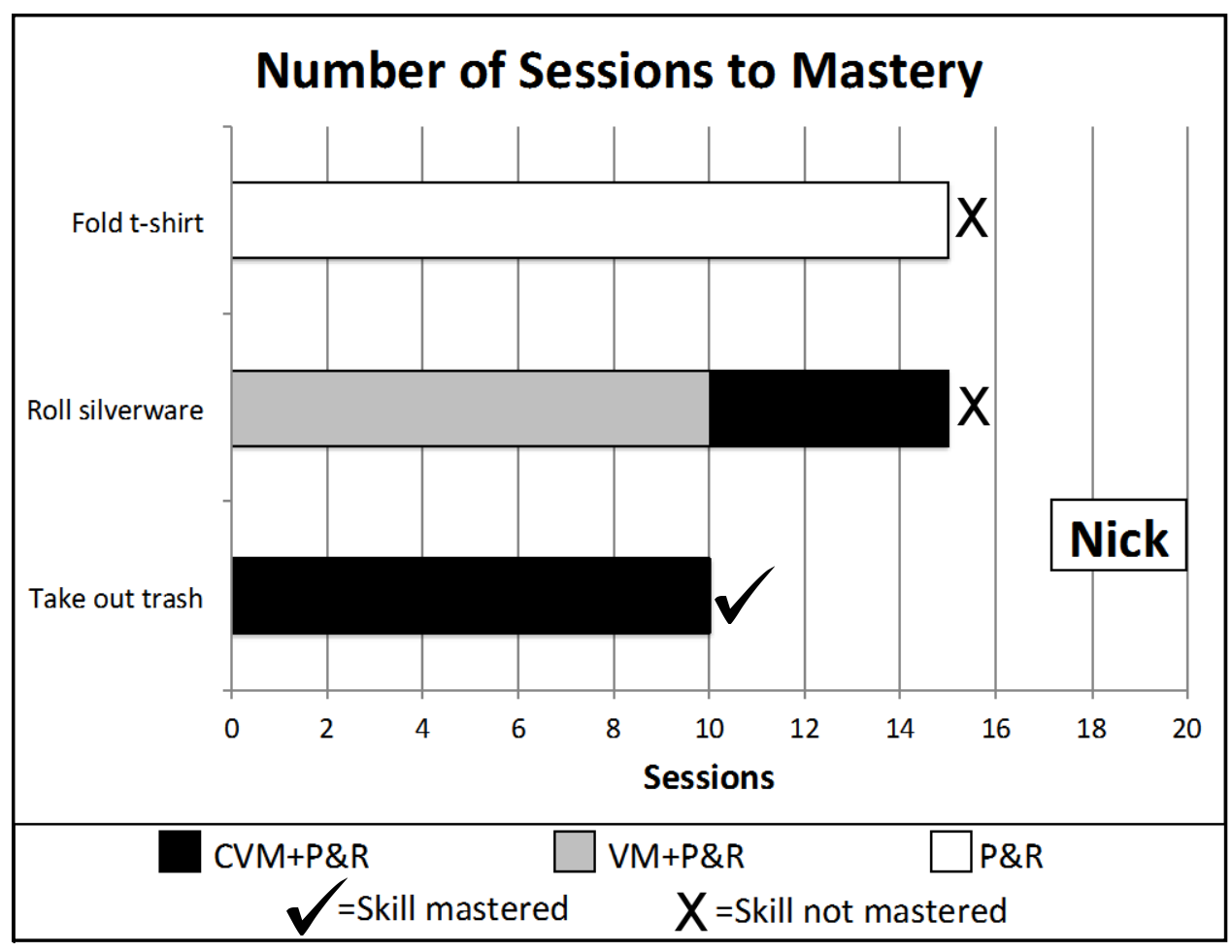

Figure 7. Number of sessions for Nick

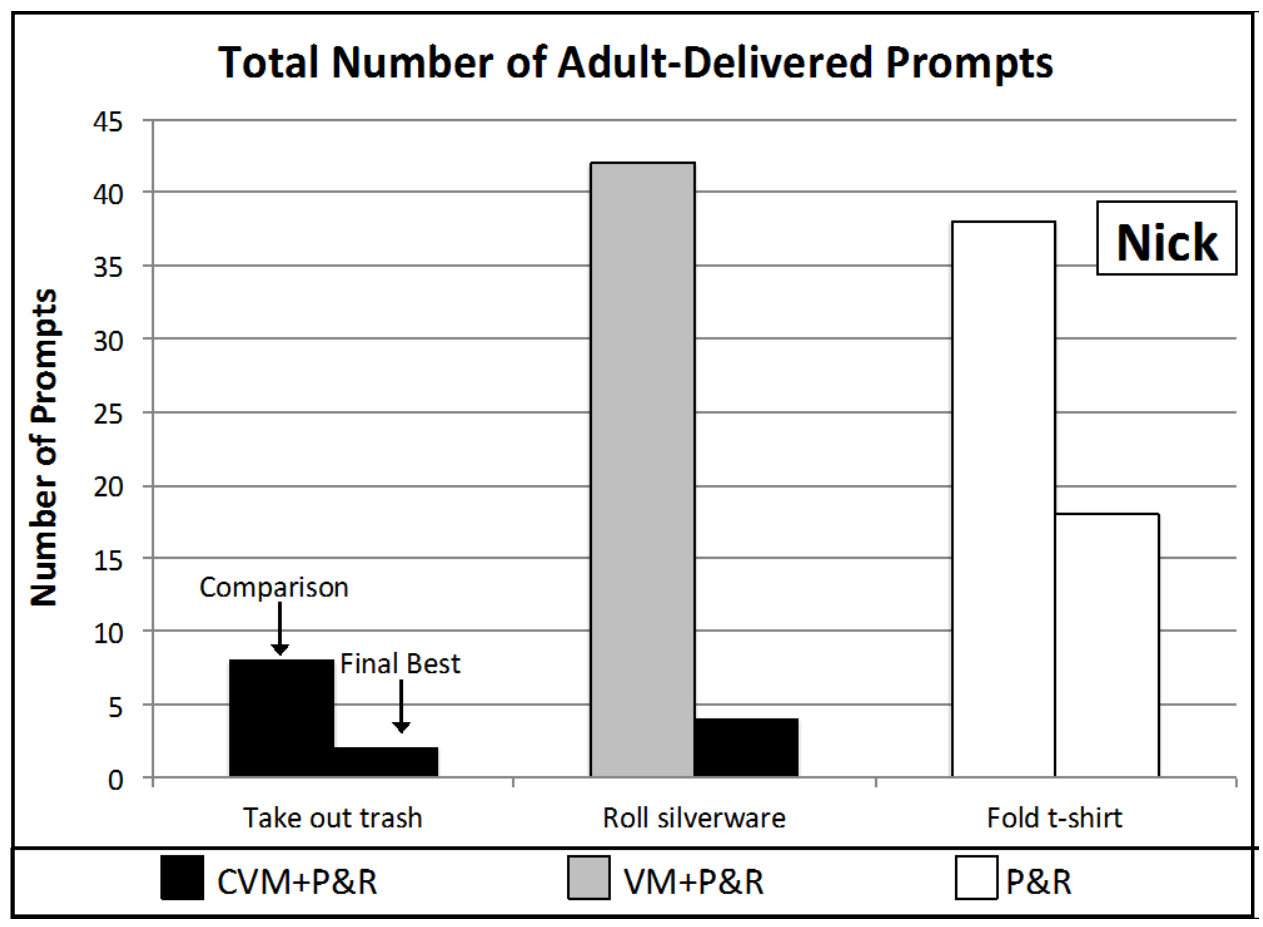

Figure 8. Total number of adult-delivered prompts for Nick 


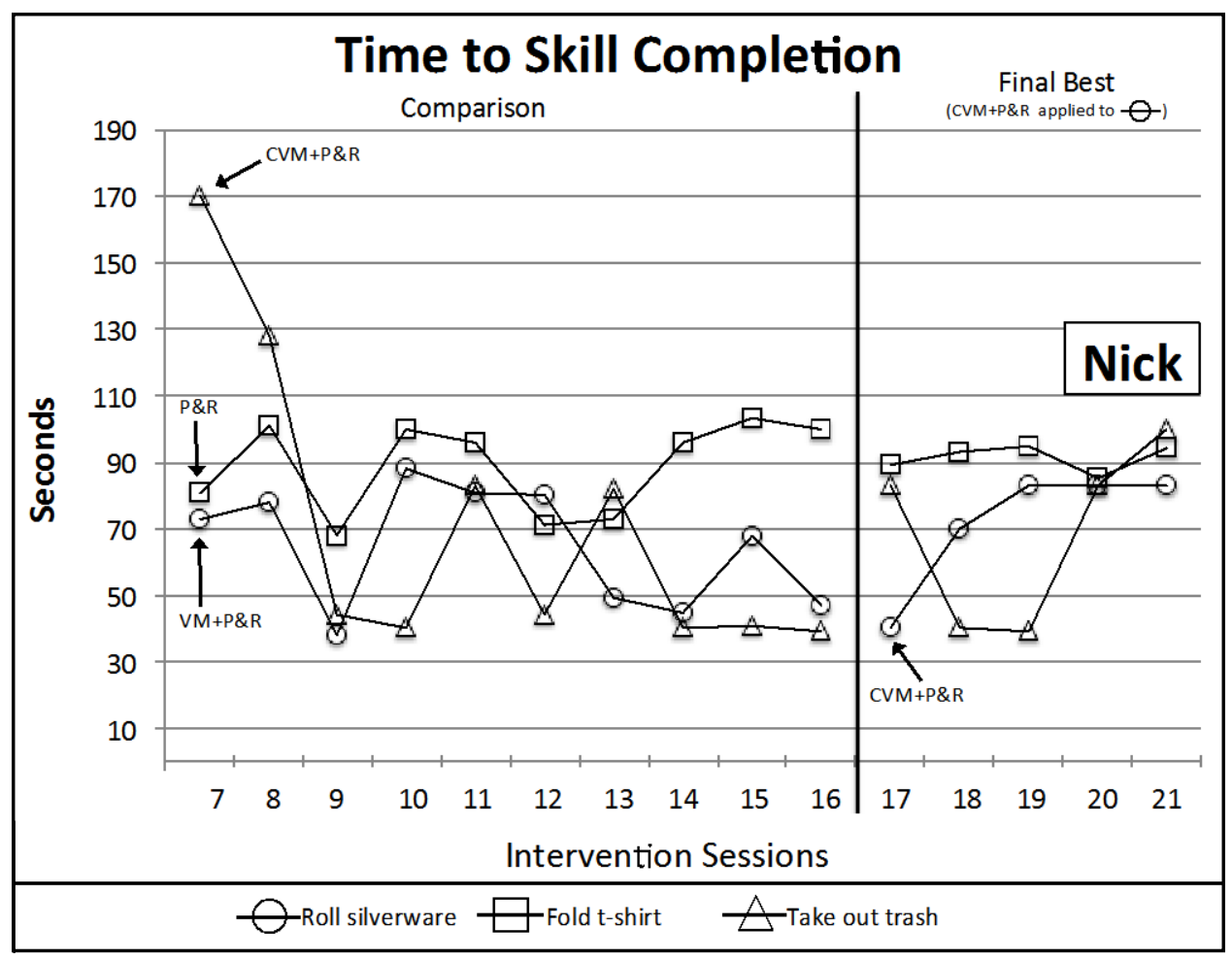

Figure 9. Time to skill completion for Nick

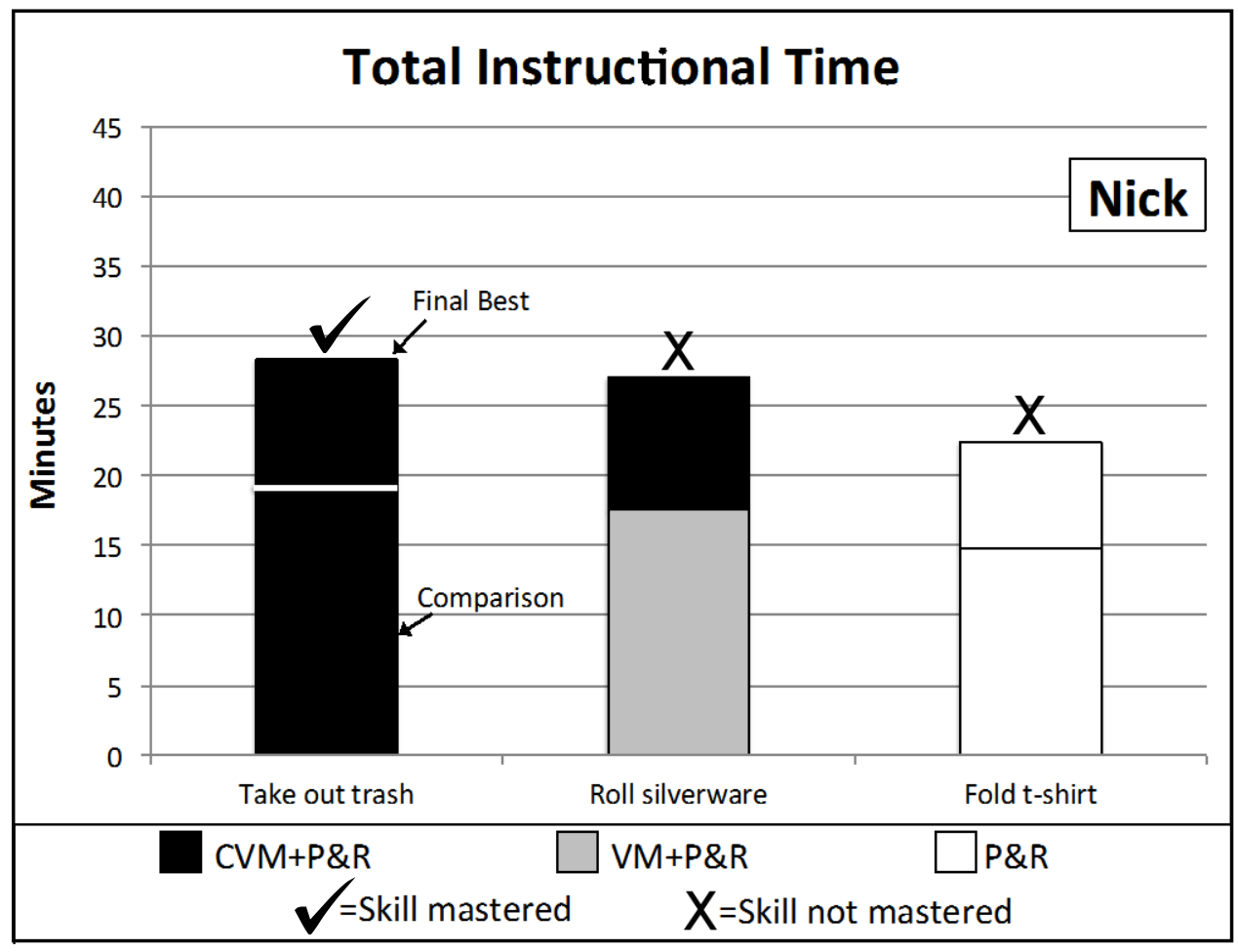

Figure 10. Total instructional time for Nick 


\subsection{PETE}

Figures 11-15 display results for Pete. Figure 11 displays Pete’s percentage of correct steps for each skill during baseline and comparison phases. Figure 12 displays the number of instructional sessions required to meet the mastery criterion for each skill. Figure 13 displays the total number of prompts Pete needed to correctly complete each skill under the assigned intervention condition. Figure 14 displays the amount of time it took Pete to complete each skill. Figure 15 shows the cumulative number of instructional minutes for each skill.

\subsubsection{Percentage of correct steps and number of sessions to mastery}

During baseline, Pete consistently performed $0 \%$ of steps correctly when asked to take out the trash and $20 \%$ of steps correctly when asked to fold the t-shirt and get a glass of water. During the comparison phase, Pete immediately improved when $\mathrm{VM}+\mathrm{P} \& \mathrm{R}$ was applied to getting a glass of water and when CVM+P\&R was applied to folding a t-shirt. Immediately after applying P\&R, there was a slight increase in taking out the trash. Ultimately, Pete was able to master all skills but he met the mastery criterion first for getting a glass of water with VM+P\&R.

There was no overlap in Pete's data from baseline to intervention for any intervention conditions (PND=100\%). Further, PND between the three interventions showed that Pete's skill performance with $\mathrm{VM}+\mathrm{P} \& \mathrm{R}$ was higher than or equal to $\mathrm{P} \& \mathrm{R}$ for $100 \%$ sessions and was highest with VM+P\&R during the majority of sessions (62.5\%). See Figure 11.

A total of 8 instructional sessions were conducted with Pete, all of which occurred during the comparison phase because Pete was able to master all skills during this phase. He did not need a “final best” phase. Pete mastered getting a glass of water with VM+P\&R in four sessions, 
folding the t-shirt with CVM+P\&R in seven sessions, and taking out the trash with $\mathrm{P} \& \mathrm{R}$ in eight sessions. See Figure 12.

\subsubsection{Total number of adult-delivered prompts}

Pete needed the fewest prompts from the researcher when asked to get a glass of water with $\mathrm{VM}+\mathrm{P} \& \mathrm{R}(N=2)$ and the most prompts when taking out the trash with $\mathrm{P} \& \mathrm{R}(N=10)$. Pete needed a total of six prompts across all sessions to fold the t-shirt with CVM+P\&R. See Figure 13.

\subsubsection{Time to skill completion}

Pete consistently took the longest to fold the t-shirt with CVM+P\&R ( $M=66.8$ seconds) followed by taking out the trash with P\&R ( $M=35.3$ seconds). Pete always got a glass of water with $\mathrm{VM}+\mathrm{P} \& \mathrm{R}$ in the shortest amount of time ( $M=13.8$ seconds). Pete got a glass of water in a comparable amount of time to the team of competent adults. See Figure 14.

\subsubsection{Total instructional time}

Pete spent the most instructional time folding the t-shirt with CVM+P\&R ( $N=14.4$ minutes), followed by getting a class of water with $\mathrm{VM}+\mathrm{P} \& \mathrm{R}$ ( $N=6.9$ minutes), and taking out the trash with P\&R ( $N=4.7$ minutes). See Figure 15. 


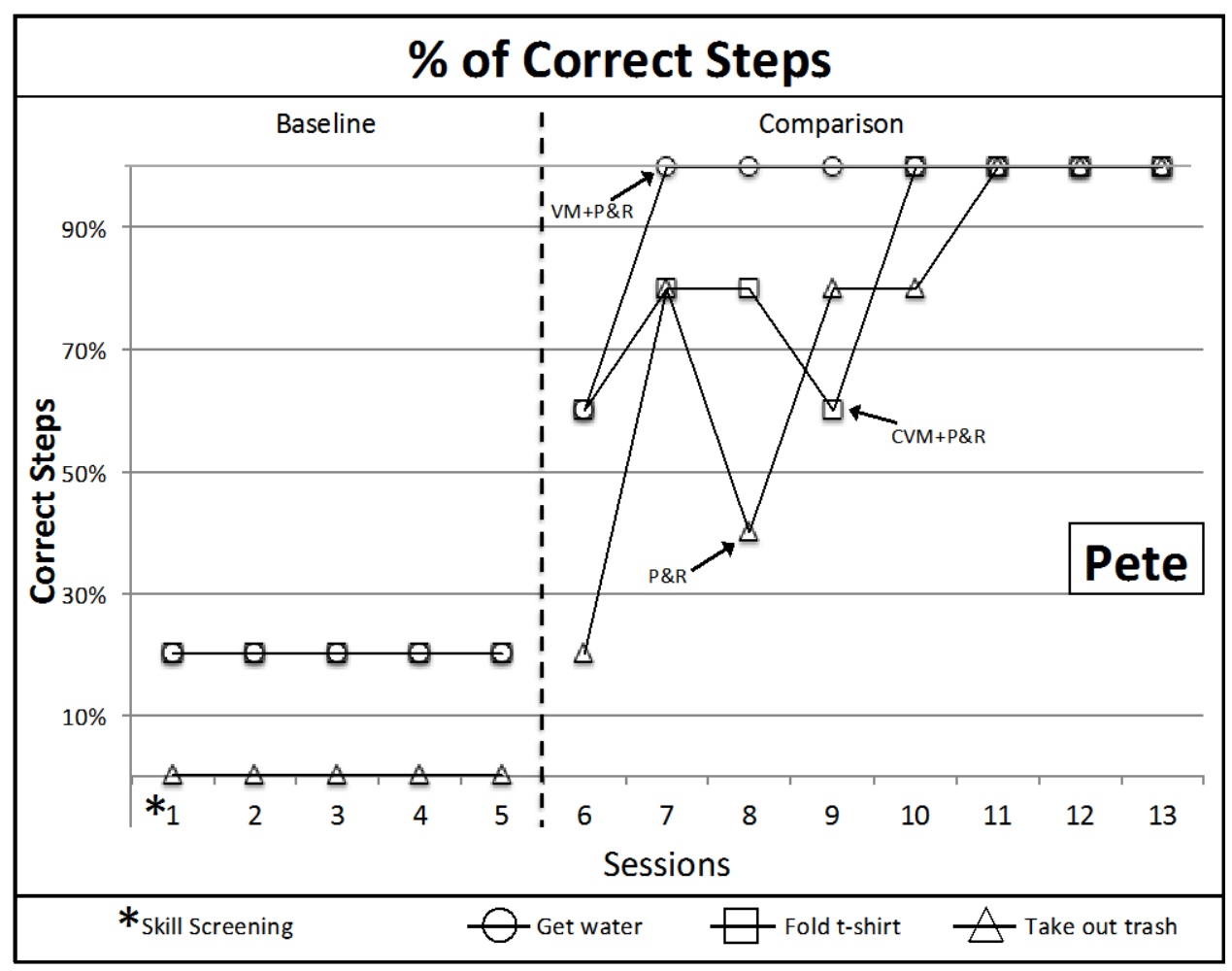

Figure 11. Percentage of correct steps for Pete

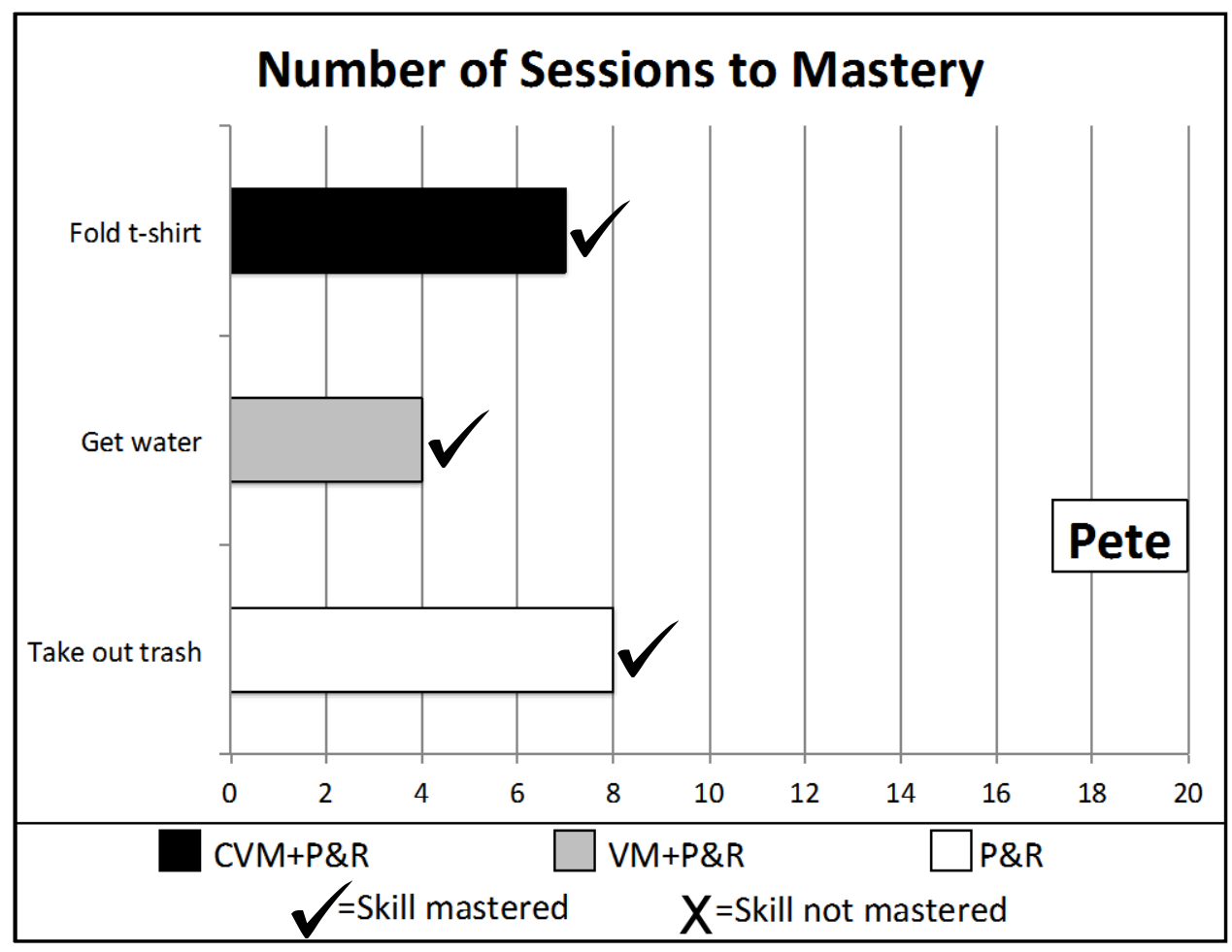

Figure 12. Number of sessions for Pete 


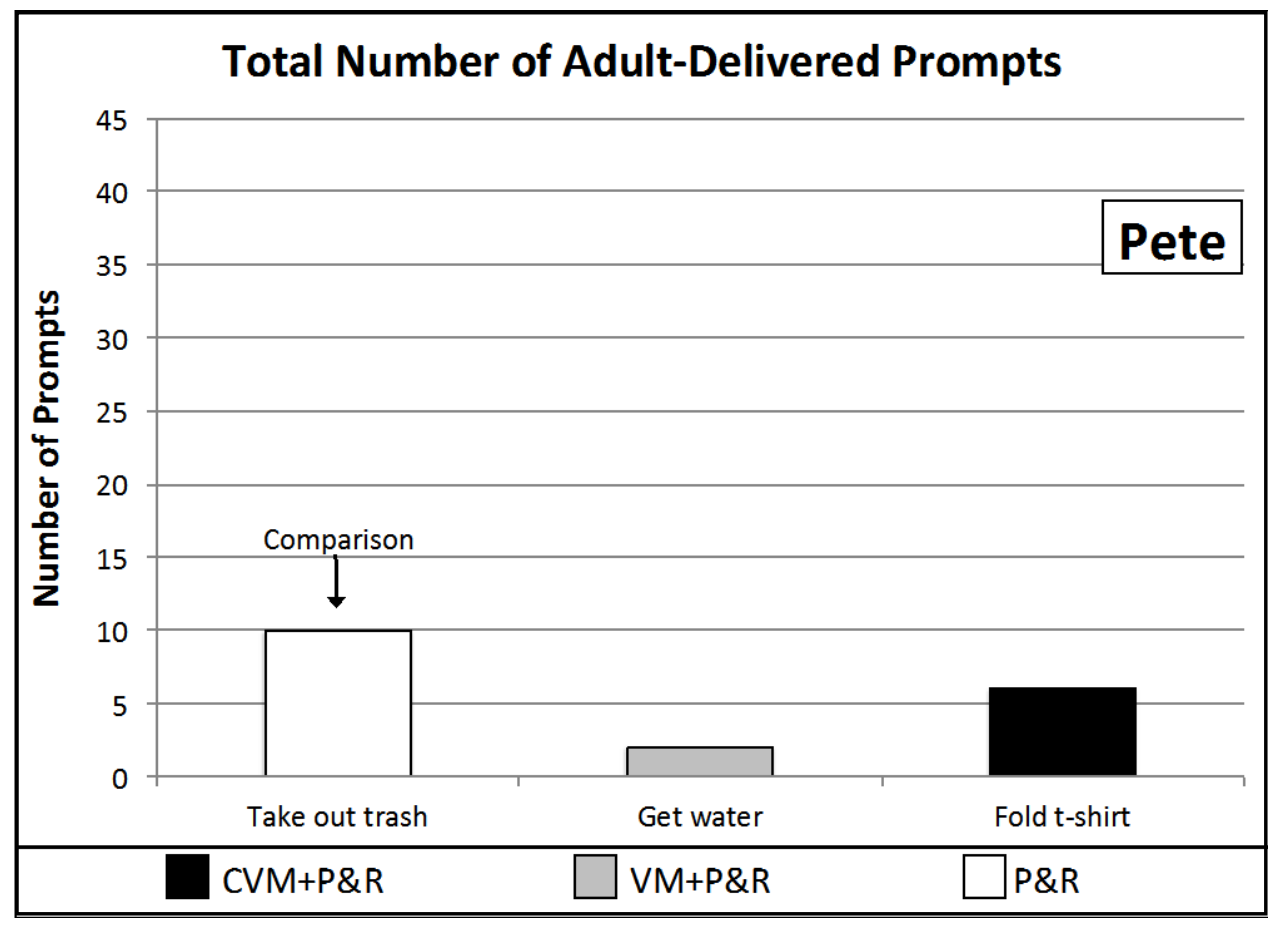

Figure 13. Total number of adult-delivered prompts for Pete

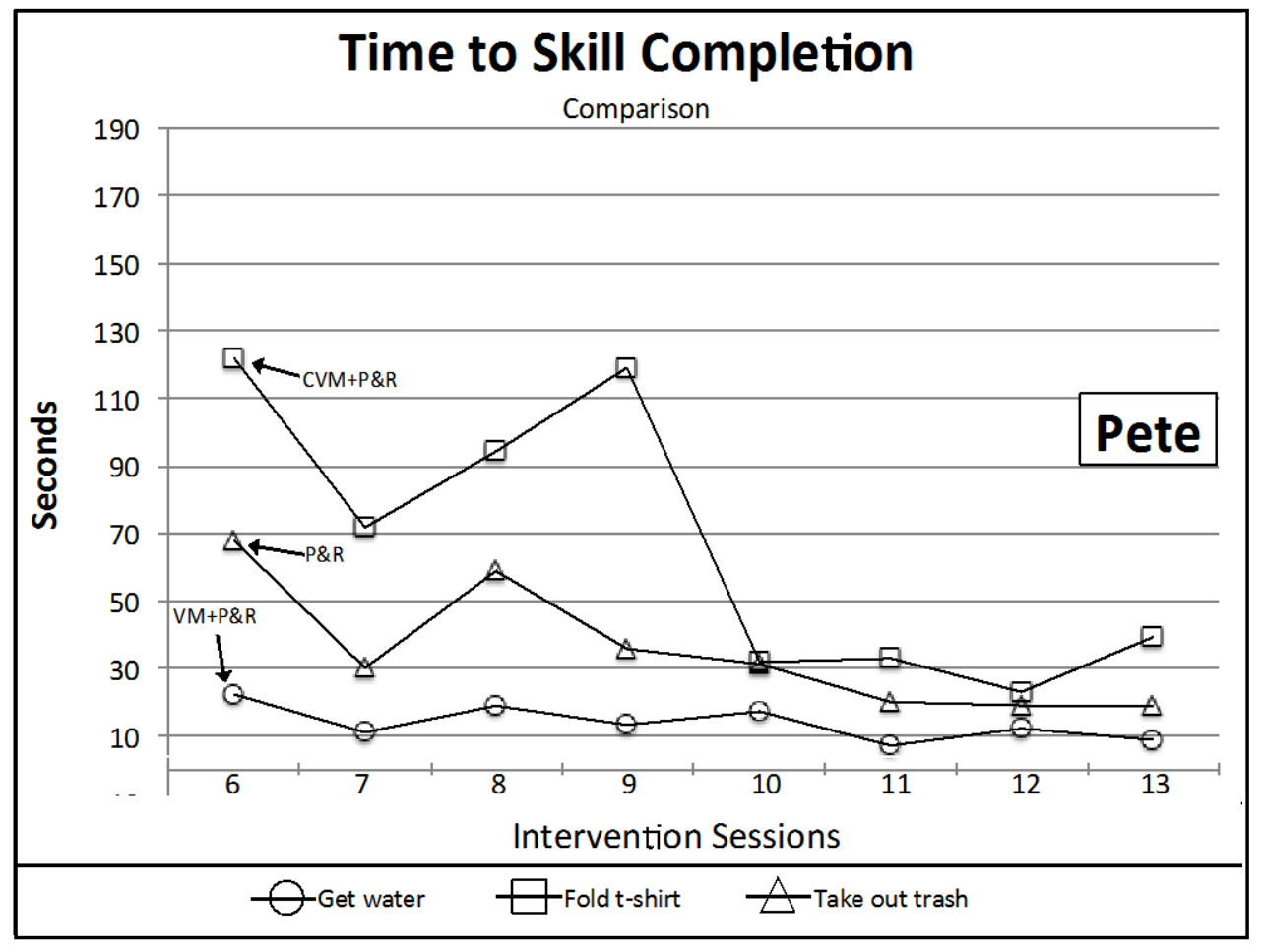

Figure 14. Time to skill completion for Pete 


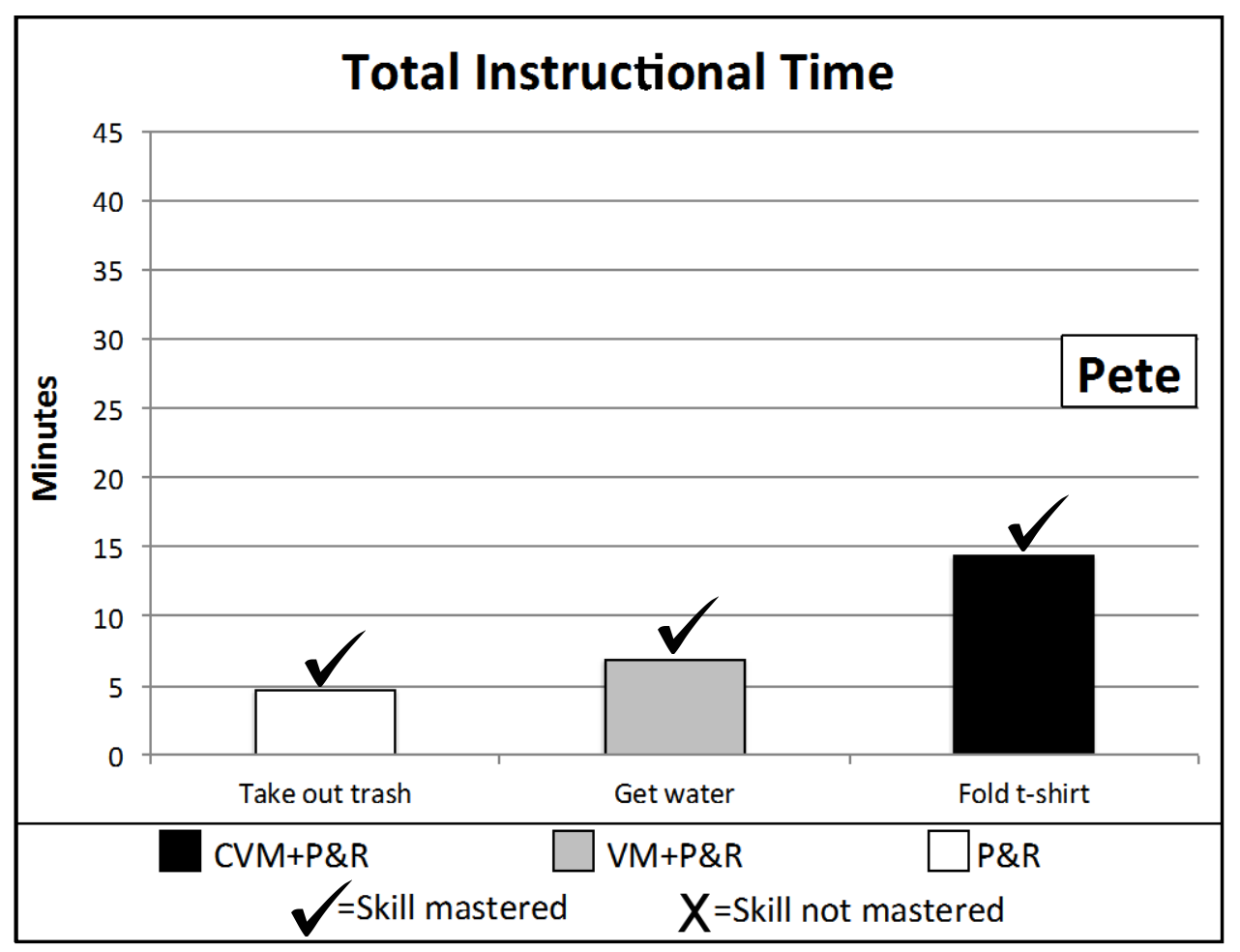

Figure 15. Total instructional time for Pete

\subsection{HOPE}

Figures 16-21 display results for Hope. Figure 16 displays Hope’s percentage of correct steps for each skill during baseline, comparison, and "final best" phases. Figure 17 displays the number of instructional sessions conducted. Figure 18 displays the total number of prompts Hope needed to correctly complete each skill under the assigned intervention condition during the comparison phase (i.e., left bar) and "final best” phase (i.e., right bar). Figure 19 displays additional data on the type of prompting Hope required. Figure 20 displays the amount of time it took Hope to complete each skill. Figure 21 shows the cumulative number of instructional minutes for each skill during the comparison phase (i.e., bottom bar) and “final best” phase (i.e., top bar). 


\subsubsection{Percentage of correct steps and number of sessions to mastery}

During baseline, Hope's performance with taking out the trash was initially at $0 \%$, however her performance increased and stabilized at $40 \%$ of steps correct. When asked to roll silverware, she initially performed $20 \%$ of steps correctly, followed by an increase to $40 \%$ of steps correct. However, Hope’s performance with rolling silverware declined back to $0 \%$ of steps correct. Her performance with wiping the microwave tray remained consistently at $20 \%$ of steps correct across all baseline sessions.

During the intervention comparison phase Hope’s performance was extremely variable. Hope's performance when asked to take out the trash with CVM+P\&R initially fluctuated between $40-60 \%$ percent, followed by an increase to $80-100 \%$ of steps correct. Her performance with taking out the trash dropped back down to $60 \%$ and $80 \%$ during the final comparison sessions. When asked to roll silverware with $\mathrm{P} \& \mathrm{R}$ her performance initially remained similar to her baseline performance, followed by increased performance between $40-60 \%$ and a decrease to $20 \%$ during the final comparison phase session. When asked to wipe the microwave tray with VM+P\&R, Hope demonstrated a steady increasing trend, culminating at $80 \%$ of steps correct followed by a steady decline in performance to between $40-60 \%$ of steps correct. Overall, the range in Hope's performance for each skill was 40-100\% for taking out the trash (CVM+P\&R); 20-60\% for rolling silverware (P\&R); and 40-80\% for wiping the microwave tray (VM+P\&R).

Visual analysis of Hope’s graph indicated that CVM+P\&R was slightly more effective than VM+P\&R followed by P\&R. However, PND analysis does not support this conclusion. From baseline to intervention sessions in the comparison phase, PND for taking out the trash (CVM+P\&R) was 71.4\%, while PND for wiping the microwave (VM+P\&R) was 92.3\%. Which indicates that $\mathrm{VM}+\mathrm{P} \& \mathrm{R}$ may have been the most effective intervention. However, $\mathrm{CVM}+\mathrm{P} \& \mathrm{R}$ 
data demonstrated an increasing trend while $\mathrm{VM}+\mathrm{P} \& \mathrm{R}$ data displayed a decreasing trend. PND for rolling silverware (P\&R) was 29.0\%, indicating P\&R was least effective for Hope. PND between the three interventions during the comparison phase was more consistent with visual analysis results. Her performance was highest with CVM+P\&R during 42.9\% of sessions and was highest with VM+P\&R during $28.6 \%$ of sessions. She performed equally well with $\mathrm{CVM}+\mathrm{P} \& \mathrm{R}$ and $\mathrm{VM}+\mathrm{P} \& \mathrm{R}$ during $28.6 \%$ of sessions. During all sessions of the comparison phase, Hope's performance with one or both of the video-based interventions was always better than or equal to her performance with P\&R.

Based on data from the comparison phase, it was surmised that CVM+P\&R was the “final best” intervention for Hope and CVM+P\&R was applied to rolling silverware instead of P\&R. There was little to no change seen in her performance with rolling silverware when CVM+P\&R was applied. Further, Hope’s performance across all skills stabilized: rolling silverware with $\mathrm{CVM}+\mathrm{P} \& \mathrm{R}$ stabilized at $40 \%$; wiping the microwave tray with $\mathrm{VM}+\mathrm{P} \& \mathrm{R}$ stabilized at 60\%; and taking out the trash with CVM+P\&R stabilized at $80 \%$ of steps correct. See Figure 16.

A total of 19 instructional sessions were conducted with Hope: 14 sessions during the comparison phase and five sessions during the "final best" phase. Hope was unable to meet he mastery criterion for any skill under any condition. See Figure 17.

\subsubsection{Total number of adult-delivered prompts}

During the comparison phase, Hope required slightly less prompting from the researcher when taking out the trash with $C V M+P \& R(N=27)$ than she needed to wipe the microwave tray with $\mathrm{VM}+\mathrm{P} \& \mathrm{R}(N=30)$. She needed the most prompting to roll the silverware with $\mathrm{P} \& \mathrm{R}(N=42)$. 
During the "final best" phase, the average number of prompts Hope needed to take out the trash with CVM+P\&R reduced from an average of 1.93 prompts per session to an average of 1.20 prompts per session. The average number of prompts per session slightly reduced from the comparison phase to the "final best" phase when asked to wipe the microwave tray with $\mathrm{VM}+\mathrm{P} \& \mathrm{R}$ from an average of 2.14 sessions to an average of 2 sessions, respectively. The number of prompts she needed to roll silverware when CVM+P\&R was applied instead of P\&R remained the same. She needed an average of 3 prompts per session to roll the silverware with both P\&R and CVM+P\&R. See Figure 18.

Due to her variable performance during the comparison phase and because no major differences appeared with the number of prompts Hope needed during each intervention, the researcher conducted additional analyses of the type of prompting required by Hope. Figure 19 shows the cumulative number of each type of prompt Hope required (i.e., the verbal + gestural task prompt used in $\mathrm{VM}+\mathrm{P} \& \mathrm{R}$ and $\mathrm{P} \& \mathrm{R}$, the verbal prompt to watch the video used in CVM+P\&R, and the physical prompting used in all interventions, if needed). During the comparison phase, she consistently needed physical prompts from the researcher to take out the trash, whereas she frequently responded to verbal prompts when wiping the microwave tray. She did respond to some verbal prompts when rolling silverware, however, she also required some physical prompting. During the "final best" phase, the average number of physical prompts per session Hope needed to take out the trash with $\mathrm{CVM}+\mathrm{P} \& \mathrm{R}$ reduced slightly from an average of 1.93 prompts during the comparison phase to an average 1.20 prompts per session. The average number of verbal and physical prompts remained relatively similar across comparison and "final best” phases when Hope wiped the microwave tray with VM+P\&R. However, the average number of physical prompts increased when $C V M+P \& R$ was applied to rolling silverware 
instead of P\&R during the "final best" phase. In summary, Hope needed the more intrusive type of prompting most often with $C V M+P \& R$ and the less intrusive type of prompting with VM+P\&R and P\&R. See Figure 19.

\subsubsection{Time to skill completion}

During the comparison phase, Hope typically took the longest to take out the trash with $\mathrm{CVM}+\mathrm{P} \& \mathrm{R}$ ( $M=111.2$ seconds), followed by wiping the microwave tray with $\mathrm{VM}+\mathrm{P} \& \mathrm{R}$ ( $M=67.3$ seconds). Hope usually rolled the silverware with $\mathrm{P} \& \mathrm{R}$ in the shortest amount of time ( $M=55.4$ seconds). During the "final best" phase, when CVM+P\&R was applied to rolling silverware and $\mathrm{P} \& \mathrm{R}$ was removed, the amount of time it took Hope to complete the task greatly increased ( $M=159.4$ seconds). While there was a great deal of overlap in the amount of time it took Hope to take out the trash with $\mathrm{CVM}+\mathrm{P} \& \mathrm{R}$ and wipe the microwave tray with $\mathrm{VM}+\mathrm{P} \& \mathrm{R}$ in the "final best" phase, it typically took her slightly longer to take out the trash with CVM+P\&R ( $M=83$ seconds versus $M=76.4$ seconds, respectively). See Figure 20.

\subsubsection{Total instructional time}

During the comparison phase, Hope spent the most instructional time taking out the trash with $\mathrm{CVM}+\mathrm{P} \& \mathrm{R}$ ( $N=34.1$ minutes), followed by wiping the microwave tray with $\mathrm{VM}+\mathrm{P} \& \mathrm{R}$ ( $N=23.2$ minutes), and rolling the silverware with P\&R ( $N=15.7$ minutes). During the "final best" phase, Hope spent slightly more instructional time taking out the trash with CVM+P\&R $(N=6.9$ minutes) than she did with wiping the microwave tray with $\mathrm{VM}+\mathrm{P} \& \mathrm{R}$ ( $N=6.4$ minutes). She spent the most time rolling silverware with CVM+P\&R ( $N=13.3$ minutes). See Figure 21. 


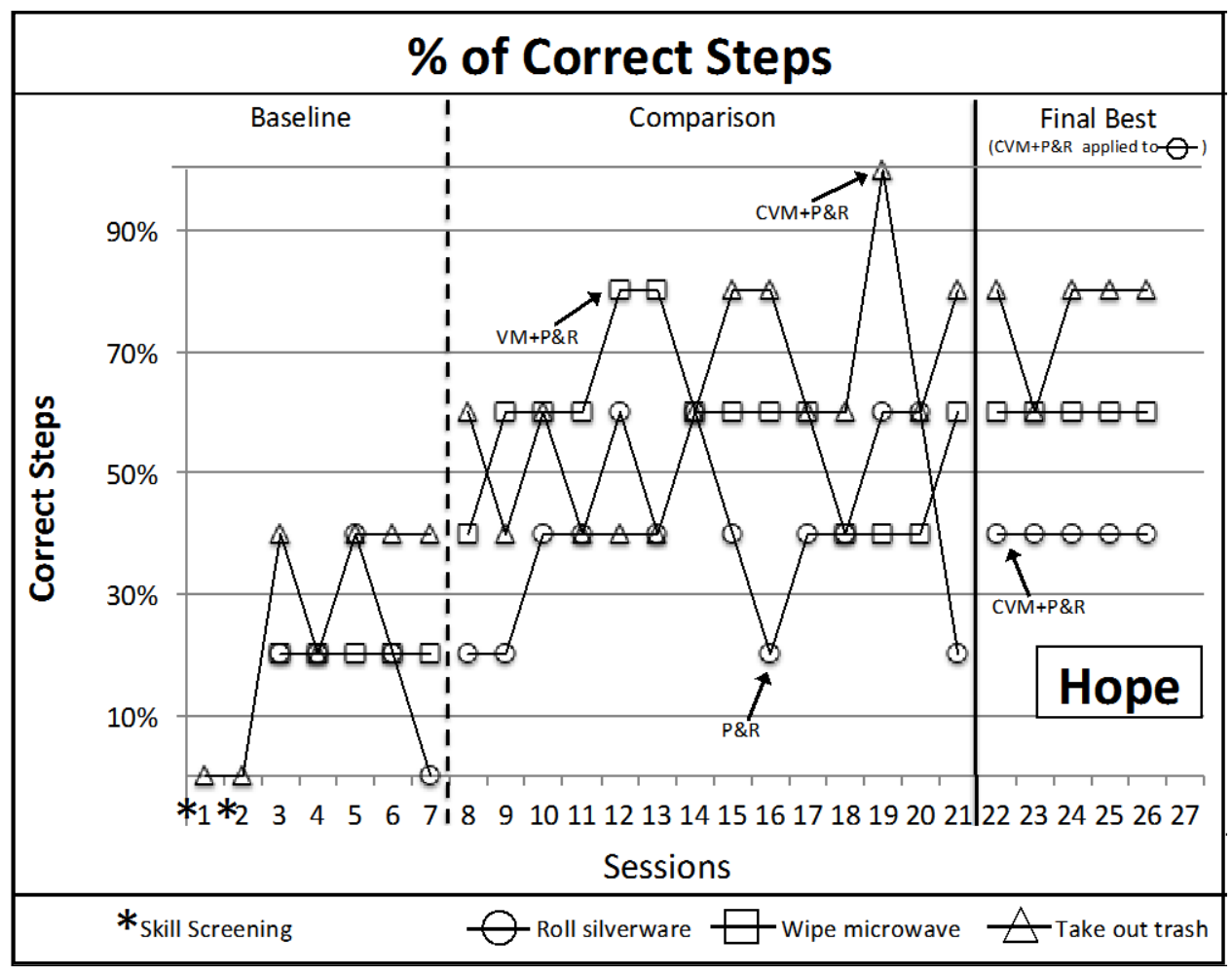

Figure 16. Percentage of correct steps for Hope

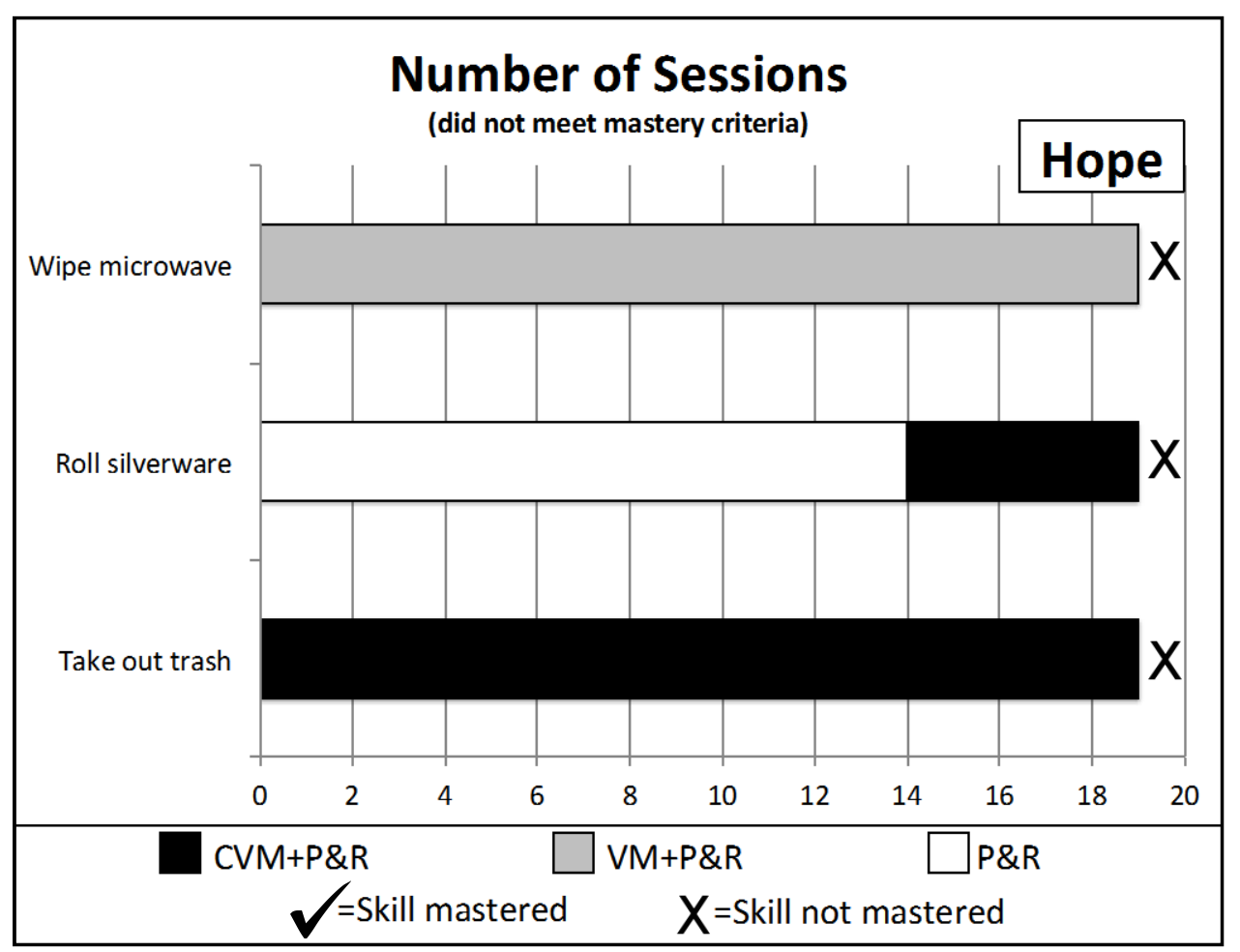

Figure 17. Number of sessions for Hope 


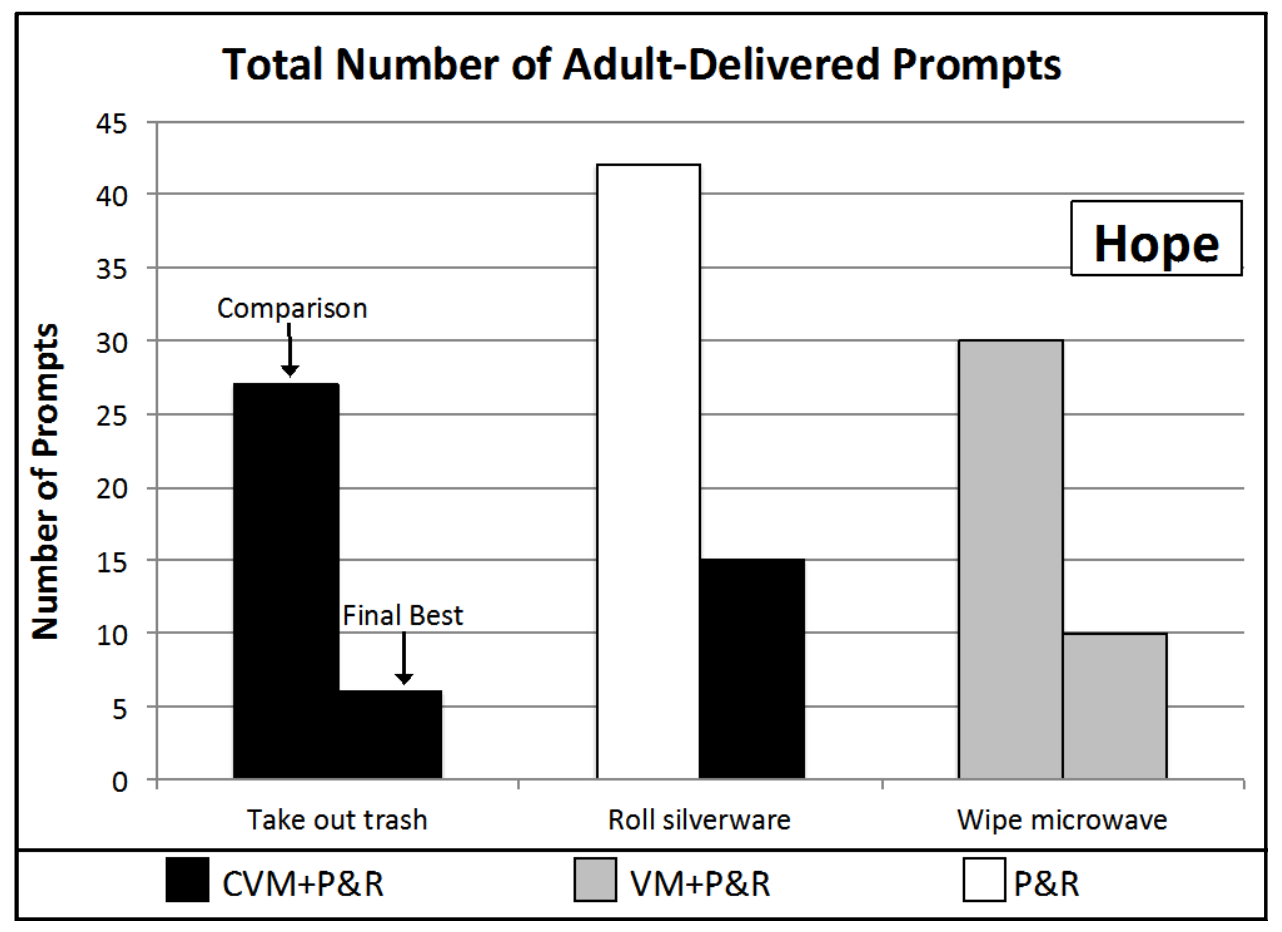

Figure 18. Total number of adult-delivered prompts for Hope

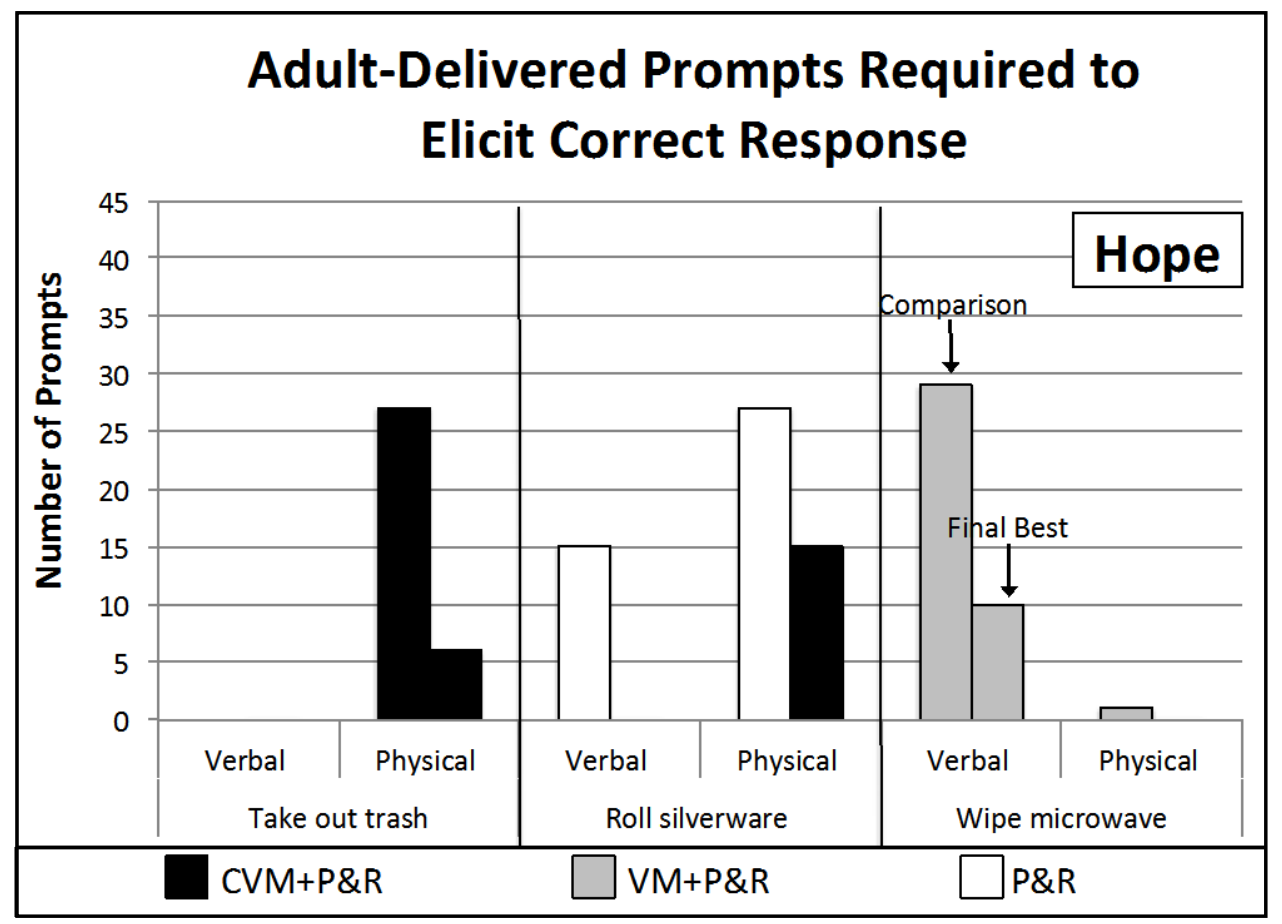

Figure 19. Type of adult-delivered prompt required to elicit a correct response from Hope 


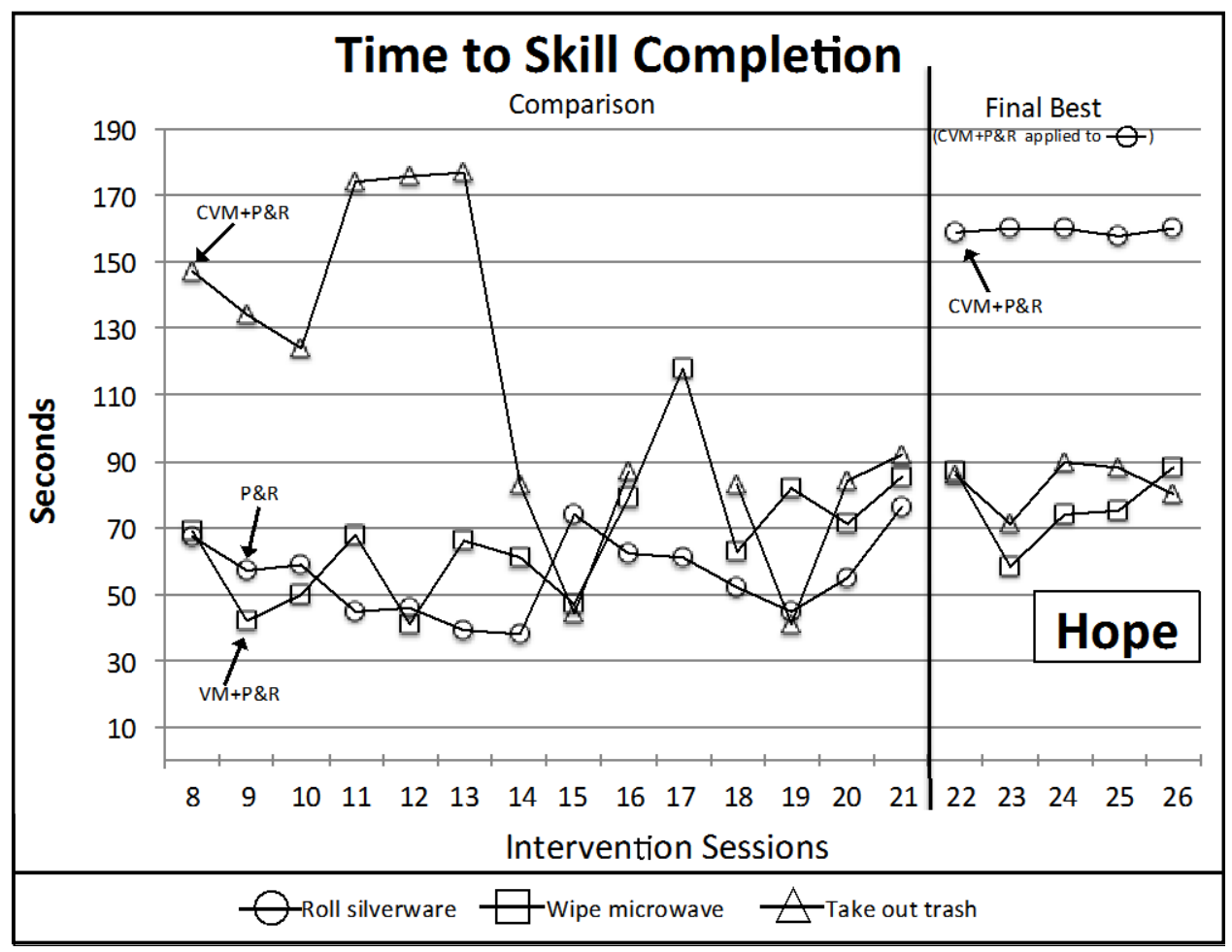

Figure 20. Time to skill completion for Hope

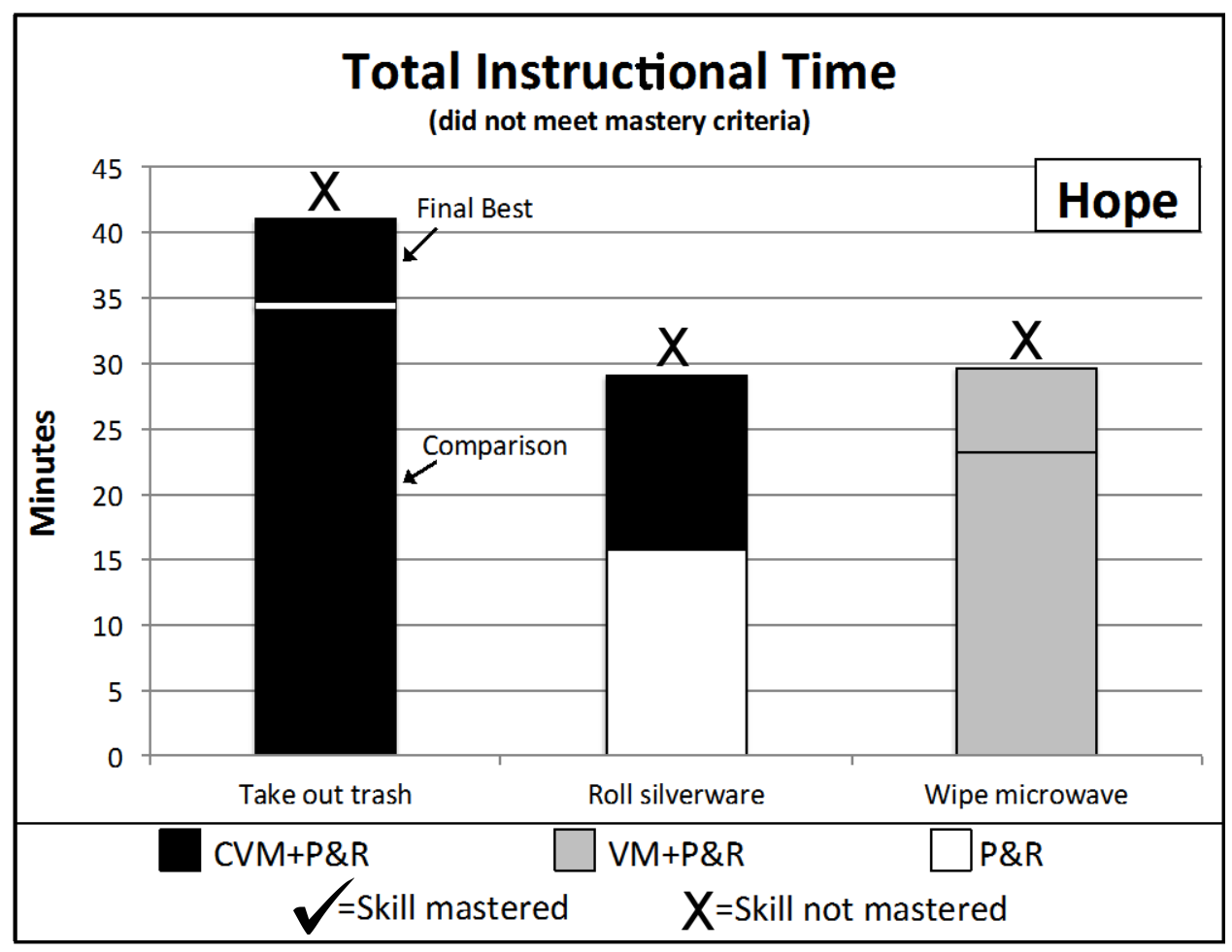

Figure 21. Total instructional time for Hope 


\subsection{GROUP RESULTS: SECONDARY DEPENDENT VARIABLES}

\subsubsection{Average number of adult-delivered prompts per session}

Figure 22 shows the average amount of adult prompting each participant required under each intervention condition per session. The combined average amount of prompting required for each intervention condition is also shown. All students required less adult prompting during one or both of the video-based intervention conditions compared to P\&R. Overall, students needed fewest prompts from the researcher during $C V M+P \& R$ and the most prompting with $P \& R$.

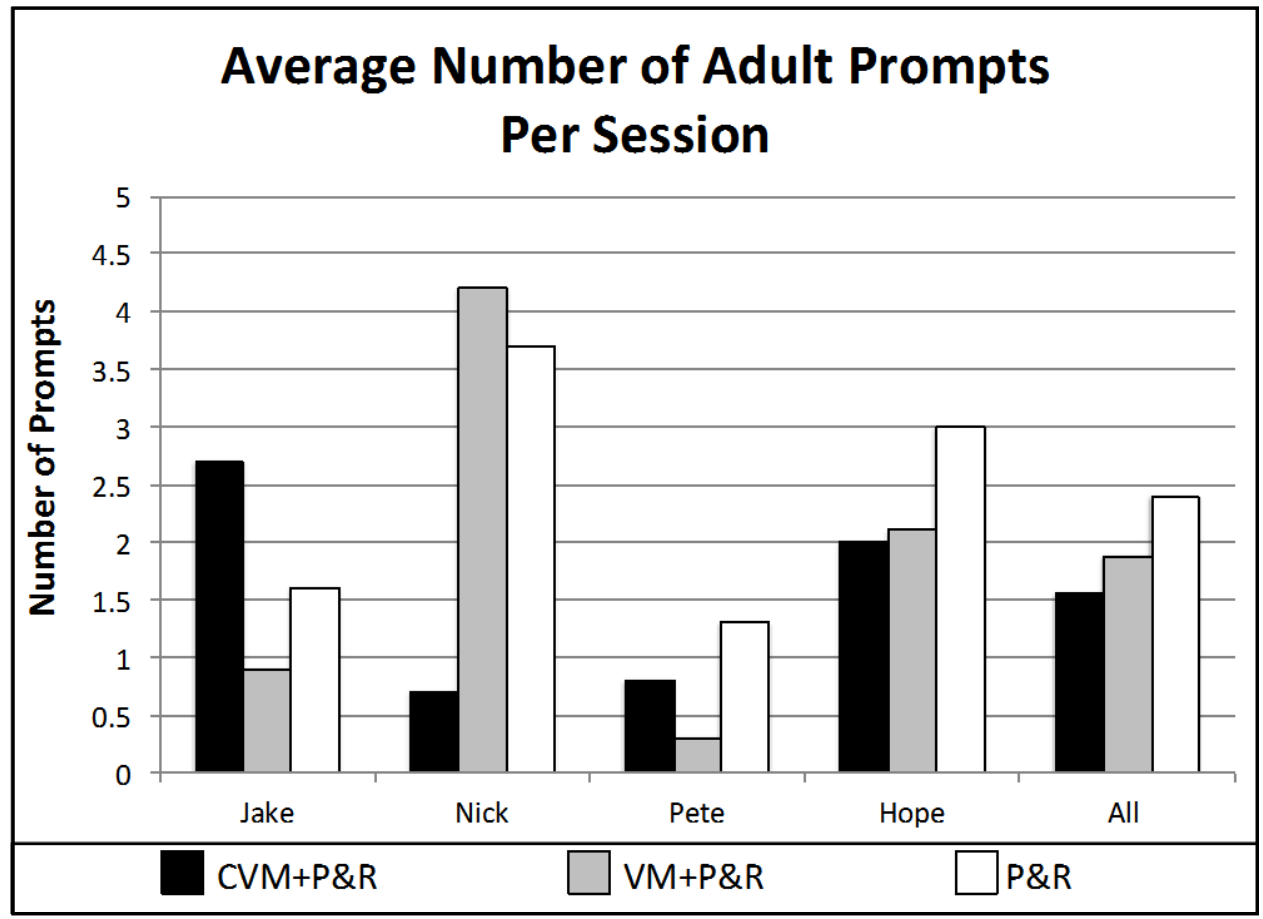

Figure 22. Average number of adult-delivered prompts per session across participants 


\subsubsection{Average time to skill completion per session}

Figure 23 shows the average time to skill completion per session under each intervention condition across participants. The combined average time to skill completion for each intervention condition for all participants is also shown. Overall, CVM+P\&R was associated with the longest time to skill completion for all participants except for Nick.

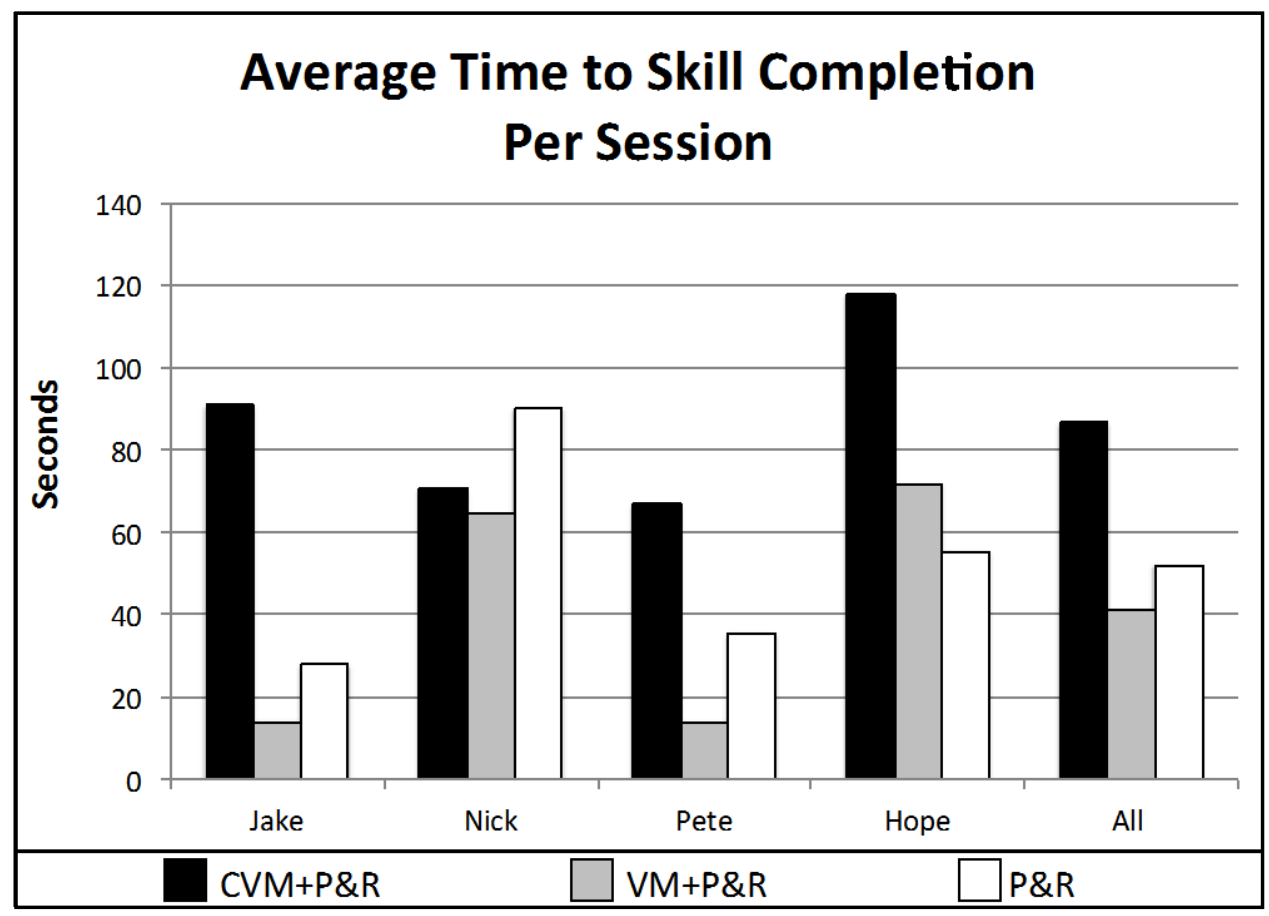

Figure 23. Average time to skill completion per session across participants

\subsubsection{Average amount of instructional time}

Figure 24 shows the average amount of instructional time required to implement each of the intervention conditions per session. Instructional time included the time students spent completing each skill as well as the amount of time spent watching videos in $\mathrm{VM}+\mathrm{P} \& \mathrm{R}$ and CVM+P\&R. Instructional time did not include the time it took the researcher to create video 
models (e.g., 40 minutes per video). The combined average instructional time needed to implement each intervention is also shown. For all students, CVM+P\&R required the most instructional minutes, followed by $\mathrm{VM}+\mathrm{P} \& \mathrm{R}$. P\&R consistently took the least amount of instructional time to implement.

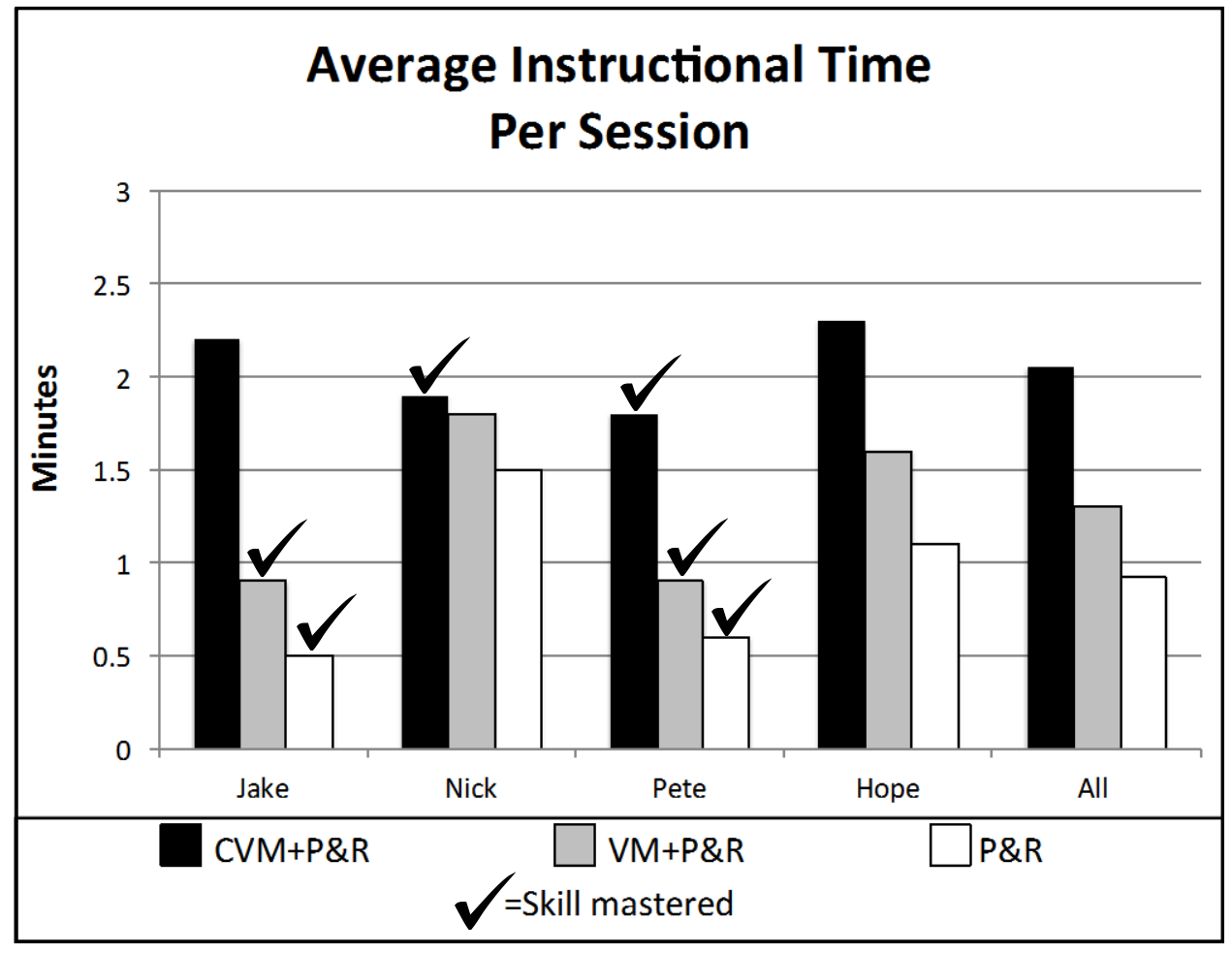

Figure 24. Average instructional time per session across participants

\subsection{SOCIAL VALIDITY}

All students indicated that they liked completing their target skills and that they liked watching the videos. Three out of four students indicated that they preferred to use a video rather than no video while one participant, Pete, said that he would rather work on skills without a video. Jake, 
Nick, and Hope indicated that they preferred having the video play on a loop, rather than just watch the video one time.

Three out of four parents responded to the survey after reviewing their child's results. The researcher did not receive a response from Pete's parent. All parents indicated that videobased interventions such as $\mathrm{VM}+\mathrm{P} \& \mathrm{R}$ and $\mathrm{CVM}+\mathrm{P} \& \mathrm{R}$ are acceptable ways to address independent living skill deficits of students with disabilities. Two of the three parents indicated that the researcher selected appropriate skills for their child, while Nick's parent felt skills were somewhat appropriate. Two of the three parents felt video-based interventions such as VM+P\&R and CVM+P\&R were greatly effective in improving their child's skills, while Hope's parent felt that such interventions minimally improved Hope's skills. Two of the three parents felt that video-based interventions such as $\mathrm{VM}+\mathrm{P} \& \mathrm{R}$ and $\mathrm{CVM}+\mathrm{P} \& \mathrm{R}$ were just as effective as other teaching strategies; however, Hope’s parent indicated that such strategies appeared less effective. Jake's parent felt that VM+P\&R was most effective, Nick's parent felt that both video-based interventions appeared effective, and Hope's parent reported that CVM+P\&R appeared most effective. Finally, Jake's parent reported that she would be most likely to use VM+P\&R and Nick's parent would be most likely to use CVM+P\&R. Hope's parent would be most likely to use CVM+P\&R or other strategies in the home.

Both teachers completed social validity surveys after reviewing results for each of their two students. The teachers indicated that the researcher selected appropriate skills for all of their students and that video-based interventions such as $\mathrm{VM}+\mathrm{P} \& \mathrm{R}$ and $\mathrm{CVM}+\mathrm{P} \& \mathrm{R}$ are acceptable strategies to use to address independent living skill deficits of students with disabilities. Teachers also reported that video-based interventions such as $\mathrm{VM}+\mathrm{P} \& \mathrm{R}$ and $\mathrm{CVM}+\mathrm{P} \& \mathrm{R}$ greatly improved the skills of three of the four participants. Hope's teacher felt that the strategies minimally 
improved Hope's skills. One teacher reported that video-based interventions such as VM+P\&R and CVM+P\&R were more effective than other interventions while the second teacher reported that such interventions are just as effective as other teaching strategies. Their teacher reported that $\mathrm{VM}+\mathrm{P} \& \mathrm{R}$ was most effective for Jake and that $\mathrm{CVM}+\mathrm{P} \& \mathrm{R}$ was most effective for Nick, while the second teacher reported that VM+P\&R seemed to be most effective for Pete and Hope. Finally, both teachers reported that they would be most likely to use both CVM+P\&R and $\mathrm{VM}+\mathrm{P} \& \mathrm{R}$ in their classrooms.

A brief summary of all results, including each participant's preferred intervention, is presented in Table 9. For each participant, the researcher attempted to rank each intervention from most to least effective as measured through each dependent variable. 
Table 9. Summary of results

\begin{tabular}{|c|c|c|c|c|}
\hline $\begin{array}{l}\text { Dependent } \\
\text { Variable }\end{array}$ & Jake & Nick & Pete & Hope \\
\hline $\begin{array}{l}\% \text { of correct } \\
\text { steps }\end{array}$ & $\mathrm{VM}+\mathrm{P} \& \mathrm{R}>\mathrm{P} \& \mathrm{R}>\mathrm{CVM}+\mathrm{P} \& \mathrm{R}$ & $\mathrm{CVM}+\mathrm{P} \& \mathrm{R}>\mathrm{VM}+\mathrm{P} \& \mathrm{R}=\mathrm{P} \& \mathrm{R}$ & $\mathrm{VM}+\mathrm{P} \& \mathrm{R}>\mathrm{CVM}+\mathrm{P} \& \mathrm{R}>\mathrm{P} \& \mathrm{R}$ & $\mathrm{CVM}+\mathrm{P} \& \mathrm{R} \geq \mathrm{VM}+\mathrm{P} \& \mathrm{R} \geq \mathrm{P} \& \mathrm{R}$ \\
\hline $\begin{array}{l}\text { Sessions to } \\
\text { skill mastery }\end{array}$ & $\mathrm{VM}+\mathrm{P} \& \mathrm{R}<\mathrm{P} \& \mathrm{R}<\mathrm{CVM}+\mathrm{P} \& \mathrm{R}$ & CVM+P\&R only & $\mathrm{VM}+\mathrm{P} \& \mathrm{R}<\mathrm{CVM}+\mathrm{P} \& \mathrm{R}<\mathrm{P} \& \mathrm{R}$ & NA \\
\hline $\begin{array}{c}\text { Total \# of } \\
\text { prompts }\end{array}$ & $\mathrm{VM}+\mathrm{P} \& \mathrm{R}<\mathrm{CVM}+\mathrm{P} \& \mathrm{R}=\mathrm{P} \& \mathrm{R}$ & $\mathrm{CVM}+\mathrm{P} \& \mathrm{R}<\mathrm{P} \& \mathrm{R}<\mathrm{VM}+\mathrm{P} \& \mathrm{R}$ & $\mathrm{VM}+\mathrm{P} \& \mathrm{R}<\mathrm{CVM}+\mathrm{P} \& \mathrm{R}<\mathrm{P} \& \mathrm{R}$ & $\mathrm{CVM}+\mathrm{P} \& \mathrm{R}=\mathrm{VM}+\mathrm{P} \& \mathrm{R}>\mathrm{P} \& \mathrm{R}$ \\
\hline $\begin{array}{l}\text { Time to skill } \\
\text { completion }\end{array}$ & $\mathrm{VM}+\mathrm{P} \& \mathrm{R}<\mathrm{P} \& \mathrm{R}<\mathrm{CVM}+\mathrm{P} \& \mathrm{R}$ & $\mathrm{CVM}+\mathrm{P} \& \mathrm{R}<\mathrm{P} \& \mathrm{R}<\mathrm{VM}+\mathrm{P} \& \mathrm{R}$ & $\mathrm{VM}+\mathrm{P} \& \mathrm{R}<\mathrm{P} \& \mathrm{R}<\mathrm{CVM}+\mathrm{P} \& \mathrm{R}$ & $\mathrm{P} \& \mathrm{R}<\mathrm{VM}+\mathrm{P} \& \mathrm{R}<\mathrm{CVM}+\mathrm{P} \& \mathrm{R}$ \\
\hline $\begin{array}{c}\text { Instructional } \\
\text { time to skill } \\
\text { mastery }\end{array}$ & $\mathrm{P} \& \mathrm{R}<\mathrm{VM}+\mathrm{P} \& \mathrm{R}<\mathrm{CVM}+\mathrm{P} \& \mathrm{R}$ & $\mathrm{CVM}+\mathrm{P} \& \mathrm{R}<\mathrm{VM}+\mathrm{P} \& \mathrm{R}=\mathrm{P} \& \mathrm{R}$ & $\mathrm{P} \& \mathrm{R}<\mathrm{VM}+\mathrm{P} \& \mathrm{R}<\mathrm{CVM}+\mathrm{P} \& \mathrm{R}$ & $\mathrm{P} \& \mathrm{R}<\mathrm{VM}+\mathrm{P} \& \mathrm{R}<\mathrm{CVM}+\mathrm{P} \& \mathrm{R}$ \\
\hline $\begin{array}{c}\text { Preferred } \\
\text { intervention }\end{array}$ & $\mathrm{CVM}+\mathrm{P} \& \mathrm{R}$ & $\mathrm{CVM}+\mathrm{P} \& \mathrm{R}$ & P\&R & $\mathrm{CVM}+\mathrm{P} \& \mathrm{R}$ \\
\hline
\end{tabular}




\subsection{DISCUSSION}

This study adds to the large body of literature demonstrating that video-based interventions can be used to improve the independent living skills of most students with disabilities (Bellini \& Akullian, 2007; Mason et al., 2013; Wang \& Koyama, 2014). Three of the four (75\%) participants in the current study, Jake, Nick, and Pete, clearly improved or mastered skills with one or both video-based interventions. Results are consistent with findings of the literature review conducted by the researcher prior to conducting the study, which showed that VM was effective or highly effective for approximately 75\% of participants with ASD or ID.

Additionally, results of social validity surveys indicated that video-based interventions such as $\mathrm{VM}+\mathrm{P} \& \mathrm{R}$ and $\mathrm{CVM}+\mathrm{P} \& \mathrm{R}$ are socially acceptable ways of addressing independent living skill deficits as reported by teachers, parents, and students. Further, this study extends the inaugural investigations of a new form of VM termed CVM by Mechling et al. (2014a) and Mechling et al. (2014b). This study is the first to investigate the effects of CVM paired with prompting and reinforcement and is the first to compare $C V M+P \& R, V M+P \& R$, and $P \& R$. Finally, this is only the second study to compare a VM intervention to a non-video based intervention (see Murzynki \& Bourret, 2007) and the only study to compare two different variations of VM to a non-video based intervention. 


\subsection{RESEARCH QUESTION \#1: COMPARATIVE INTERVENTION EFFECTS}

The primary research question was: what are the comparative effects of two video-based interventions, $\mathrm{VM}+\mathrm{P} \& \mathrm{R}$ and $\mathrm{CVM}+\mathrm{P} \& \mathrm{R}$, and one non-video-based intervention, $\mathrm{P} \& \mathrm{R}$ on the independent living skills of students with ASD and ID? The researcher hypothesized that a single intervention would emerge as the superior treatment across all participants: however, this was not the case. Depending on the data set under examination for a particular participant, different conclusions were drawn and will be discussed. Overall, CVM+P\&R appeared to be most effective for Nick while VM+P\&R appeared to be most effective for Jake and Pete. However, Jake and Pete also responded well to P\&R. The high variability of Hope's data during the comparison phase and the stabilization seen across all skills during the "final best" phase made it difficult to determine which intervention was superior. However, some evidence showed that the video-based interventions lead to greater independence with skill completion over $\mathrm{P} \& \mathrm{R}$ for Hope.

Overall, findings were consistent with some of the previous research investigating the effects of VM interventions compared to a non-VM intervention. The study conducted by Cannella Malone et al. (2011) showed that one intervention (e.g., VP) was superior across all participants, which was not the case in the current study. However, findings of several other comparative studies were more aligned with the results of the current study. For example, authors of two studies showed that participants responded differently to each of the video-based interventions under investigation (e.g., VP, CVM, or VM in Mechling et al., 2014b and VP or VM in Taber-Doughty et al., 2011) while authors of a third study found that participants responded to a VM intervention (e.g., VM plus prompting) in fewer sessions than a non-video 
based intervention (e.g., prompting alone; Murzynki \& Bourret, 2007). Findings of the latter three studies are fairly consistent with results of the current study.

Considering results of a second set of comparative studies that investigated the effects of two or more versions of VM (i.e., Cihak \& Schrader, 2008; Mechling \& Ayres, 2012; Mechling \& Collins, 2012; Smith, M. et al., 2013; Taber-Doughty et al., 2008; Van Laarhoven et al., 2009), findings were somewhat consistent with results of the current study in several respects. First, for $100 \%$ of participants in all of the previous studies comparing different versions of VM, both versions of VM were effective or highly effective according to results of PND analysis across baseline and intervention phases. In the current study, results of PND analysis across baseline and intervention phases for Jake and Pete are consistent with findings of previous studies in that both versions of VM were effective or highly effective in improving independent living skills. However, P\&R was also highly effective for Jake and Pete.

Next, for Hope, PND analysis also showed that both VM+P\&R and CVM+P\&R lead to at least some improved skill performance from baseline to intervention, but P\&R did not. It is important to remember that no intervention lead to skill mastery for Hope. However, also considering results of previous studies, some participants in past studies were also unable to master skills according to the mastery criteria set by the authors of the study nor did the participants meet the mastery criteria used in the current study: all steps of a skill completed correctly across three consecutive sessions (see Canella-Malone et al., 2011; Mechling et al., 2014b; Mechling \& Collins, 2012; Taber-Doughty et al., 2011). Although visual analysis of Hope's graph did not allow the researcher to identify which, if any, of the treatments were superior, results of PND analysis from baseline to intervention for Hope were similar to results of PND analysis for several other participants' graphs see in previous studies noted above. 
Overall, results of PND analysis for the Jake, Pete, and Hope were consistent with PND analysis results of participants in many previous studies comparing different versions of VM included in the literature review. However, PND analysis for Nick showed that only CVM+P\&R, and not $\mathrm{VM}+\mathrm{P} \& \mathrm{R}$, was effective in improving his independent living skills, indicating that both VM interventions did not lead to at least some skill improvement.

\subsection{RESEARCH QUESTION \#2: STUDENT CHARACTERISTICS AND RESPONSE TO INTERVENTIONS}

Secondary research questions were related to whether connections could be drawn between student characteristics and how participants responded to the different interventions under investigation. Overall, students appeared to respond in different ways to each of the interventions.

\subsubsection{VM+P\&R responders}

Overall, considering the primary dependent variable, percentage of correct steps over time, Pete and Jake seemed to respond best to VM+P\&R. In this intervention, students were asked to watch a video one time, then received least-to-most prompting when an error or no response occurred. For Jake, performance with taking out the trash using $\mathrm{VM}+\mathrm{P} \& \mathrm{R}$ not only resulted in the fewest number of sessions to skill acquisition, but his overall time to completion was faster with $\mathrm{VM}+\mathrm{P} \& \mathrm{R}$ compared to $\mathrm{P} \& \mathrm{R}$ and $\mathrm{CVM}+\mathrm{P} \& \mathrm{R}$. Jake also required the fewest number of prompts from the researcher with $\mathrm{VM}+\mathrm{P} \& \mathrm{R}$ during the comparison phase and the number of prompts 
required decreased when $\mathrm{VM}+\mathrm{P} \& \mathrm{R}$ was applied to rolling silverware instead of $\mathrm{CVM}+\mathrm{P} \& \mathrm{R}$ during the "final best" phase. P\&R was employed with folding socks across comparison and "final best" phases in an attempt to demonstrate experimental control. Because Jake's performance with folding socks appeared to stabilize, the researcher predicted that it would remain stable, but this was not the case. Outcomes raise questions regarding whether VM+P\&R truly was the superior intervention for Jake, which will be discussed.

Pete was able to meet the mastery criterion for all skills under all intervention conditions. It took him the fewest sessions to master getting a glass of water with $\mathrm{VM}+\mathrm{P} \& \mathrm{R}$, followed by folding a t-shirt with CVM+P\&R, and finally, taking out the trash with P\&R. Similarly, Pete required the least amount of adult prompting with $\mathrm{VM}+\mathrm{P} \& \mathrm{R}$, followed by $\mathrm{CVM}+\mathrm{P} \& \mathrm{R}$, and then P\&R. His average time to skill completion demonstrates further support for the superiority of $\mathrm{VM}+\mathrm{P} \& \mathrm{R}$ for Pete. Pete was able to get a glass of water with VM+P\&R much faster than he was able to take out the trash with P\&R or fold the t-shirt with CVM+P\&R.

While much of the evidence points to the effectiveness of VM+P\&R over the other two interventions, it is important to consider the total amount of instructional time required by each intervention, not just the percentage of correct steps completed and number of sessions to skill mastery. Although the time to skill completion was fastest with VM+P\&R for Jake and Pete, both students required fewer minutes of instructional time with P\&R than either of the videobased interventions. This is due in large part to the amount of time required to sit and view the video, but is an important consideration given that teachers are constantly struggling to find sufficient time to plan and deliver instruction (Johnson \& Semmelroth, 2014). Compounding this argument is the fact that it took 40 minutes to create one video while no prep time was needed to implement P\&R. 
One of the aims of this study was to compare participant characteristics and intervention effects to attempt to identify which students may be more responsive to video-based interventions such as $\mathrm{VM}+\mathrm{P} \& \mathrm{R}$ or $\mathrm{CVM}+\mathrm{P} \& \mathrm{R}$. Jake and Pete had few common characteristics, yet both responded best to $\mathrm{VM}+\mathrm{P} \& \mathrm{R}$. Jake was diagnosed with ASD and Pete had a diagnosis of Down syndrome. Unfortunately, an IQ score was not available for Jake so IQ could not be compared to Pete's IQ score. However, according to VABS-II scores, Pete had the highest scores and Jake had the lowest scores of all participants. Jake was nonverbal and Pete communicated verbally. Jake was a non-reader and Pete read at the pre-primer level. Jake demonstrated challenging behavior while Pete did not.

One potentially important similarity was identified. Jake and Pete were the only participants who clearly responded to both $\mathrm{VM}+\mathrm{P} \& \mathrm{R}$ and $\mathrm{P} \& \mathrm{R}$, but both met mastery criteria in fewer sessions with the video-based intervention. However, given the findings related to the total amount of instructional minutes required by both students, P\&R may have actually been the more efficient intervention. Further, having the video play on a loop appeared to interfere with skill completion of both students. "Doing while viewing” did not seem to benefit Jake or Pete. For Pete, having the video play on a loop seemed to slow him down while the video seemed to distract or frustrate Jake.

\subsection{2 $\quad C V M+P \& R$ responder}

Nick clearly responded best with CVM+P\&R. He greatly benefited from "doing while viewing.” The researcher observed him watching the video as it played and copying the model's behavior in the video. During VM+P\&R and P\&R, Nick would simply wait for the verbal or physical 
prompt from the researcher. In some instances, he would even look at or reach out to the researcher for help. He did not do this during CVM+P\&R; he used the video instead.

Although Nick did not meet the mastery criterion for rolling silverware with CVM+P\&R, his performance clearly improved compared to his performance with $\mathrm{VM}+\mathrm{P} \& \mathrm{R}$ for the same skill. His performance stabilized because Nick appeared to have difficulty understanding the concept of "the corner of the napkin" (see Step 3 of the task analysis). Except for the first session in the "final best" phase, he consistently needed a prompt to place the silverware in the corner of the napkin. It is possible that due to spatial or conceptual deficits, Nick had difficulty performing this step without a prompt.

Nick appeared to be a prime candidate for CVM+P\&R. The independence with which he completed skills with this intervention greatly exceeded his level of independence for skills using $\mathrm{VM}+\mathrm{P} \& \mathrm{R}$ and $\mathrm{P} \& \mathrm{R}$ as seen in the dramatically reduced number of adult-delivered prompts he required. Nick was also the only participant for whom $C V M+P \& R$ did not result in the slowest time to skill completion. For Nick, CVM+P\&R did not appear to slow his skill completion time compared to his other skills/interventions as well as compared to the other participants. Like all other participants, $\mathrm{CVM}+\mathrm{P} \& \mathrm{R}$ took the greatest amount of instructional time for Nick. However, CVM+P\&R appeared to be the only effective intervention for Nick.

When comparing participant characteristics, Nick was the oldest and had the lowest reported IQ score. No other characteristics appeared to be significant factors with regard to why Nick responded best to CVM+P\&R. However, based on observations by the researcher and the research assistant, Nick seemed to pay closest attention to the videos during both the initial viewing and while it played on a loop compared to other participants. 


\subsubsection{Non-responder and mixed findings}

Of all participants, Hope had the highest, yet most variable baseline data. Further, Hope was the participant who showed the highest level of performance during skill screening sessions. During screening, Hope demonstrated elevated ability compared to other participants when getting a glass of water, folding and storing socks, folding a t-shirt, starting a load of laundry, and removing laundry from the dryer. She completed the skills with relatively high levels of accuracy (i.e., over $40 \%$ of steps completed correctly). In addition to demonstrating the highest ability level initially, Hope's mother reported that she was able to perform many independent living tasks at home, especially skills related to doing laundry. It is possible that Hope simply responds better (and has been responding) to other teaching strategies as evidenced by her larger repertoire of skills and her minimal response to the interventions in the study.

In addition to ID, Hope also had a diagnosis of ADHD. Despite evidence in the literature suggesting the VM may be especially effective for students easily distracted by environmental factors (McCoy \& Hermansen, 2007), this was not the case with Hope. She was highly distractible during each session. While every attempt was made to limit distractions for all participants, classrooms are naturally busy places. Students, teachers, and support staff often moved in, out, and around the classroom; side conversations between students and adults frequently occurred; announcements were made over the school's PA system; bells rang; and noise from the hallways was common. While the other participants did not seem to be affected by the outside factors, Hope was. Anytime one of the aforementioned distractions occurred, Hope's attention was taken away from the video or the task at hand and she needed frequent redirection from the researcher. This could have played a major role in Hope’s minimal response to the interventions. 
Hope was not the only participant unable to demonstrate skill mastery. Jake and Nick were unable to master one skill under a seemingly effective intervention condition. VM+P\&R for Jake and CVM+P\&R for Nick lead to improved performance, but not skill mastery. Jake made consistent errors on either Step 1 or Step 2 of rolling silverware (see below for an explanation), while Nick made a consistent error on Step 3 of rolling silverware as explained above. However, Hope never demonstrated consistency with her errors for any skill. Over the course of the study, Hope demonstrated the ability to perform all steps of all skills correctly, but only performed all steps of a skill correctly in the same session once (e.g., she took out the trash correctly and independently during session 19). Hope never displayed a recognizable error pattern. It is possible that Hope requires more intensive interventions such as step-by-step video prompting (VP). Due to time constraints, this intervention was not implemented with Hope. Further, the scope of this study did not include the investigation of VP interventions.

Another important contradiction was Jake’s performance in the “final best” phase. Data showed that Jake improved with rolling silverware when VM+P\&R was applied but that he was unable to meet criterion. Further, because he eventually met criterion with $P \& R$, one may question whether $\mathrm{VM}+\mathrm{P} \& \mathrm{R}$ was truly the superior intervention for Jake. Similar to Nick’s performance with rolling silverware, Jake was unable to reach the mastery criterion with his presumed superior intervention (VM+P\&R) because of a consistent error. The first two steps of the skill required students to pick up the fork (Step 1) and the spoon (Step 2). Jake never picked up both utensils. While he always picked up either the fork or the spoon, he always needed a prompt to pick up the other. He did not seem to understand that he needed to roll both utensils in the napkin. It is also possible that repeated exposure to $C V M+P \& R$, an apparently ineffective 
intervention for Jake, could have impacted his performance with rolling silverware under VM+P\&R (i.e., sequence effects; Kazdin \& Hartman, 1978).

\subsection{OVERALL FINDINGS: SECONDARY DEPENDENT VARIABLES}

\subsubsection{Time to skill completion and instructional time}

Overall, the use of CVM+P\&R was associated with longer time to skill completion for all students with the exception of Nick. Several dramatic examples of the slowing impact of $\mathrm{CVM}+\mathrm{P} \& \mathrm{R}$ on skill completion time were seen across the data. First, the average time to completion greatly decreased when $\mathrm{VM}+\mathrm{P} \& \mathrm{R}$ was introduced and $\mathrm{CVM}+\mathrm{P} \& \mathrm{R}$ was removed from rolling silverware for Jake. Second, when Hope used CVM+P\&R to roll silverware and P\&R was removed, her time to skill completion drastically increased and remained at the increased level. Anecdotally, Pete was observed on multiple occasions to wait for the video to catch up to where he was with his own folding of the t-shirt. Interestingly, Nick was the only student who did not have large and lasting discrepancies between the lengths of time it took him to complete skills under the different interventions and Nick was the only student to clearly respond to $\mathrm{CVM}+\mathrm{P} \& \mathrm{R}$.

One of the most interesting, and often overlooked variables with regard to the implementation of teaching strategies is the amount of instructional time required by a student to engage in the intervention activities to achieve successful outcome. In terms of total instructional minutes required for each intervention, Nick appears to be the only student for whom a videobased intervention was both effective and efficient. For all students, video-based interventions, 
specifically $\mathrm{CVM}+\mathrm{P} \& \mathrm{R}$, required more instructional time. However, Nick was the only participant who responded only to $C V M+P \& R$. For Jake and Pete, while VM+P\&R lead to greater independence with skill completion in fewer sessions, P\&R may have ultimately been the more efficient intervention for them as it required the fewest instructional minutes. For Hope, it is likely that an intervention other than one of the three investigated in this study would have been more efficient.

\subsubsection{Instructional time versus independence}

Overall, the purpose of the study was to add to the VM literature and begin to tease out the comparative effects of $\mathrm{VM}+\mathrm{P} \& \mathrm{R}, \mathrm{CVM}+\mathrm{P} \& \mathrm{R}$, and $\mathrm{P} \& \mathrm{R}$ on the independent living skills of students with ASD and ID. Further, the researcher was primarily interested in measuring the amount of independence with which students completed target skills. This was measured through the primary dependent variable: percentage of steps completed correctly and independently. While more instructional time was needed for students to engage in the video-based interventions, all students were able to complete skills with the least amount of researcherdelivered prompts (i.e., verbal + gestural skill prompts, verbal prompts to watch the video, or physical prompts) with one or both of the video-based interventions.

While students did require more instructional time to complete the video-based interventions, it is important to consider results as a whole. Jake and Pete needed the least amount of adult prompting with $\mathrm{VM}+\mathrm{P} \& \mathrm{R}$ while Nick and Hope needed the least amount of adult prompting with CVM+P\&R. Combined, the most adult prompting was required under the P\&R condition while the least amount of adult prompting was needed with CVM+P\&R. Ultimately, the intervention selected to deliver independent living skill instruction for a 
particular student may greatly depend on the purpose of instruction. Is the purpose to reduce instructional time for teaching a particular skill or is the purpose to increase the independence with which the student completes a skill?

\subsection{IMPLICATIONS FOR PRACTICE}

Results of this study are relatively consistent with the larger VM literature base in that one or both VM interventions improved the independent living skills for most participants (Bellini \& Akullian, 2007; Mason et al., 2013; Wang \& Koyama, 2014). A second purpose of this study was to add new data to the broad VM literature base to help understand who is mostly likely to benefit from VM interventions, which may be of particular interest to practitioners.

A great deal of research exists specifically on the effects of VM to address skill deficits of students with ASD and much of the research suggests that students with ASD respond well to VM. However, the researcher's review of the literature focused on the use of VM interventions to address independent living skill deficits in students with ASD and/or ID showed that participants without ASD (ID only) were just as likely, if not more likely, to respond well to VM. Results of the current single-subject study are consistent with the literature in that students with ID, with or without ASD, can respond to video-based interventions. Two students with ASD and one student with Down syndrome improved skills with a video-based intervention. Interestingly, the student with Down syndrome improved skills with $\mathrm{VM}+\mathrm{P} \& \mathrm{R}$ and $\mathrm{CVM}+\mathrm{P} \& \mathrm{R}$ as well as P\&R. However, each of the two students with ASD responded to different video-based

interventions. Jake seemed to respond better to $\mathrm{VM}+\mathrm{P} \& \mathrm{R}$ over $\mathrm{CVM}+\mathrm{P} \& \mathrm{R}$ while Nick responded only to CVM+P\&R. 
Hope, the only participant who did not clearly respond to any of the interventions, was also the only student with a diagnosis of ADHD and was the student most easily distracted during sessions. With that said, the most important proposed implication is not surprising, especially in the field of special education where individualized instruction is the gold standard: students are likely to respond differently to each intervention.

Second, it is important for practitioners to set an intention for instruction when addressing independent living skill deficits. Consider the findings related to the amount of preparation time and instructional time required for the video-based interventions. If the purpose is to decrease the amount of time required to prepare for and deliver instruction, it may not be in the best interest of the teacher or the student to implement a video-based intervention. The more traditional method of P\&R may be more efficient in terms of reduced minutes of instructional time and preparation time. If a teacher has little to no planning time and limited resources, and P\&R may be the best option.

However, if the teacher hopes to increase the level of independence with which a student completes a skill, then a video-based intervention may be the more effective method of instruction. If aiming to increase independence, it is recommended that teachers carefully consider the student's particular strengths and past learning tendencies. It may be helpful to test both $\mathrm{VM}+\mathrm{P} \& \mathrm{R}$ and $\mathrm{CVM}+\mathrm{P} \& \mathrm{R}$, collect preliminary data, and see which intervention leads to greater independence. For example, Nick clearly showed signs that he was responding to $\mathrm{CVM}+\mathrm{P} \& \mathrm{R}$ compared to the other participants (i.e., his eyes were consistently on the video while it played on a loop, his own movements and behaviors were often in sync with the video). Teachers should consider looking for behavioral signs, such as the ones Nick displayed, when trying to determine the intervention most likely to be effective for a student. It is also important 
to keep in mind that some students may need interventions above and beyond the interventions under investigation in this study, as was the case with Hope.

\section{$5.5 \quad$ LIMITATIONS}

Several limitations are important to consider when interpreting results of the study. First, while every attempt was made to ensure that all skills targeted were of equal difficulty, it proved to be nearly impossible to predict the skill equivalence for individual students, despite having conducted skill analyses, skill screenings and baseline sessions. It is possible that some skills were easier for some students due to reasons unbeknownst to the researcher, teachers, and parents. The issue of task equivalency (or lack thereof) for a student is one that significantly limits conclusions drawn from the study. Any question as to whether the tasks truly were equivalent disproves any apparent superiority of one intervention over another. While some evidence suggests that participants either responded, or did not respond, to a particular intervention, findings and conclusions regarding a "final best" intervention for any participant other than Nick should be interpreted with caution.

A second important limitation also relates to the target skills selected. One of the benefits of an adapted alternating treatments design is that different skills may be targeted, as opposed to a traditional alternating treatments design in which the same target skill is measured under different intervention conditions. However, due to unforeseen issues with students having increased ability levels with certain target skills, all students did not complete all of the same skills, which is typically (but not always) the case with adapted alternating treatment designs (Miltenberger \& Charlop, 2015; Taber-Doughty et al., 2011). Ideally, all participants should 
have completed all of the same skills allowing for the equal distribution of $V M+P \& R$, $\mathrm{CVM}+\mathrm{P} \& \mathrm{R}$, and $\mathrm{P} \& \mathrm{R}$ across the target skills. Because students did not complete all of the same skills and because of the unequal number of interventions (i.e., three), participants (i.e., four), and potential target skills (i.e., six), it was not possible to truly counter-balance all interventions and skills across participants. As such, conclusions drawn based on study results are limited and should be interpreted with caution.

Third, while the researcher made every attempt to create video models of equal quality and containing the same components and points-of-view, some slight differences existed among the video models depending on how the researcher most clearly and easily captured steps of a particular skill. Potentially, participants may have interpreted or followed one video model more easily than another, which then impacted his or her performance on that particular skill.

Finally, while every attempt was made to create a quiet, distraction free setting conducive to the true investigation of the independent variables, during many of the sessions, other students, teachers, and staff often moved in, out, and around the classroom. Further, students, teachers, and staff often conversed during sessions, which may have impacted the participants’ performance, especially for Hope. While the third and fourth limitations are important to note, it was also the intent of the researcher to replicate the conditions under which a practicing teacher may prepare and implement the interventions. Classrooms are not sterile laboratories and this study was not conducted in a laboratory-like setting. 


\subsection{CONCLUSIONS AND DIRECTIONS FOR FUTURE RESEARCH}

For three of the four participants, a video-based intervention was effective in improving independent living skills. VM+P\&R was more effective for two students and CVM+P\&R was most effective for one student. However, considering the time commitment that comes with implementing video-based interventions and the ultimate goal of the intervention, $\mathrm{P} \& \mathrm{R}$ may be the more efficient intervention for some students. It is important to clarify the intention of the intervention prior to implementing a teaching strategy to address independent living skills. If the goal is to decrease preparation and instructional time, P\&R may be the better option. However, if the goal is to increase student independence with skill completion, one of the video-based interventions may be more effective.

Because of the rather large discrepancy in the amount of preparation time required for video-based interventions compared to $\mathrm{P} \& \mathrm{R}$, one area that may be particularly interesting to investigate is the use of existing video models to teach new students the target skills demonstrated in the already-created video models. Videos for this study were created in the participants' classroom, using the same materials participants used during study sessions. Perhaps the same videos used in this study could improve performance of the same target skills for other students completing the skills in different settings and with different materials. Given this scenario, little to no preparation time would be required since the videos have already been created. For teachers or supervisors who work with large numbers of students with similar independent living skills deficits, this may be a cost and time efficient way of improving skills with reduced preparation time and decreased adult prompting. Some research shows that commercially made video models are less effective than custom-made video models (Mechling, Ayres, Foster, \& Bryant, 2013; Rosenberg, et al. 2010) but there are no known studies 
investigating the effects of previously created customized videos used to implement VM or CVM interventions on the independent living skills of new participants.

Another area worthy of continued investigation relates to the fact that the researcher set out and put away materials for the students in all conditions and started the video for students in $\mathrm{VM}+\mathrm{P} \& \mathrm{R}$ and $\mathrm{CVM}+\mathrm{P} \& \mathrm{R}$ conditions. Future research should focus on VM interventions aimed at building student independence as well as teaching students to self-manage materials and use the technology to access video models independently. 
APPENDIX A

STUDY APPROVAL/SUPPORT DOCUMENTS 


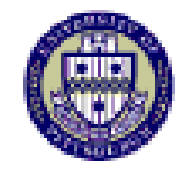

\section{University of Pittsburgh Institutional Review Board}

\section{Memorandum}

To: $\quad$ Kaylee Wynkoop

From: IRB Office

Date: $10 / 27 / 2015$

IRB\#. PRO15060548

Subject The Effects of Two Video Modeling Interventions on the Independent Living Skills of Students with Autism Spectrum Disorders

The University of Pittsburgh Institutional Review Board reviewed and approved the above referenced study by the expedited review procedure authorized under 45 CFR 46.110 and 21 CFR 56.110. Your research study was approved under:

45 CFR 46.110.(6)

45 CFR 46.110 .(7)

The risk level designation is Minimal Risk.

$$
\begin{array}{ll}
\text { Approval Date: } & 10 / 27 / 2015 \\
\text { Expiration Date: } & 10 / 26 / 2018
\end{array}
$$

This study meets the criteria for an extended approval period of three years. In the event that any type of federal funding is obtained during this interval, a modification must be submitted immediately so the IRB can reassess the approval period.

For studies being conducted in UPMC facilities, no clinical activities can be undertaken by investigators until they have received approval from the UPMC Fiscal Review Office.

Please note that it is the investigator's responsibility to report to the IRB any unanticipated problems involving risks to subjects or others [see 45 CFR 46.103(b)(5) and 21 CFR 56.108(b)]. Refer to the IRB Policy and Procedure Manual regarding the reporting requirements for unanticipated problems which include, but are not limited to, adverse events. If you have any questions about this process, please contact the Adverse Events Coordinator at 412-383-1480.

Please be advised that your research study may be audited periodically by the University of

Figure 25. IRB approval form 


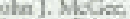

W. 407062058

SCHOOL PERMISSION TO CONDUCT RFSEARCH

September 24, 2015

Dear University of Pitsburgh Institutional Review Board:

The purpose of this letter is to inform you thas Kaylee Wynkoop permission has been granted permission to conduct the research titled The Effects of Two Video Madeling Interveritions an the Independent Living Skills of Sradents wieh Aurism Spectrum

Disonders at Fox Chapel Area High School within the Fox Chapel Area School District. Permission has been granted with the understanding that Kayloe Wynkoop will receive approval from the University of Pittsburgh Institutional Review Board and that the privacy, rights, and welfare of the participants involved will be protected. This also serves as assurance that this school complies with requirements of the Family Educational Rights and Privacy Act (PERPA) and the Protection of Pupil Rights Amendment (PPRA) and will ensure that these requirements are followed in the conduct of this research.

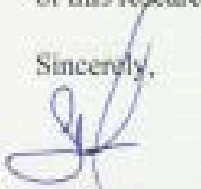

John J. McGee, Ph.D.

Assistant Principal - Senior Program

Figure 26. School permission to conduct research letter 


\section{APPENDIX B}

\section{SAMPLE DATA COLLECTION FORMS}

\begin{tabular}{|c|c|c|c|c|c|c|c|}
\hline \multicolumn{2}{|c|}{ Skill: Removing bag of trash from trashcan } & \multirow{4}{*}{$\begin{array}{l}\text { Time } \\
\text { Goal }\end{array}$} & \multicolumn{4}{|c|}{ Prompt: "Take out the trash." } & \\
\hline \multicolumn{2}{|r|}{ Intervention: } & & & & & & \\
\hline \multicolumn{2}{|r|}{ Date: } & & & & & & \\
\hline & & 1 or 0 & 1 or 0 & 1 or 0 & 1 or 0 & 1 or 0 \\
\hline \multirow{2}{*}{\multicolumn{2}{|c|}{$\begin{array}{c}\text { Steps } \\
\text { nhook top of trash bag from trash can } \\
\text { Grasp strings on either side of bag }\end{array}$}} & $10 \mathrm{~s}$ & & & & & \\
\hline & & $10 \mathrm{~s}$ & & & & & \\
\hline \multicolumn{2}{|r|}{ Pull strings to close bag } & $10 \mathrm{~s}$ & & & & & \\
\hline \multicolumn{2}{|r|}{ Lift bag out of trashcan } & $10 \mathrm{~s}$ & & & & & \\
\hline \multicolumn{2}{|r|}{ Place bag on ground } & $10 \mathrm{~s}$ & & & & & \\
\hline & Total & $50 \mathrm{~s}$ & & & & & \\
\hline
\end{tabular}

- 1 = correct/independent; 0 = error/prompted

Materials: Small trashcan, full trashbag

Figure 27. Data collection sheet: Take out trash

\begin{tabular}{|c|c|c|c|c|c|c|c|}
\hline \multicolumn{2}{|c|}{ Skill: Rolling silverware } & \multirow{4}{*}{\begin{tabular}{|l|} 
Time \\
Goal
\end{tabular}} & \multicolumn{4}{|c|}{ Prompt: "Roll the silverware." } & \\
\hline \multirow{2}{*}{\multicolumn{2}{|c|}{$\frac{\text { Intervention: }}{\text { Date: }}$}} & & & & & & \\
\hline & & & & \multirow[b]{2}{*}{1 or 0} & \multirow[b]{2}{*}{1 or 0} & \multirow[b]{2}{*}{1 or 0} & \multirow[b]{2}{*}{1 or 0} \\
\hline \multicolumn{2}{|r|}{ Steps } & & \multirow[t]{2}{*}{1 or 0} & & & & \\
\hline 1. & Pick up fork & $10 \mathrm{~s}$ & & & & & \\
\hline 2. & Pick up spoon & $10 \mathrm{~s}$ & & & & & \\
\hline 3. & Lay fork and spoon on corner of napkin & $10 \mathrm{~s}$ & & & & & \\
\hline 4. & Fold corner of napkin over fork and spoon & $10 \mathrm{~s}$ & & & & & \\
\hline 5. & Roll fork and spoon in napkin & $10 \mathrm{~s}$ & & & & & \\
\hline & Total & $50 \mathrm{~s}$ & & & & & \\
\hline
\end{tabular}

Figure 28. Data collection sheet: Roll silverware 


\begin{tabular}{|c|c|c|c|c|c|c|c|}
\hline \multicolumn{2}{|c|}{ Skill: Wiping tray in microwave } & \multirow{4}{*}{$\begin{array}{l}\text { Time } \\
\text { Goal }\end{array}$} & \multicolumn{4}{|c|}{ Prompt: "Wipe the tray in the microwave." } & \\
\hline \multicolumn{2}{|r|}{ Intervention: } & & & & & & \\
\hline \multicolumn{2}{|r|}{ Date: } & & & & & & \\
\hline \multicolumn{2}{|c|}{ Steps } & & 1 or 0 & 1 or 0 & 1 or 0 & 1 or 0 & 1 or 0 \\
\hline \multicolumn{2}{|r|}{ Open microwave door } & $10 \mathrm{~s}$ & & & & & \\
\hline \multicolumn{2}{|r|}{ Pick up wipe } & $10 \mathrm{~s}$ & & & & & \\
\hline \multicolumn{2}{|r|}{ Wipe tray } & $45 \mathrm{~s}$ & & & & & \\
\hline \multicolumn{2}{|r|}{ Close microwave door } & $10 \mathrm{~s}$ & & & & & \\
\hline \multicolumn{2}{|r|}{ Throw wipe away } & $10 \mathrm{~s}$ & & & & & \\
\hline & Total & $85 s$ & & & & & \\
\hline
\end{tabular}

- 1 = correct/independent; 0 = error/prompted

Materials: Wipe, microwave, trashcan

Figure 29. Data collection sheet: Wipe microwave tray

\begin{tabular}{|c|c|c|c|c|c|c|c|}
\hline \multicolumn{2}{|c|}{ Skill: Folding t-shirt } & \multirow{4}{*}{$\begin{array}{l}\text { Time } \\
\text { Goal }\end{array}$} & \multicolumn{4}{|c|}{ Prompt: "Fold the t-shirt." } & \\
\hline \multicolumn{2}{|r|}{ Intervention: } & & & & & & \\
\hline \multicolumn{2}{|r|}{ Date: } & & & & & & \\
\hline \multicolumn{2}{|r|}{ Steps } & & 1 or 0 & 1 or 0 & 1 or 0 & 1 or 0 & 1 or 0 \\
\hline \multicolumn{2}{|r|}{ Pick up shirt from basket } & $10 \mathrm{~s}$ & & & & & \\
\hline \multicolumn{2}{|r|}{ 2. Place shirt flat on table with bottom facing you } & $10 \mathrm{~s}$ & & & & & \\
\hline 3. & Fold shirt in half length-wise (match sleeves) & $10 \mathrm{~s}$ & & & & & \\
\hline 4. & Fold shirt in half bringing bottom up to neck & 10 s & & & & & \\
\hline 5. & Place shirt in basket & $10 \mathrm{~s}$ & & & & & \\
\hline \multicolumn{2}{|r|}{ Total } & $50 \mathrm{~s}$ & & & & & \\
\hline
\end{tabular}

Figure 30. Data collection sheet: Fold t-shirt

\begin{tabular}{|c|c|c|c|c|c|c|c|}
\hline \multicolumn{2}{|c|}{ Skill: Filling cup with water from faucet } & \multirow{4}{*}{$\begin{array}{l}\text { Time } \\
\text { Goal }\end{array}$} & \multicolumn{4}{|c|}{ Prompt: "Get a cup of water." } & \\
\hline \multirow{2}{*}{\multicolumn{2}{|c|}{\begin{tabular}{r|} 
Intervention: \\
Date:
\end{tabular}}} & & & & & & \\
\hline & & & & & & & \\
\hline \multicolumn{2}{|c|}{ Steps } & & 1 or 0 & 1 or 0 & 1 or 0 & 1 or 0 & 1 or 0 \\
\hline \multicolumn{2}{|c|}{ Pick up cup from counter } & $10 \mathrm{~s}$ & & & & & \\
\hline \multicolumn{2}{|r|}{ Turn on cold water } & $10 \mathrm{~s}$ & & & & & \\
\hline \multicolumn{2}{|r|}{ Fill cup with water } & $10 \mathrm{~s}$ & & & & & \\
\hline \multicolumn{2}{|r|}{ Turn off water } & $10 \mathrm{~s}$ & & & & & \\
\hline \multicolumn{2}{|r|}{ Place cup on counter } & $10 \mathrm{~s}$ & & & & & \\
\hline & Total & $50 \mathrm{~s}$ & & & & & \\
\hline
\end{tabular}

- $1=$ correct/independent; $0=$ error/prompted Materials: Cup, sink, counter.

Figure 31. Data collection sheet: Get water

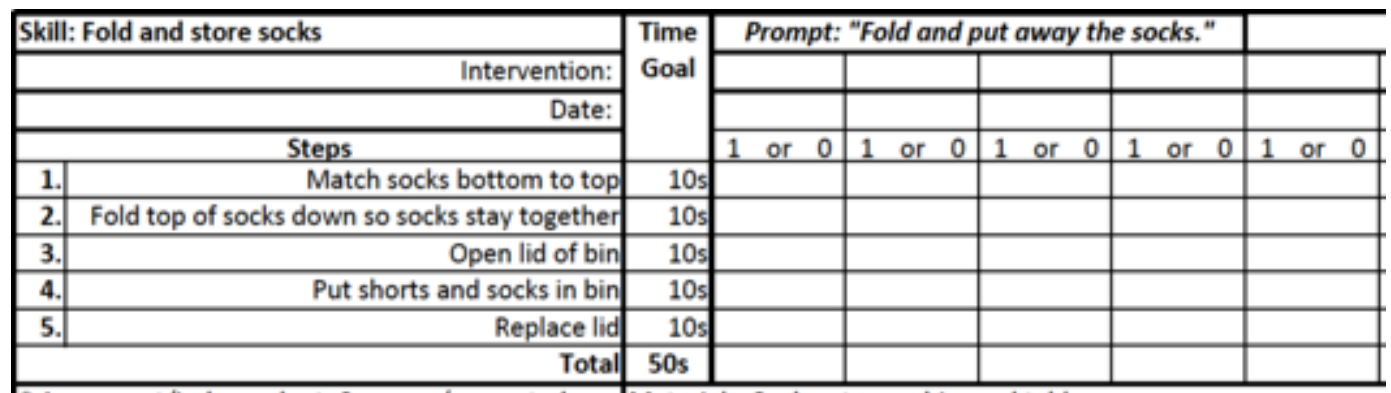

- $1=$ correct $/$ independent $; 0=$ error/prompted

Materials: Socks, storage bin, and table

Figure 32. Data collection sheet: Fold and store socks 
Directions:

Type 1 to indicate if each procedure is implemented correctly by the $\mathrm{Pl}$.

Type $\mathbf{0}$ if a procedure is not correctly implemented.

Type NA if a procedure does not apply to the student/session.

\begin{tabular}{|c|c|c|c|c|c|}
\hline Participant: $\quad$ Skill Level: & & & & & \\
\hline \multicolumn{6}{|l|}{ Date } \\
\hline \multicolumn{6}{|l|}{ Skill Code (C=Cleaning; F=Food Prep; L= Laundry) } \\
\hline Condition Code (Baseline; VM; CVM; or P\&R) & Baseline & Baseline & Baseline & Baseline & Baseline \\
\hline Description of Procedures & \begin{tabular}{|c|}
1,0 , or NA \\
below
\end{tabular} & $\begin{array}{l}1,0 \text {, or NA } \\
\text { below }\end{array}$ & $\begin{array}{l}1,0 \text {, or NA } \\
\text { below }\end{array}$ & $\begin{array}{l}1,0 \text {, or NA } \\
\text { below }\end{array}$ & $\begin{array}{c}1,0 \text {, or NA } \\
\text { below }\end{array}$ \\
\hline \multicolumn{6}{|l|}{ All materials appear to be available to the student. } \\
\hline \multicolumn{6}{|l|}{ Student has been or is directed to the to proper setting. } \\
\hline \multicolumn{6}{|l|}{ The PI prompts the student to begin the skill (i.e., "Get a glass of water.") } \\
\hline \multicolumn{6}{|l|}{ Non-responder } \\
\hline \multicolumn{6}{|l|}{$\begin{array}{l}\text { a) If the student does not respond within } \mathbf{2 0} \text { seconds, the PI delivers a second } \\
\text { prompt (i.e., "Just do any steps you know how to do.") }\end{array}$} \\
\hline \multicolumn{6}{|l|}{$\begin{array}{l}\text { b) If the student still does not respond within } 10 \text { seconds of the second prompt, } \\
\text { discontinue the probe. }\end{array}$} \\
\hline \multicolumn{6}{|l|}{ Incorrect responses } \\
\hline \multicolumn{6}{|l|}{ a) The PI ends the probe after $\mathbf{3 0}$ consecutive seconds of incorrect responses. } \\
\hline \multicolumn{6}{|l|}{$\begin{array}{l}\text { b) If the student correctly performs a step, the PI gives the student } 30 \text { consecutive } \\
\text { seconds following the correct step to complete any additional steps before ending the } \\
\text { probe. }\end{array}$} \\
\hline \multicolumn{6}{|l|}{ No prompts or feedback are delivered for correct or incorrect responses. } \\
\hline \multicolumn{6}{|l|}{ Total 1's (correct procedures) } \\
\hline \multicolumn{6}{|l|}{ Total 1's + 0's (correct and incorrect procedures) } \\
\hline Procedural Integrity \% & & & & & \\
\hline
\end{tabular}

Figure 33. Procedural integrity form: Baseline 
Directions:

Type 1 to indicate if each procedure is implemented correctly by the PI.

Type $\mathbf{0}$ if a procedure is not correctly implemented.

Type NA if a procedure does not apply to the student/session.

\begin{tabular}{|c|c|c|c|c|c|}
\hline Participant: $\quad$ Skill Level: & & & & & \\
\hline \multicolumn{6}{|l|}{ Date } \\
\hline \multicolumn{6}{|l|}{ Skill Code (C=Cleaning; F=Food Prep; L= Laundry) } \\
\hline Condition Code (Baseline; VM; CVM; or P\&R) & VM & VM & VM & VM & VM \\
\hline Description of Procedures & $\begin{array}{l}1,0 \text {, or NA } \\
\text { below }\end{array}$ & $\begin{array}{l}1,0 \text {, or NA } \\
\text { below }\end{array}$ & $\begin{array}{l}1,0 \text {, or NA } \\
\text { below }\end{array}$ & $\begin{array}{l}1,0 \text {, or NA } \\
\text { below }\end{array}$ & $\begin{array}{l}1,0 \text {, or NA } \\
\text { below }\end{array}$ \\
\hline \multicolumn{6}{|l|}{ All materials appear to be available to the student. } \\
\hline \multicolumn{6}{|l|}{ Student has been or is directed to the to proper setting. } \\
\hline \multicolumn{6}{|l|}{ The PI prompts the student to watch video. } \\
\hline \multicolumn{6}{|l|}{ The PI redirects student to watch video if needed. } \\
\hline \multicolumn{6}{|l|}{ The PI prompts the student to begin the skill (i.e., "Get a glass of water.") } \\
\hline \multicolumn{6}{|l|}{$\begin{array}{l}\text { The PI follows the least-to-most prompting procedure for every error or if no response } \\
\text { occurs within } 3 \text { seconds. }\end{array}$} \\
\hline \multicolumn{6}{|l|}{$\begin{array}{l}\text { a) The PI gives a verbal + gestural task prompt and waits } 3 \text { seconds (i.e., points to the } \\
\text { cup \& says "get the cup.") }\end{array}$} \\
\hline \multicolumn{6}{|l|}{$\begin{array}{l}\text { b) If the student does not correct error, the PI gives full physical prompt (i.e., hand } \\
\text { over hand guidance). }\end{array}$} \\
\hline \multicolumn{6}{|l|}{ The PI ensures that the student completes the entire skill. } \\
\hline \multicolumn{6}{|l|}{ The PI delivers reinforcer to the student. } \\
\hline \multicolumn{6}{|l|}{ Total 1's (correct procedures) } \\
\hline \multicolumn{6}{|l|}{ Total 1's + 0's (correct and incorrect procedures) } \\
\hline Procedural Integrity \% & & & & & \\
\hline
\end{tabular}

Figure 34. Procedural integrity form: VM+P\&R 
Directions:

Type 1 to indicate if each procedure is implemented correctly by the PI.

Type $\mathbf{0}$ if a procedure is not correctly implemented.

Type NA if a procedure does not apply to the student/session.

\begin{tabular}{|c|c|c|c|c|c|}
\hline Participant: & & & & & \\
\hline \multicolumn{6}{|l|}{ Date } \\
\hline \multicolumn{6}{|l|}{ Skill Code (C=Cleaning; F=Food Prep; L= Laundry) } \\
\hline Condition Code (Baseline; VM; CVM; or P\&R) & CVM & CVM & CVM & CVM & CVM \\
\hline Description of Procedures & $\begin{array}{l}1,0 \text {, or NA } \\
\text { below }\end{array}$ & $\begin{array}{l}1,0 \text {, or NA } \\
\text { below }\end{array}$ & $\begin{array}{l}1,0 \text {, or NA } \\
\text { below }\end{array}$ & $\begin{array}{l}1,0 \text {, or NA } \\
\text { below }\end{array}$ & $\begin{array}{l}1,0 \text {, or NA } \\
\text { below }\end{array}$ \\
\hline \multicolumn{6}{|l|}{ All materials appear to be available to the student. } \\
\hline \multicolumn{6}{|l|}{ Student has been or is directed to the to proper setting. } \\
\hline \multicolumn{6}{|l|}{ The PI prompts the student to watch video. } \\
\hline \multicolumn{6}{|l|}{ The PI redirects student to watch video if needed. } \\
\hline \multicolumn{6}{|l|}{ The PI prompts the student to begin the skill (i.e., "Get a glass of water.") } \\
\hline \multicolumn{6}{|l|}{ The video plays on a continuous loop. } \\
\hline \multicolumn{6}{|l|}{$\begin{array}{l}\text { The PI follows the least-to-most prompting procedure for every error or if no response } \\
\text { occurs within } 3 \text { seconds. }\end{array}$} \\
\hline \multicolumn{6}{|l|}{$\begin{array}{l}\text { a) The PI gives a verbal + gestural video prompt (i.e., points to the iPad \& says "Let's } \\
\text { watch the video.") and ensures student watches video loop until step during which the } \\
\text { error/no response occurred plays; wait } 3 \text { seconds. }\end{array}$} \\
\hline \multicolumn{6}{|l|}{$\begin{array}{l}\text { b) If the student does not correct error, the PI gives full physical prompt (i.e., hand } \\
\text { over hand guidance). }\end{array}$} \\
\hline \multicolumn{6}{|l|}{ The PI ensures that the student completes the entire skill. } \\
\hline \multicolumn{6}{|l|}{ The PI delivers reinforcer to the student. } \\
\hline \multicolumn{6}{|l|}{ Total 1's (correct procedures) } \\
\hline \multicolumn{6}{|l|}{ Total 1's + 0's (correct and incorrect procedures) } \\
\hline Procedural Integrity \% & & & & & \\
\hline
\end{tabular}

Figure 35. Procedural integrity form: CVM+P\&R 
Directions:

Type 1 to indicate if each procedure is implemented correctly by the PI.

Type $\mathbf{0}$ if a procedure is not correctly implemented.

Type NA if a procedure does not apply to the student/session.

\begin{tabular}{|c|c|c|c|c|c|}
\hline Participant: $\quad$ Skill Level: & & & & & \\
\hline \multicolumn{6}{|l|}{ Date } \\
\hline \multicolumn{6}{|l|}{ Skill Code (C=Cleaning; F=Food Prep; L= Laundry) } \\
\hline Condition Code (Baseline; VM; CVM; or P\&R) & P\&R & P\&R & P\&R & P\&R & P\&R \\
\hline Description of Procedures & $\begin{array}{l}1,0 \text {, or NA } \\
\text { below }\end{array}$ & \begin{tabular}{|c|}
$\begin{array}{l}1,0 \text {, or NA } \\
\text { below }\end{array}$ \\
\end{tabular} & $\begin{array}{l}1,0 \text {, or NA } \\
\text { below }\end{array}$ & $\begin{array}{l}1,0 \text {, or NA } \\
\text { below }\end{array}$ & $\begin{array}{l}1,0 \text {, or NA } \\
\text { below }\end{array}$ \\
\hline \multicolumn{6}{|l|}{ All materials appear to be available to the student. } \\
\hline \multicolumn{6}{|l|}{ Student has been or is directed to the to proper setting. } \\
\hline \multicolumn{6}{|l|}{ The PI prompts the student to begin the skill (i.e., "Get a glass of water.") } \\
\hline \multicolumn{6}{|l|}{$\begin{array}{l}\text { The PI follows the least-to-most prompting procedure for every error or if no response } \\
\text { occurs within } 3 \text { seconds. }\end{array}$} \\
\hline \multicolumn{6}{|l|}{$\begin{array}{l}\text { a) The PI gives a verbal + gestural task prompt and waits } 3 \text { seconds (i.e., points to the } \\
\text { cup \& says "get the cup.") }\end{array}$} \\
\hline \multicolumn{6}{|l|}{$\begin{array}{l}\text { b) If the student does not correct error, the PI gives full physical prompt (i.e., hand } \\
\text { over hand guidance). }\end{array}$} \\
\hline \multicolumn{6}{|l|}{ The PI ensures that the student completes the entire skill. } \\
\hline \multicolumn{6}{|l|}{ The PI delivers reinforcer to the student. } \\
\hline \multicolumn{6}{|l|}{ Total 1's (correct procedures) } \\
\hline \multicolumn{6}{|l|}{ Total 1's + 0's (correct and incorrect procedures) } \\
\hline Procedural Integrity \% & & & & & \\
\hline
\end{tabular}

Figure 36. Procedural integrity form: $P \& R$ 


\section{Social Validity Survey}

How did you feel about the skills we worked on?
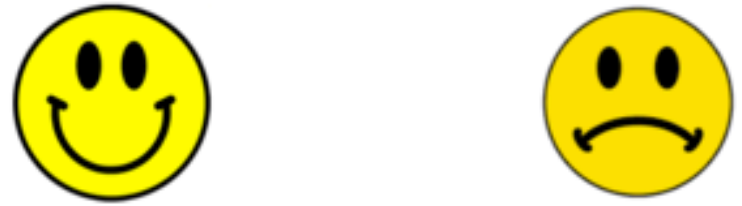

How did you feel about watching the videos?
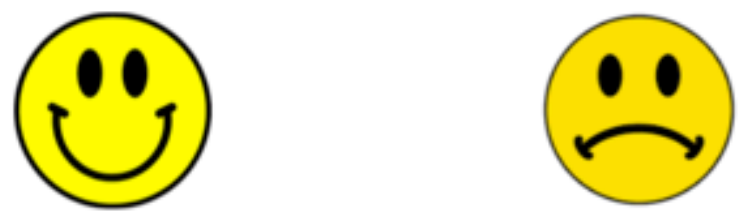

Which did you like better: video or no video?
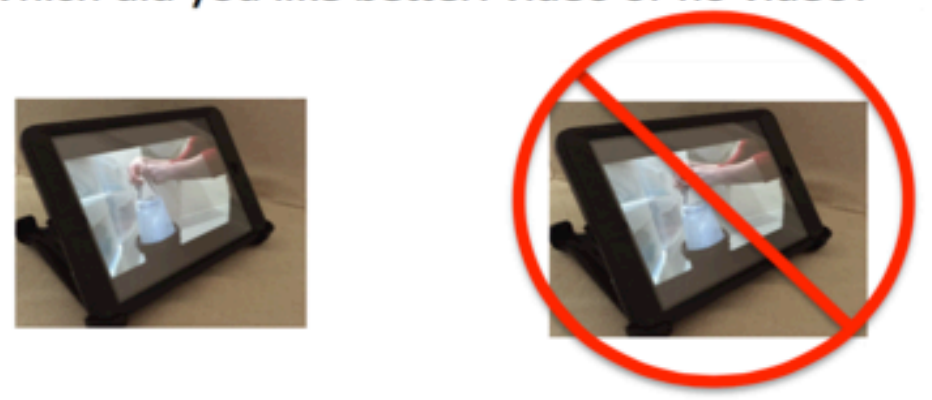

Which did you like better: video loop or video 1 time?
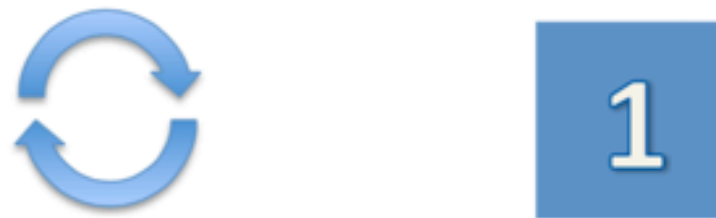

Figure 37. Social validity survey: Participant 


\section{University of Pittsburgh}

Video Modeling Survey

The target skills selected for my child/student were

$\square$ not appropriate for his/her skill level

somewhat appropriate for his/her skill level

$\square$ appropriate of his/her skill level

Video-based interventions my child/student's target skills.

$\square$ did not appear to improve

appeared to minimally improve

appeared to greatly improve

Using video-based interventions is

not an acceptable way to teach independent living skills

an acceptable way to teach independent living skills

Video-based interventions than other teaching strategies.

seem less effective than

seem to be just as effective

seem more effective

Please choose the video-based intervention(s) you feel was most effective for your child/student.

(VM+P\&R) Video modeling plus prompting and reinforcement (i.e., watches video $1 \mathrm{x}$ then performs the skill.

(CVM+P\&R) Continuous video modeling plus prompting and reinforcement (i.e., watches video $1 \mathrm{x}$ and the video keeps playing while he/she performs the skill)

Both video-based interventions seemed to be equally effective

Please choose the intervention you would most likely use in your home/classroom.

$\square$ (VM+P\&R) Video modeling plus prompting and reinforcement (i.e., watches video $1 \mathrm{x}$ then performs the skill.

(CVM+P\&R) Continuous video modeling plus prompting and reinforcement (i.e., watches video $1 \mathrm{x}$ and the video keeps playing while he/she performs the skill)

I would be most likely to use another strategy. Please feel free to list the strategy(s).

Figure 38. Social validity survey: Parent and teacher 


\section{BIBLIOGRAPHY}

**Acar, C. \& Diken, I. H. (2012). Reviewing instructional studies conducted using video modeling to children with autism. Educational Sciences: Theory \& Practice, 12(4), 27312735.

*Alcantara, P.R. (1994). Effects of videotape instructional package on purchasing skills of children with autism. Exceptional Children, 6, 40-55.

*Alexander, J. L., Ayres, K. M., Smith, K. A., Shepley, S. B., Mataras, T. K. (2013). Using video modeling on an iPad to teach generalized matching on a sorting mail task to adolescents with autism. Research in Autism Spectrum Disorders 7(11), 13461357.doi:10.1016/j.rasd.2013.07.021

*Allen, K. D., Wallace, D. P., Renes, D., Bowen, S. L., Burke, R. V. (2010a). Use of video modeling to teach vocational skills to adolescents and young adults with autism spectrum disorders. Education \& Treatment of Children, 33(3), 339-349.

*Allen, K. D., Wallace, D. P., Greene, D. J., Bowen, S. L., \& Burke, R. V. (2010b). Communitybased vocational instruction using videotaped modeling for young adults with autism spectrum disorders performing in air-inflated mascots. Focus on Autism and Other Developmental Disabilities, 25, 186-192. doi:10.1177/1088357610377310

**Ayres, K. M. \& Langone, J. (2005). Intervention and instruction with video for students with autism: A review of the literature. Education and Training in Developmental Disabilities, 40(2), 183-196.

Ayres, K.M., Lowery, K.A., Douglas, K.H., \& Sievers, C. (2011). I can identify Saturn but I can't brush my teeth: What happens when the curricular focus for students with severe disabilities shifts. Education and Training in Autism and Developmental Disabilities, $46(1), 11-12$.

Bainbridge, N. \& Myles, B. S. (1994). The use of priming to introduce toilet training to a child with autism. Focus Autism Other Developmental Disabilities, 14(2), 106-109.

* Indicates references used in the literature review.

** Indicates references included in the search of pertinent literature reviews. 
Bandura, A. (1965). Influence of models' reinforcement contingencies on the acquisition of imitative responses. Journal of Personality and Social Psychology, 1(6), 589-595.

Barton, E. E., Lawrence, K., and Deurloo, F. (2012). Individualizing interventions for young children with autism in preschool. Journal of Autism and Developmental Disabilities, 42(6), 1205-1217. doi: 10.1007/s10803-011-1195-z

**Bellini S. \& Akullian, J. (2007). A meta-analysis of video modeling and video self-modeling interventions for children and adolescents with autism spectrum disorder. Exceptional Children, 73(3), 264-287. doi:10.1177/001440290707300301

Bennet, K., Ramasamy, R., \& Honsberger, T. (2013). Further examination of covert audio coaching on improving employment skills among secondary students with autism. Journal of Behavioral Education, 22, 103-119. doi: 10.1007/s10864-013-9168-2

Blood, E., Johnson, J. W., Ridenour, L., Simmons, K., \& Crouch, S. (2011). Using and iPod touch to teach social and self-management skills to an elementary student with emotional/behavioral disorders. Education and Treatment of Children, 34(3), 299-322.

Bouck, E.C. (2010). Reports of life skills training for students with intellectual disabilities in and out of school. Journal of Intellectual Disability Research, 54(12), 1093-1103. doi: 10.1111/j.1365-2788.2010.01339.x

Burgess, S. \& Cimera, R. E. (2014). Employment outcomes of transition-aged adults with autism spectrum disorders: A state of the states report. American Journal on Intellectual and Developmental Disabilities, 119(1), 64-83. doi: 10.1352/1944-7558-119.1.64

*Cannella-Malone, H. I., Fleming, C., Chung, Y. C., Wheeler, G. M., Basbagill, A. R., \& Singh, A. H. (2011). Teaching daily living skills to seven individuals with severe intellectual disabilities: A comparison of video prompting to video modeling. Journal of Positive Behavior Interventions, 13(3), 144-153. doi:10.1177/1098300710366593

Cannella-Malone, H. I., Mizrachi, S. B., Sabielny, L. M., \& Jimenez, E. D. (2013). Teaching physical activities to students with significant disabilities using video modeling. Developmental Neurorehabilitation,16(3), 145-154. doi: 10.3109/17518423.2012.763192

Cannella-Malone, H., Sigafoos, J., O’Reilly, M., de la Cruz, B., Edrisinha, C., \& Lancioni, G. E. (2006). Comparing video prompting to video modeling for teaching daily living skills to six adults with developmental disabilities. Education and Training in Developmental Disabilities, 41(4), 344-356.

Center for Disease Control and Prevention. (March 28, 2014). Prevalence of autism spectrum disorder among children aged 8 years -Autism and developmental disabilities monitoring network, 11 sites, United States, 2010 (CDC 63(SS02)). Retrieved from http://www.cdc.gov/mmwr/preview/mmwrhtml/ss6302a1.htm 
Charlop-Christy, M. H. \& Daneshvar, S. (2003). Using video modeling to teach perspective taking to children with autism. Journal of Positive Behavior Interventions, 5(1), 12-21. doi: $10.1177 / 10983007030050010101$

Charlop-Christy, M. H., Le, L., \& Freeman, K. A. (2000). A comparison of video modeling with in vivo modeling for teaching children with autism. Journal of Autism and Developmental Disorders, 30(6), 537-552. doi: 0162-3257/00/1200-0537\$18.00/0

Cihak, D., Fahrenkrog, C., Ayres, K. M., \& Smith, C. (2010). The use of video modeling via a video iPod and a system of least prompts to improve transitional behaviors for students with autism spectrum disorders in the general education classroom. Journal of Positive Behavior Interventions, 12(2), 103-115. doi: 10.1177/1098300709332346

*Cihak, D. F. \& Schrader, L. (2008). Does the model matter? Comparing video self-modeling and video adult modeling for task acquisition and maintenance by adolescents for autism spectrum disorders. Journal of Special Education Technology, 23(3), 9-20.

Cooper, J. O., Heron, T. E., \& Heward, W. L. (2007). Applied behavior analysis $2^{\text {nd }}$ ed. Upper Saddle Ridge, NJ: Pearson Education, Inc.

**Corbett, B. A. \& Abdullah, M. (2005). Video modeling: Why does it work for children with autism? Journal of Early and Intensive Behavior Intervention, 2(1), 2-8. http://dx.doi.org/10.1037/h0100294

D’Ateno, P., Mangiapanello, K., \& Taylor, B.A. (2003). Using video modeling to teach complex play sequences to a preschooler with autism. Journal of Positive Behavior Interventions, 5(1), 5-11.

**Delano, M. E. (2007). Video modeling interventions for individuals with autism. Remedial and Special Education, 28(1), 33-42. doi:10.1177/074193250702800010401

Diament, M. (2015, May). As more with autism near adulthood, clues to success emerge. Disability Scoop. Retrieved from http://www.disabilityscoop.com/2015/05/14/as-autismadulthood-clues/20299/

DeLeon, I. G. \& Iwata, B. A. (1996). Evaluation of a multiple stimulus presentation format for assessing reinforcer preferences. Journal of Applied Behavior Analysis, 29(4), 519-533.

Diament, M. (2015, May). As more with autism near adulthood, clues to success emerge. Disability Scoop. Retrieved from http://www.disabilityscoop.com/2015/05/14/as-autismadulthood-clues/20299/

Drahota, A., Wood, J. J., Sze, K. M., \& Van Dyke, M. (2010). Effects of cognitive behavioral therapy on daily living skills in children with high-functioning autism and concurrent anxiety disorders. Journal of Autism and Developmental Disabilities 41, 257-265. doi: 10.1007/s10803-010-1037-4 
Gardner, S. \& Wolf, P. (2013). Use of video modeling and video prompting interventions for teaching daily living skills to individuals with autism spectrum disorders: A review. Research \& Practice for Persons with Severe Disabilities, 38(2), 73-87.

**Gelbar, N. W., Anderson, C., McCarthy, S., \& Buggey, T. (2012). Video self-modeling as an interventions strategy for individuals with autism spectrum disorders. Psychology in the Schools, 49(1), 15-22. doi: 10.1002/pits.20628

Giangreco, M. F. \& Broer, S. M. (2005). Questionable utilization of paraprofessionals in inclusive schools: Are we addressing symptoms or causes? Focus on Autism and Other Developmental Disabilities, 20(1), 10-26.

Giangreco, M. F. \& Broer S. M. (2007). School-based screening to determine overreliance on paraprofessionals. Focus on Autism and Other Developmental Disabilities, 22(3), 149158.

Gillham, J. E., Carter, A. S., Volkmar, F. R., \& Sparrow, S. S., (2000). Toward a developmental operational definition of autism. Journal of Autism and Developmental Disorders, 30(4). 269-278. doi:10.1023/A:1005571115268

Green, S. A. \& Carter, A. S. (2011). Predictors and course of daily living skills development in toddlers with autism spectrum disorder. Journal of Autism and Developmental Disabilities, 44(2), 256-263. doi:10.1007/s10803-011-1275-0

*Hagiwara, T., \& Myles, B. S. (1999). A multimedia social story intervention: Teaching skills to children with autism. Focus on Autism and Other Developmental Disabilities, 14(2), 8295. doi: 10.1177/108835769901400203

Hardman, M. L., Drew, C. J., \& Egan, M. W. (2014). Human exceptionality: School, community, and family $11^{\text {th }}$ ed. Belmont, CA: Cengage Learning.

Haring, T. G., Breen, C. G., Weiner, J., Kennedy, C. H., \& Bednersh, F. (1995). Using video modeling to facilitate generalized purchasing skills. Journal of Behavioral Education, 5(1), 29-53. doi: 1053-0819/95/0300-0029507.50

Haring, T. G., Kennedy, C. H., Adams, M. J., \& Pitts-Conway, V. (1987). Teaching generalization of purchasing skills across community settings to autistic youth using videotape modeling. Journal of Applied Behavior Analysis, 20(1), 89-96. doi: 10530819/95/0300-0029507.50/

Hendricks, D. R., Smith, M. D., and Wehman, P. (2009) Teaching youth for success. In Wehman, P., Smith, M. D., \& Schall, C., Autism and the transition to adulthood: Success beyond the classroom. Baltimore, MD: Paul H. Brookes Publishing Co. 
The Henry J. Kaiser Family Foundation. (2010). Generation $M^{2}$ Media in the Lives of 8- to 18Year-Olds.Retrievedfrom https://kaiserfamilyfoundation.files.wordpress.com/2013/04/8010.pdf

Horner, R. H., Carr, E. G., Halle, J., McGee, G., Odom, S., \& Wolery, M. (2005). The use of single-subject research to identify evidence-based practice in special education. Exceptional Children, 71(2), 165-179. doi:10.1177/001440290507100203

Hume, K., Loftin, R., \& Lantz, J. (2009). Increasing independence in autism spectrum disorders: A review of three focused interventions. Journal of Autism and Developmental Disorders, 39(9), 1329-1338. doi: 10.1007/s10803-009-0751-2

Iovannone, R., Dunlap, G., Huber, H., \& Kincaid, D. (2003). Effective educational practices for students with autism spectrum disorders. Focus on Autism and Other Developmental Disabilities, 18(3), 150-165.

Johnson, E. \& Semmelroth, C.L. (2014). Special education teacher evaluation: Why it matters, what makes it challenging, and how to address these challenges. Assessment for Effective Intervention, 39(2), 71-82. doi: 10.1177/1534508413513315

Johnston, J. M., \& Pennypacker, H. S. (2009). Strategies and tactics of behavioral research ( $^{\text {rd }}$ ed.). New York: Routledge. ISBN: 9780805858822

Klinger, L. G., Klinger, M. R., Mussey, J. L., Thomas, S. P., \& Powell, P. S. (2015, May). Correlates of middle adult outcome: A follow-up study of children diagnosed with ASD from 1970-1999. Paper presented at the 2015 International Meeting for Autism Research, Salt Lake City, UT.

Koegel, R. L. \& Egel, A. L. (1979). Motivating autistic children. Journal of Abnormal Psychology, 88(4), 418-426. doi: 0021-843X/79/8804-0418\$00.75

Koyama, T. \& Wang, H. (2011). Use of activity schedule to promote independent performance of individuals with autism and other intellectual disabilities: A review. Research in Developmental Disabilities, 32, 2235-2242. doi: 10.1016/j.ridd.2011.05.003

Lasater, M. W. \& Brady, M. P. (1995). Effects of video self-modeling and feedback on task fluency: A home-based intervention. Education and Treatment of Children, 18(4), 389408.

LeBlanc, L. A., Coates, A. M., Daneshvar, S., Charlop-Christy, M. H., Morris, C., \& Lancaster, B. M. (2003). Using video modeling and reinforcement to teach perspective-taking skills to children with autism. Journal of Applied Behavior Analysis, 36(2), 253-257. doi.org/10.1901/jaba.2003.36-253

Liss, M., Harel, B., Fein, D., Allen, D., Dunn, M., Feinstein, C., Morris, R., Waterhouse, L., \& Rapin, I. (2001). Predictors and correlates of adaptive functioning in children with 
developmental disorders. Journal of Autism and Developmental Disabilities, 31(2), 219230. doi: 0162-3257/01/0400-0219\$19.50/0

Loughrey, T. O., Marshall, G. K., Bellizzi, A., \& Wilder, D. A. (2013). The use of video modeling, prompting, and feedback to increase credit card promotion in a retail setting. Organizational Behavior Management, 33, 200-208. doi: 10.1080/01608061.2013.815097

Lowy Apple, A., Billingsley, F., \& Schwartz, I. S. (2005).Effects of video modeling alone and with self-management on compliment-giving behaviors of children with high-functioning ASD. Journal of Positive Behavior Interventions, 7(1), 33-46.

Madden, M., Lenhart, A., Duggan, M., Cortesi, S., \& Gasser, U. (2013). Teens and Technology 2013. Retrieved from Pew Research Center: Internet, Science, \& Tech website: http://www.pewinternet.org/2013/03/13/teens-and-technology-2013/

Manley, K., Collins, B.C., Stenhoff, D.M., \& Kleinhart, H. (2008). Using a system of least prompts procedure to teach telephone skills to elementary students with cognitive disabilities. Journal of Behavioral Education, 17, 221-236. doi: 10.1007/s10864-0089065-2

**Mason, R. A., Davis, H. S., Boles, M. B., \& Goodwyn, F. (2013). Efficacy of point-of-view video modeling: A meta-analysis. Remedial and Special Education, 34, 333-345. doi: $10.1177 / 0741932513486298$

**Mason, R. A., Ganz, J. B., Parker, R. I., Boles, M. B., Davis, H. S., \& Rispoli, M. (2013). Video -based modeling: Differential effects due to treatment protocol. Research in Autism Spectrum Disorders, 7, 120-131. doi: 10.1016/j.rasd.2012.08.003

**Mason, R. A., Ganz, J. B., Parker, R. I., Burke, M. D., Camargo, S. P. (2012). Moderating factors of video-modeling with other as model: A meta-analysis of single-case studies. Research in Developmental Disabilities 33, 1076-1086. doi:10.1016/j.ridd.2012.01.016

McConville, M. L., Hantula, D. A., \& Axelrod, S. (1998). Matching training procedures to outcomes: A behavioral and quantitative analysis. Behavior Modification, 22(3), 391414.

**McCoy, K. \& Hermansen, E. (2007). Video modeling for individuals with autism: A review of model types and effects. Education and Treatment of Children, 30(4), 183-213. doi:10.1353/ect.2007.0029

*Mechling, L. C. \& Ayres, K. M. (2012). A comparative study: Completion of fine motor office related tasks by high school students with autism using video models on large and small screen sizes. Journal of Autism and Developmental Disorders, 42(11), 2364-2373. doi: 10.1007/s10803-012-1484-1 
Mechling, L.C., Ayres, K.M., Foster, A.L., \& Bryant, K.J. (2013). Comparing the effects of commercially available and custom-made video prompting for teaching cooking skills to high school students with autism, Remedial and Special Education 34(6), 317-383. doi:10.1177/0741932513494856

*Mechling, L. C., Ayres, K. M., Bryant, K. J., \& Foster, A. L. (2014a). Continuous video modeling to assist with completion of multi-step home living tasks by young adults with moderate intellectual disability, Education and Training in Autism and Developmental Disabilities, 49(3), 368-380.

*Mechling, L. C., Ayres, K. M., Bryant, K. J., \& Foster, A. L. (2014b). Comparison of the effects of continuous video modeling, video prompting, and video modeling on task completion by young adults with moderate intellectual disability, Education and Training in Autism and Developmental Disabilities, 49(4), 491-504.

*Mechling, L.C. \& Collins, T. S., (2012). Comparison of the effects of video models with and without verbal cueing on task completion by young adults with moderate intellectual disability. Education and Training in Autism and Developmental Disabilities, 47(2), 223235.

*Mechling, L.C., Gast, D.L., \& Gustofson, M.R. (2009). Use of video modeling to teach extinguishing of cooking related fires to individuals with moderate intellectual disabilities. Education and Training in Developmental Disabilities, 44(1), 67-69.

Miltenberger C. A. \& Charlop, M. H. (2015). The comparative effectiveness of portable video modeling vs. traditional video modeling interventions with children with autism spectrum disorders. Journal of Developmental and Physical disabilities, 27(3), doi:10.1007/s10882-014-9416-y

*Murzynki, N. T. \& Bourret, J. C. (2007). Combining video modeling and least-to-most prompting for establishing response chains. Behavioral Interventions, 22(2), 147-152. doi: 10.1002/bin.224

National Center for Education Statistics; NCES (2010). Educational Technology in U.S. Public Schools: Fall 2008. (NCES Publication 2010-034). Retrieved from http://nces.ed.gov/pubs2010/2010034.pdf

O’Riordan, M. A., Plaisted, K. C., Driver, J., \& Baron-Cohen, S. (2001). Superior visual search in autism. Journal of Experimental Psychology: Human Perception and Performance, 27(3), 719-730. dio:10.1037//0096-1523.27.3.719

Plavnick, J. B. (2013). Video modeling (VM) fact sheet. Chapel Hill: The University of North Carolina, Frank Porter Graham Child Development Institute, The National Professional Development Center on Autism Spectrum Disorders. 
Rai K. (2008). Technology to teach self-help skills to elementary students with mental disabilities. Journal of the Indian Academy of Applied Psychology, 34(2), 201-214

Rayner, C. (2011). Teaching students with autism to tie a shoelace knot using video prompting and backward chaining. Developmental Neurorehabilitation, 14, 339-47.

**Rayner, C., Denholm, C., \& Sigafoos, J. (2009). Video-based interventions for individuals with autism: Key questions that remain unanswered. Research in Autism Spectrum Disorders, 3, 291-303. doi:10.1016/j.rasd.2008.09.001

Riley-Tillman, T.C., Burns, M.K., \& Gibbons, K. (2013). RTI applications, Volume 2: Assessment, analysis, and decision making. New York: Guildford Press. [ISBN 978-14625-0914-0]

Rosenberg, N. E., Schwartz, I. S., \& Davis, C.A. (2010). Evaluating the utility of commercial videotapes for teaching hand washing to children with autism. Education and Treatment of Children 33(3), 443-455. doi:10.3109/17518421003801489

Sanford, C., Newman, L., Wagner, M., Cameto, R., Knokey, A. M., \& Shaver, D. (2011). The post-high school outcomes of young adults with disabilities up to 6 Years after high school. Key findings from the National Longitudinal Transition Study-2 (NLTS2) NCSER 2011-3004). Menlo Park, CA: SRI International. Retrieved from www.nlts2.org/reports/

Schieve, L.A., Clayton, H.B., Durkin, M. S. Wingate, M.S., \& Drews-Botsh, C.D. (2015). Comparison of perinatal risk factors associated with autism spectrum disorder (ASD), intellectual disability (ID), and co-occurring ASD and ID. Journal of Autism Developmental Disorder, 45, 2361-2372. doi: 10.1007/s10803-015-2402-0

*Scott, R., Collins, B., Knight, V., \& Kleinert, H. (2013). Teaching adults with moderate intellectual disability ATM use via the iPod. Education and Training in Autism and Developmental Disabilities, 48(2), 190-199.

Scruggs, T. E. \& Mastropieri, M. A. (1998). Summarizing single-subject research: Issues and applications. Behavior Modification, 22(3), 221-242. Doi: 10.1177/014544555980223001

Scruggs, T. E. \& Mastropieri, M. A. (2013). PND at 25: Past, present, and future trends in summarizing single-subject research. Remedial and Special Education, 34(1), 9-19. doi: $10.1177 / 0741932512440730$

Scruggs, T. E., Mastropieri, M. A., \& Castro, G. (1987). The quantitative synthesis of singlesubject research: Methodology and validation. Remedial and Special Education, 8(2), 2433. doi: 074l-9325/87/0082-0024\$ 
Shipley-Benamou, R., Lutzker, J. R., \& Taubman, M. (2002). Teaching daily living skills to children with autism through video modeling. Journal of Positive Behavior Interventions, 4(3), 165-175. doi:10.1177/10983007020040030501

Shrestha, A., Anderson, A., \& Moore, D. W. (2013). Using point-of-view modeling and forward chaining to teach a functional self-help skill to a child with autism. Journal of Behavioral Education 22(2), 157-167. doi: 10.1007/s10864-012-9165-x

Sigafoos, J., O’Reilly, M., Cannella, H., Upadhyaya., M., Edrisinha, C., Lancioni, G. E., Hundley, A., Andrews, A., Garver, C., \& Young, D. (2005). Computer-presented video prompting for teaching microwave oven use to three adults with developmental disabilities. Journal of Behavioral Education, 14(3), 189-201. doi:10.1007/s10864-005$6297-2$

Sindelar, P. T., Rosenberg, M. S., \& Wilson, R. J. (1985). An adapted alternating treatments design for instructional research. Education \& Treatment of Children, 8(1), 67-76.

*Smith, M., Ayres, K., Mechling, L., Smith, K. (2013). Comparison of the effects of video modeling with narration vs. video modeling on the functional skill acquisition of adolescents with autism. Education and Training in Autism and Developmental Disabilities, 48(2), 164-178.

*Smith, K. A., Sheply, S. B., Alexander, J. L., Davis, A., Ayres, K. M. (2015). Selfinstruction using mobile technology to learn functional skills. Research in Autism Spectrum Disorders, 11, 93-100. doi: 10.1016/j.rasd.2014.12.001

Smith, M. D. \& Targett P. (2009). Critical life skills. In Wehman, P., Smith, M. D., \& Schall, C., Autism and the transition to adulthood: Success beyond the classroom. Baltimore, MD: Paul H. Brookes Publishing Co.

Software \& Information Industry Association (2014). 2014 Results from the SII Vision K-20 Survey, Retrieved from https://www.siia.net/visionk20/2014_VK20.pdf

*Taber-Doughty, T., Bouck, E. C., Tom, K., Jasper, A. D., Flanagan, S. M., Bassette, L. (2011). Video modeling and prompting: A comparison of two strategies for teaching cooking skills to students with mild intellectual disabilities. Education and Training and Autism and Developmental Disabilities, 46(4), 499-513.

*Taber-Doughty, T., Patton, S. E., \& Brennan, S. (2008). Simultaneous and delayed video modeling: An examination of system effectiveness and student preferences. Journal of Special Education Technology, 23(1), 1-18.

Taylor, J. L. \& Mailick, M. R. (2013). A longitudinal examination of 10-year change in vocational and educational activities for adults with autism spectrum disorders. Developmental Psychology, 50(3), 699-708. doi: 10.1037/a0034297 
Tekin-Iftar,E. \& Birkan, B. (2010). Small group instruction for students with autism. The Journal of Special Education, 44(1), 50-63. doi: 10.1177/0022466908325219

Thelen, M.H., Fry, R. A., Fehrenbach, P.A., \& Frautchi, N.M. (1979). Therapeutic videotape and film modeling: A review. Psychological Bulletin, 86(4), 701-720.

U.S. Department of Education, Office of Special Education and Rehabilitative Services, Office of Special Education Programs, 35th Annual Report to Congress on the Implementation of the Individuals with Disabilities Education Act, 2013, Washington, D.C. 2014.

Van Laarhoven, T. \& Van Laarhoven-Myers, T. (2006). Comparison of three video-based instructional procedures for teaching daily living skills to persons with developmental disabilities. Education and Training in Developmental Disabilities, 41(4), 365-381.

*Van Laarhoven, T., Zurita, L. M., Johnson, J. W., Grider, K. M., \& Grider, K. L. (2009). Comparison of self, other, and subjective video models for teaching daily living skills to individuals with developmental disabilities. Education and Training in Developmental Disabilities, 44(4), 509-522.

**Wang, H. \& Koyama, T. (2014). An analysis and review of the literature and a three-tier video modeling intervention model. Research in Autism Spectrum Disorders, 8, 746-758. http://dx.doi.org/10.1016/j.rasd.2014.03.010

Wehman, P., Schall, C., Carr, S., Targett, P., West, M., \& Cifu, G. (2014). Transition from school to adulthood for youth with autism spectrum disorder: What we know and what we need to know. Journal of Disability Policy Studies, 25(1), 30-40. doi: $10.1177 / 1044207313518071$

Wheeler, A. J., Miller, R. A., Springer, B. M., Pittard, N. C., Phillips, J. F., \& Myers, A. M. (2001). Murdoch Center Program Library, $3^{\text {rd }}$ ed. Raleigh, NC: Murdoch Center Foundation.

West, E. A. (2008). Effects of verbal cues versus pictorial cues on the transfer of stimulus control for children with autism. Focus on Autism and Other Developmental Disabilities, 23(4), 229-241. doi: 10.1177/1088357608324715

Wolery, M., Gast, D. L., \& Ledford, D. (2014). Comparison designs. In D.L. Gast and J. R. Ledford (Eds.), Single case research methodology: Applications in special education and behavioral sciences ( ${ }^{\text {nd }}$ Edition). Florence, KY: Taylor Francis.

Woodman, A.C., Mailick, M.R., Anderson, K.A., and Esbensen, A.J. (2014). Residential transitions among adults with intellectual disability across 20 years. American Journal of Intellectual and Developmental Disabilities, 119(6), 496-515. doi: 10.1352/1944-7558119.6.496 
Zisimopoulos, D., Sigafoos, J., \& Koutromanos, G. (2011). Using video prompting and constant time delay to teach an internet search basic skill to students with intellectual disabilities. 